A〕1105 968601

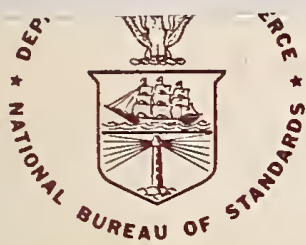

NBS TECHNICAL NOTE 1088

NBS

Reference PUBLICATIONS

U.S. DEPARTMENT OF COMMERCE / National Bureau of Standards

Fitness-for-Service Criteria for Assessing the Significance of Fatigue Cracks in Offshore Structures

Yi-Wen Cheng

$-Q C$

100

.45753

No. 1088

1985 
he National Bureau of Standards ${ }^{1}$ was established by an act of Congress on March 3, 1901. The

Bureau's overall goal is to strengthen and advance the nation's science and technology and facilitate their effective application for public benefit. To this end, the Bureau conducts research and provides: (1) a basis for the nation's physical measurement system, (2) scientific and technological services for industry and government, (3) a technical basis for equity in trade, and (4) technical services to promote public safety. The Bureau's technical work is performed by the National Measurement Laboratory, the National Engineering Laboratory, the Institute for Computer Sciences and Technology, and the Center for Materials Science.

\section{The National Measurement Laboratory}

Provides the national system of physical and chemical measurement; coordinates the system with measurement systems of other nations and furnishes essential services leading to accurate and uniform physical and chemical measurement throughout the Nation's scientific community, industry, and commerce; provides advisory and research services to other Government agencies; conducts physical and çhemical research; develops, produces, and distributes Standard Reference Materials; and provides calibration services. The Laboratory consists of the following centers:
- Basic Standards ${ }^{2}$

- Radiation Research

- Chemical Physics

- Analytical Chemistry

\section{The National Engineering Laboratory}

Provides technology and technical services to the public and private sectors to address national needs and to solve national problems; conducts research in engineering and applied science in support of these efforts; builds and maintains competence in the necessary disciplines required to carry out this research and technical service; develops engineering data and measurement capabilities; provides engineering measurement traceability services; develops test methods and proposes engineering standards and code changes; develops and proposes new engineering practices; and develops and improves mechanisms to transfer results of its research to the ultimate user. The Laboratory consists of the following centers:
- Applied Mathematics

- Electronics and Electrical Engineering ${ }^{2}$

- Manufacturing Engineering

- Building Technology

- Fire Research

- Chemical Engineering ${ }^{2}$

\section{The Institute for Computer Sciences and Technology}

Conducts research and provides scientific and technical services to aid Federal agencies in the selection, acquisition, application, and use of computer technology to improve effectiveness and economy in Government operations in accordance with Public Law 89-306 (40 U.S.C. 759), relevant Executive Orders, and other directives; carries out this mission by managing the Federal Information Processing Standards Program, developing Federal ADP standards guidelines, and managing Federal participation in ADP voluntary standardization activities; provides scientific and technological advisory services and assistance to Federal agencies; and provides the technical foundation for computer-related policies of the Federal Government. The Institute consists of the following centers:
- Programming Science and Technology

- Computer Systems Engineering

\section{The Center for Materials Science}

Conducts research and provides measurements, data, standards, reference materials, quantitative understanding and other technical information fundamental to the processing, structure, properties and performance of materials; addresses the scientific basis for new advanced materials technologies; plans research around cross-country scientific themes such as nondestructive evaluation and phase diagram development; oversees Bureau-wide technical programs in nuclear reactor radiation research and nondestructive evaluation; and broadly disseminates generic technical information resulting from its programs. The Center consists of the following Divisions:
- Inorganic Materials

- Fracture and Deformation ${ }^{3}$ - Polymers

- Metallurgy

- Reactor Radiation 


\section{Fitness-for-Service Criteria for Assessing the Significance of Fatigue Cracks in Offshore Structures}

Yi-Wen Cheng

Fracture and Deformation Division Institute for Materials Science and Engineering National Bureau of Standards

U.S. Department of Commerce

Boulder, Colorado 80303

Sponsored by

U.S. Department of Interior

Minerals Management Service

12203 Sunrise Valley Drive

Reston, Virginia 22091

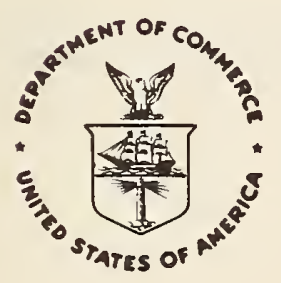

U.S. DEPARTMENT OF COMMERCE, Malcolm Baldrige, Secretary

NATIONAL BUREAU OF STANDARDS, Ernest Ambler, Director

Issued August 1985 
National Bureau of Standards Technical Note 1088

Natl. Bur. Stand. (U.S.), Tech Note 1088, 72 pages (Aug. 1985)

CODEN:NBTNAE

U.S. GOVERNMENT PRINTING OFFICE

WASHINGTON: 1985

For sale by the Superintendent of Documents, U.S. Government Printing Office, Washington, DC 20402 


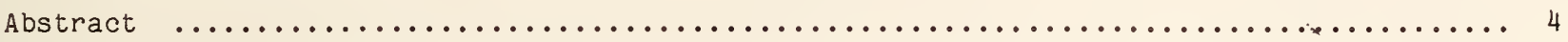

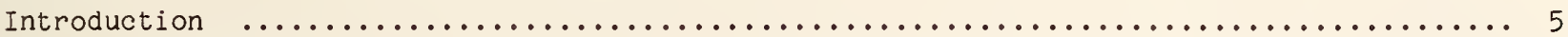

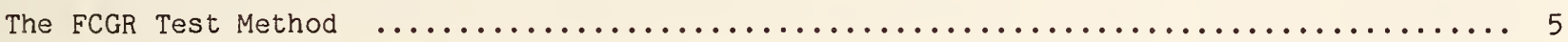

Equipment for the Automated FCGR Test system $\ldots \ldots \ldots \ldots \ldots \ldots$

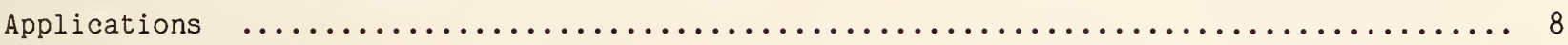

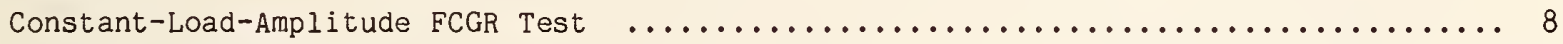

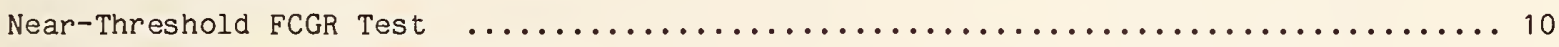

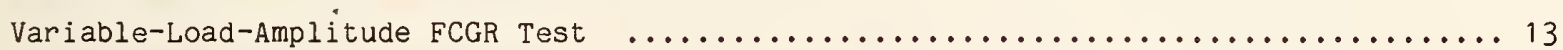

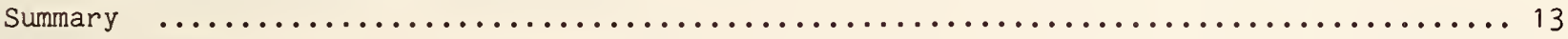

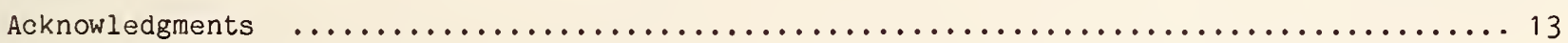

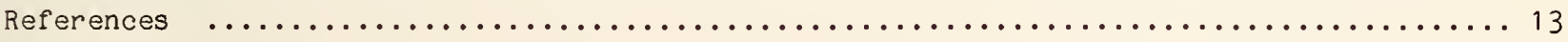

THE FATIGUE CRACK GROWTH OF A SHIP STEEL IN SALTWATER UNDER SPECTRUM LOAdING ............ 15

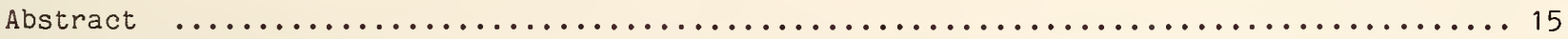

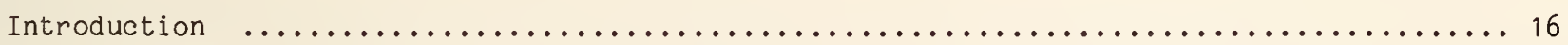

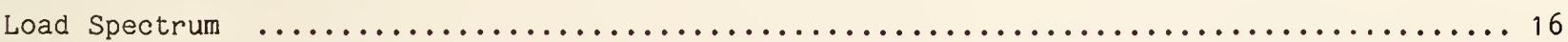

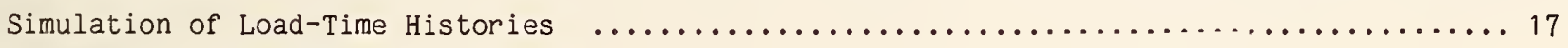

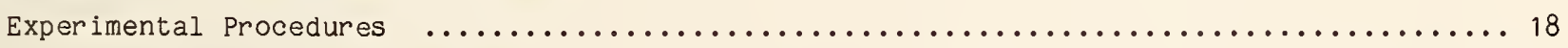

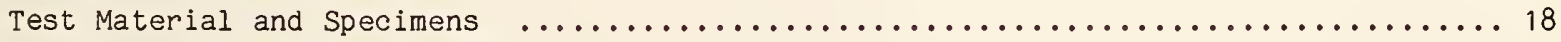

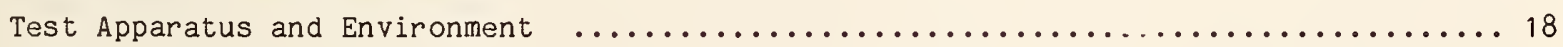

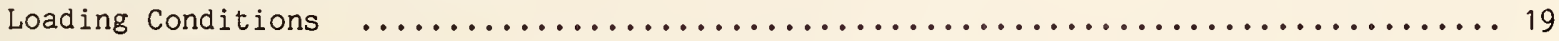

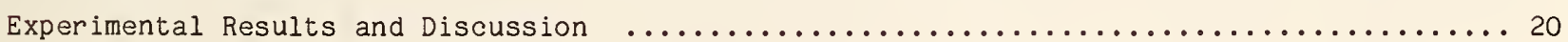

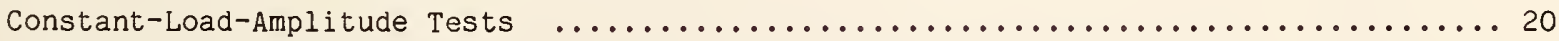

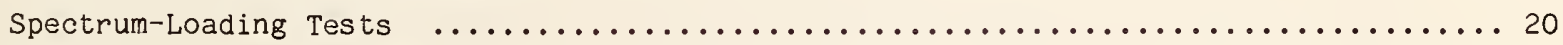

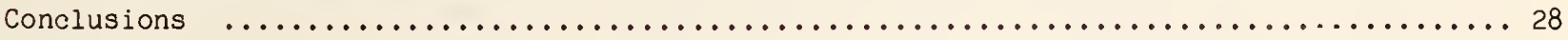

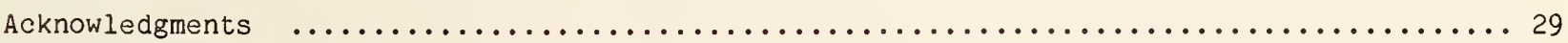

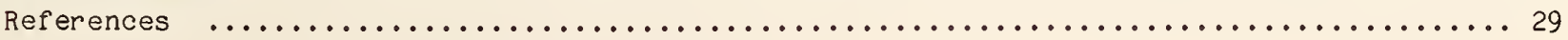

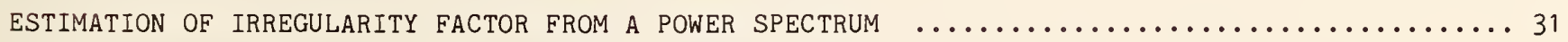

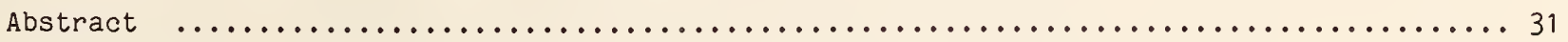

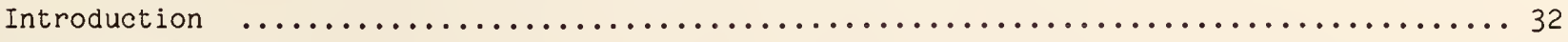

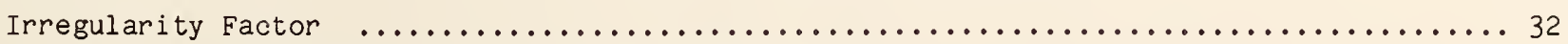

Evaluation of Irregularity Factor from Power spectra $\ldots \ldots \ldots \ldots \ldots \ldots$

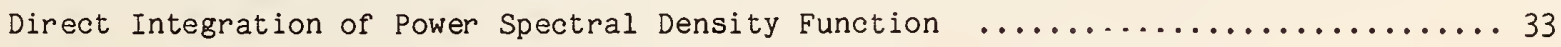

Estimation from Characteristic Width and Center Frequency of the Power Spectrum ... 34 
Acknowledgments

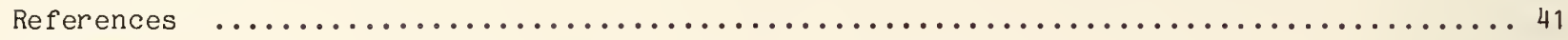

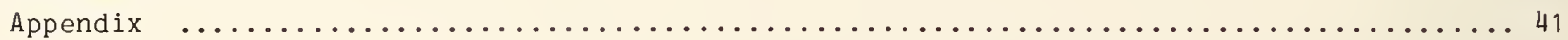

FATIGUE CRACK GROWTH IN AREAS OF STRESS CONCENTRATION -- PLASTICITY AND SMALL-CRACK EFFECTS .. 43

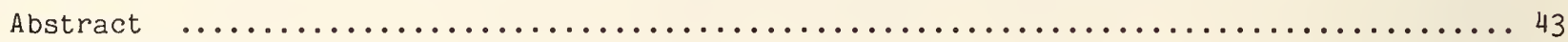

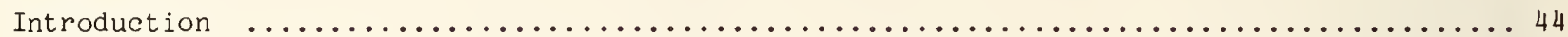

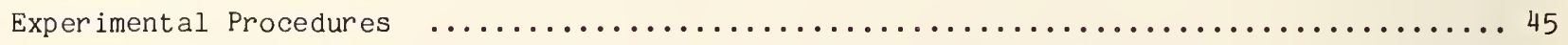

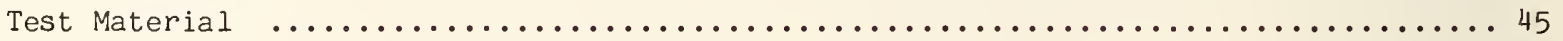

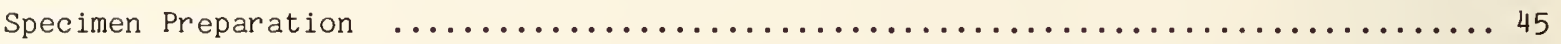

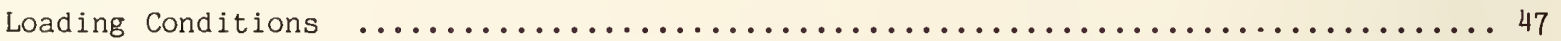

Test Environment and Crack-Length Measurements .......................... 47

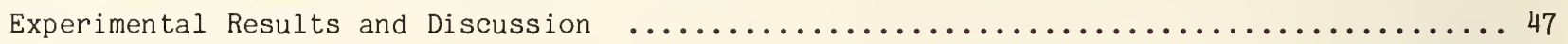

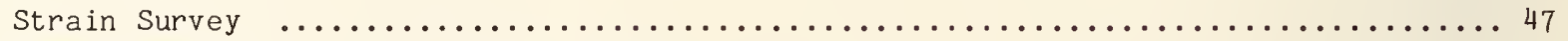

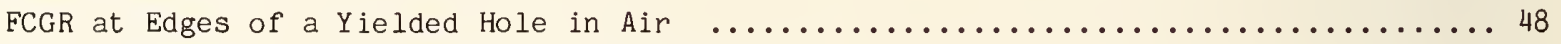

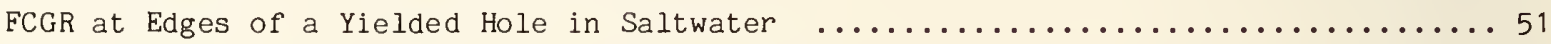

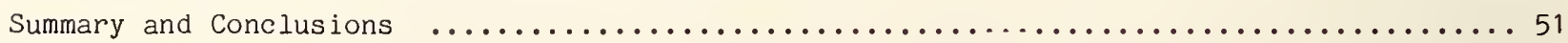

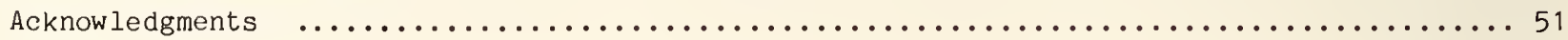

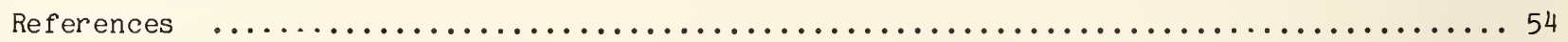

HIGH/LOW STRESS AMPLITUDE EFFECTS ON FATIGUE CRACK GROWTH RATES OF A SHIP STEEL

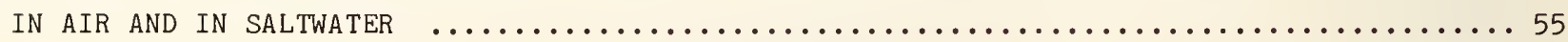

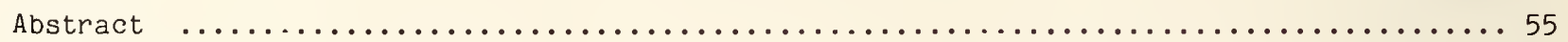

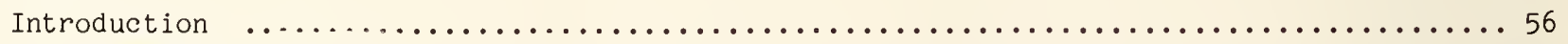

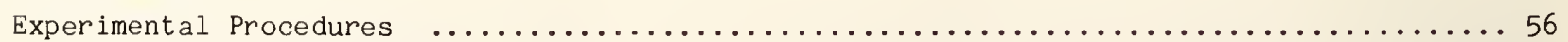

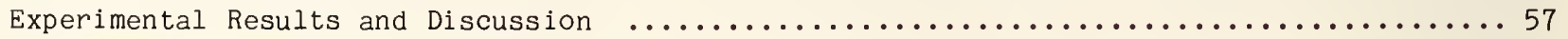

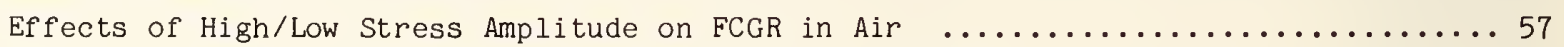

Effects of High/Low Stress Amplitude on FCGR in Saltwater $\ldots \ldots \ldots \ldots$

Effects of Tensile Overload Prior to Crack Initiation on FCGR ..............6

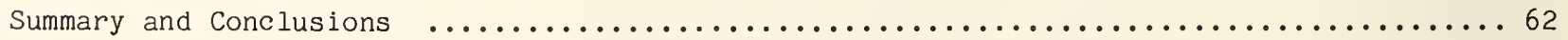

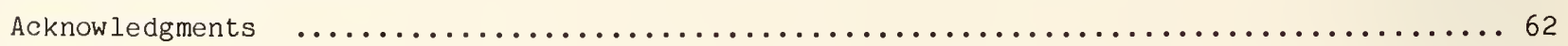

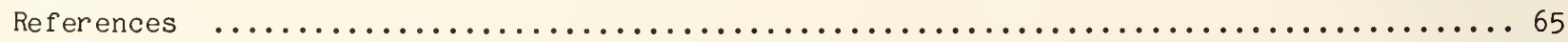




\title{
FITNESS-FOR-SERVICE CRITERIA FOR ASSESSING THE SIGNIFICANCE \\ OF FATIGUE CRACKS IN OFFSHORE STRUCTURES
}

\author{
Yi-Wen Cheng \\ Fracture and Deformation Division \\ National Bureau of Standards \\ Boulder, Colorado 80303
}

Results of a research program to develop fitness-for-service criteria for assessing the significance of fatigue cracks in offshore structures are presented in five papers. Each paper describes the goals and approaches to a specific task and details the results of the study. Highlights of these results are:

1. An automated fatigue crack growth rate test system has been developed that can be used for tests under constant-and variable-amplitude loadings.

2. A digital simulation of random signal from a power spectrum characteristic of the North Sea environment was developed to apply random-amplitude loading. Experimental results showed that the average fatigue crack growth rates under spectrum loading and under constant-amplitude loading were in excellent agreement when fatigue crack growth rate was plotted as a function of the appropriately defined equivalent-stress-intensity range. This procedure is equivalent to applying Miner's summation rule in fatigue life calculations.

3. Simplified methods of evaluating the irregularity factor of a power spectrum were derived.

4. The linear-elastic fracture mechanics analysis of fatigue crack growth at stress concentrations appeared to be adequate in yielded regions that are caused by monotonic loading but which have a linear stress-strain relation under cyclic loading. Small-crack behavior was observed in an ABS grade EH36 steel when crack length was less than $1.5 \mathrm{~mm}$ in air and less than $3 \mathrm{~mm}$ in 3.5 percent NaCl solution. The problem of small-crack behavior was accounted for by adding an intrinsic crack length to the physical crack length.

5. The tensile overload retardation effects on fatigue crack growth rates were similar in the elastic regions and at the edges of a yielded hole and also in air and in 3.5 percent $\mathrm{NaCl}$ solution. Tensile overload prior to crack initiation appeared to retard subsequent fatigue crack growth in areas of stress concentration. The retardation was explained by the presence of beneficial residual stresses and crack closure.

A subsequent report will incorporate these technical findings into a procedure for calculating fatigue crack growth in offshore structures under realistic conditions.

Key words: fatigue crack growth; fitness-for-service criteria; fracture mechanics; offshore structures; random-loading fatigue. 


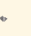


Offshore structures are designed to withstand the cyclic stresses caused by wave loading. However, the presence of undetected defects in the as-fabricated structure may cause fatigue cracking during service. If a fatigue crack is detected during the in-service inspection of an offshore structure, a methodology is needed to assess its significance with respect to the safety of the facility. This need was clearly identified by the Committee on Offshore Energy of the Marine Board. The committee's recommendations to the U.S. Department of the Interior for implementing a postinstallation inspection program for fixed steel structures included: "Develop procedures and standards for acceptance of remedial actions carried out in response to the results of an inspection." In consideration of this need, a research program is being conducted at the National Bureau of Standards for the Minerals Management Service with the following overall objective:

To develop a technical basis for recommending remedial actions to be taken in the event that a fatigue crack is discovered during in-service inspection of an offshore structure.

The basis on which remedial actions are to be taken is the fatigue crack growth (FCG) behavior under service conditions. The desired representation of FCG behavior is a fatigue crack lengthversus-time curve; figure 1 is an example. FCG behavior is best described by the fracture mechanics approach, in which fatigue crack growth rates, da/dN, are correlated to the applied stress intensity factor range, $\Delta K$ :

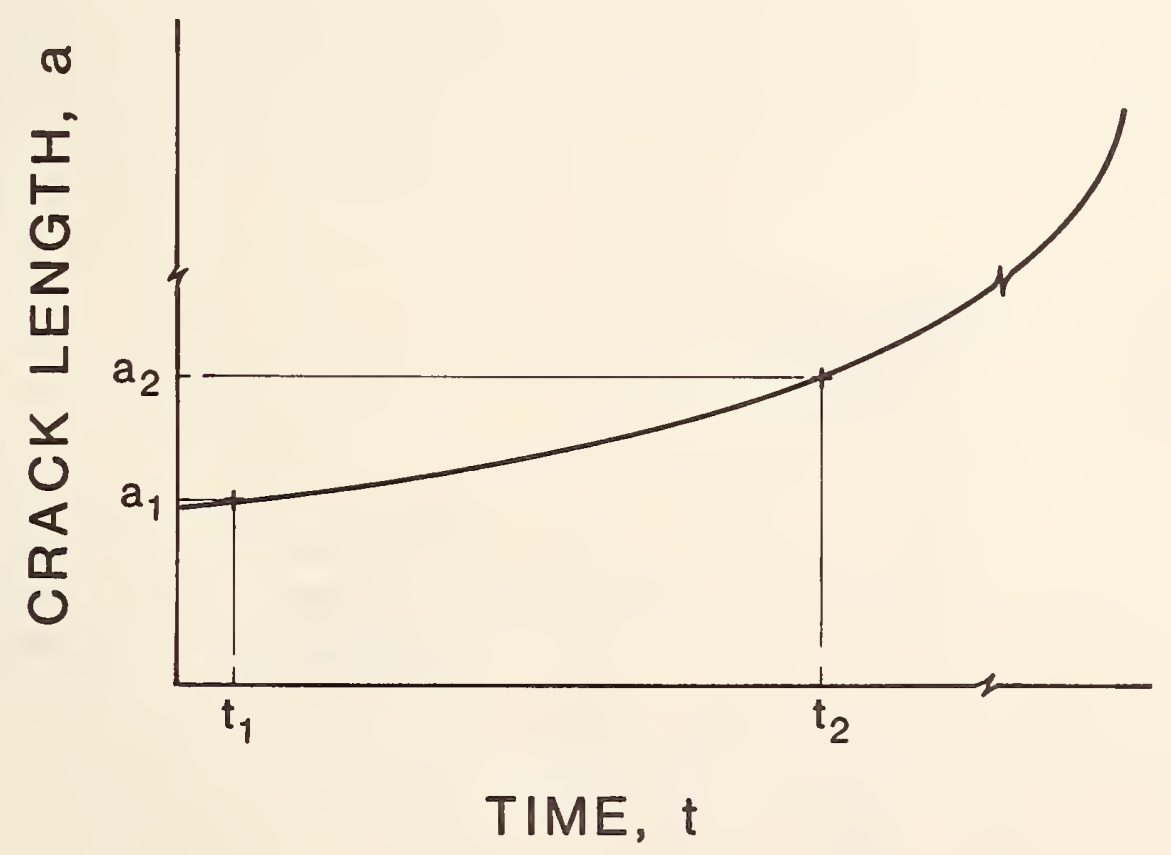

Figure 1. Schematic fatigue crack growth behavior with respect to time. 
where $\mathrm{C}$ and $\mathrm{m}$ are material parameters determined from laboratory specimen tests, and $\Delta \mathrm{K}$ is a function of the applied stress range, $\Delta S$, the crack length, a, and a geometrical factor, $F$ :

$$
\Delta K=\Delta S \sqrt{\pi a} F
$$

Integration of equation (1) gives crack length-versus-time (a-versus-t) results.

From equations ( 1 ) and (2), one must know the values of $c, m, \Delta S, a$, and $F$ to evaluate $F C G$ behavior. With reference to figure 2 and equations (1) and (2), the basic ingredients for fatigue damage assessment are service loading history (reflected in $\Delta S$ ), component $K$ solution (reflected in F), material da/dN data (reflected in $C$ and $m$ ), and crack length, $a$, found by inspection of the structure. Two problems associated with the service loading history are calculation of stress range, and cycle counting in cases of irregular loading histories, such as sea loadings on of shore structures. The determination and modeling of each piece of information relevant to evaluation of FCG in an offshore structure is a major task by itself. Even with all the basic information available, crack growth calculation is not as straightforward as an integration of equation (1) because of load-sequence interaction effects, which must be understood and taken into account.

Owing to the complexity involved in fatigue analysis and limited resources available, the major portion of this research program has focused on development, improvement, and verification of models for FCG analysis under random-amplitude loading. The specific output of this program is a procedure to calculate the stress range and count cycles from which $\Delta S$ and $N$ in equations (1) and (2) are determined. The research results are given in five technical papers that follow in this report.

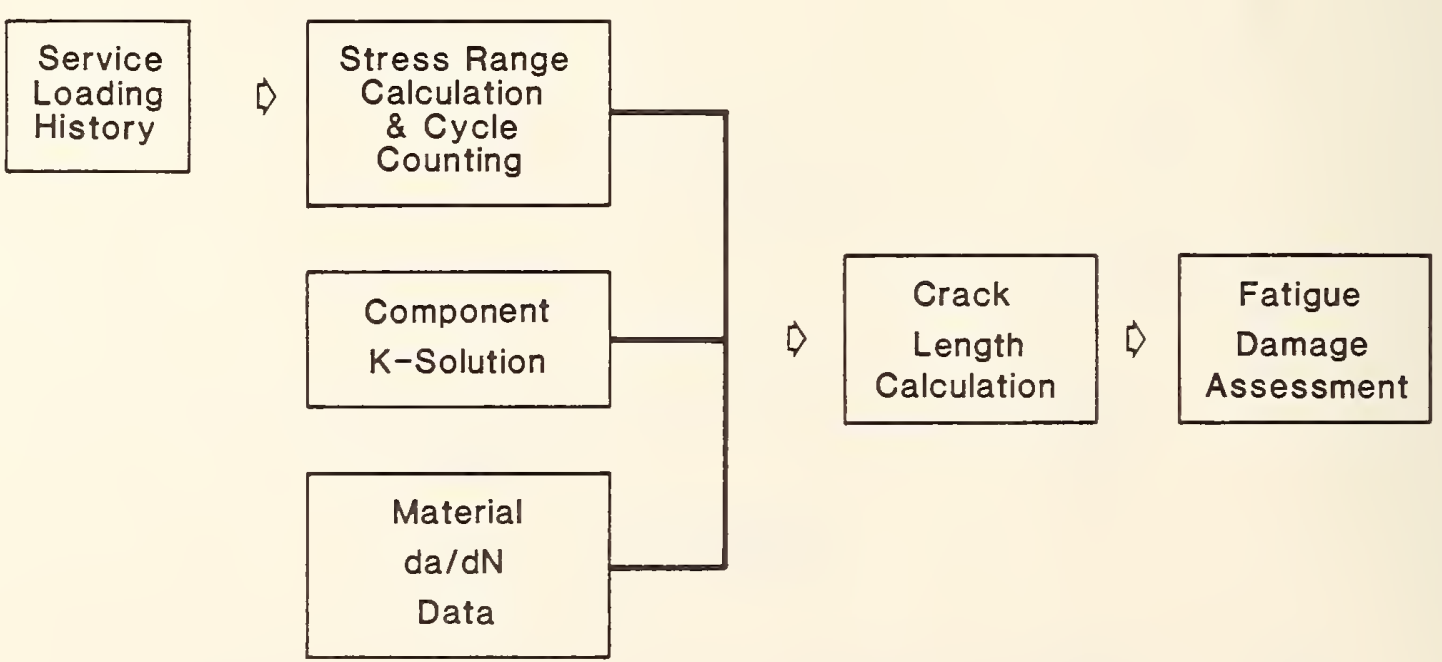

Figure 2. Fatigue damage assessment diagram. 
The additional detailed information needed for accurate FCG analysis of specific offshore structural components, such as service loading histories, stress redistribution due to crack growth, component $\mathrm{K}$ solutions, and material da/dN data, must be sought in the literature, especially the results from the European research program on the fatigue behavior of welded tubular joints in offshore structures for the North Sea, and from the fabricators and operators of individual structures. 
AN AUTOMATED FATIGUE CRACK GROWTH RATE TEST SYSTEM ${ }^{+}$

\author{
Yi-Wen Cheng \\ David T. Read \\ Fracture and Deformation Division \\ National Bureau of Standards \\ Boulder, Colorado
}

\title{
Abstract
}

An automated fatigue crack growth rate (FCGR) test system has been developed that can be used for tests of constant-load-amplitude FCGR above $10^{-8} \mathrm{~m} / \mathrm{cycle}$ (ASTM E647-83) at normal ( $10 \mathrm{~Hz}$ ) or low $(-0.1 \mathrm{~Hz})$ cyclic frequencies and for tests of near-threshold and variable-load-amplitude FCGR. The test system consists of a minicomputer, a programmable arbitrary waveform generator, a servohydraulic test frame, and a programmable digital oscilloscope. The crack length is measured using the compliance technique; the FCGR and the stress intensity factor range are calculated and plotted automatically during the test.

Key words: automated test system; compliance technique; fatigue crack growth rate; fatigue of materials; near-threshold fatigue test; variable-load-amplitude fatigue test.

\footnotetext{
${ }^{+}$To be published in ASTM STP 877.
} 
Fatigue/ crack growth rate (FCGR) data are used for material characterization and for fracture mechanics reliability analysis of structures subjected to cyclic loading. A standard test method for measuring such data above $10^{-8} \mathrm{~m} /$ cycle under constant-amplitude loading has been developed and published in the 1983 Annual Book of ASTM Standards under the designation ASTM E647-83.

With the increased interest in near-threshold FCGR $[1,2]^{*}$ and FCGR under environmental influences at low cyclic frequencies [3], the demand for FCGR measurements has increased. Obtaining such data can be tedious and time-consuming. An automated FCGR test system, such as that described in this paper, allows testing to proceed, data to be taken, and loads to be altered in the absence of an operator. The automated test system minimizes testing time. Data scatter is reduced owing to higher precision in crack length measurement and better control in data point spacing [4]. Because the testing is interactive and automatic in nature, the procedure is relatively easy to follow and requires minimal operator training. Finally, this approach eliminates the subjective interpretation and influence of the experimenter.

The FCGR Test Method

The sequence of the FCGR test is: first, obtain the raw data, namely, fatigue crack length, a, versus elapsed fatigue cycles, $\mathrm{N}$; second, reduce this data to a plot of da/dN versus $\Delta K$, where da/dN is the FCGR in $\mathrm{m} / \mathrm{cycle}$ and $\Delta \mathrm{K}$ is the crack-tip stress-intensity factor range in MPa/m. Typical outputs are presented in figure 1.

The number of elapsed fatigue cycles can be obtained from counters (electronic or mechanical) or conversion from time elapsed at the actual testing frequency. The methods of crack length measurement are complicated and have been a subject of extensive study $[5,6]$. Although several methods of crack length measurement have been developed, some require specialized equipment not commonly available in mechanical testing laboratories. The compliance technique, however, requires only monitoring of the load cell and the clip gage outputs, which is routinely achieved in mechanical testing. Compliance is defined as the specimen deflection per unit load, which is a function of crack length for a given material and specimen geometry. The load and deflection signals (voltages) can be interfaced to a computer. Because of the simple instrumentation and the need in our laboratory for environmental chambers for cryogenic-temperature and saltwater corrosion-fatigue tests, the compliance technique was chosen to measure the crack length.

Equipment for the Automated FCGR Test System

A schematic of the automated FCGR test system is shown in figure 2. Figure 2 also shows the sequence of operation and interaction between various components. The test system consists of a closed-loop servo-controlled hydraulic testing machine, a programmable digital oscilloscope, a programmable arbitrary waveform generator, and a minicomputer.

\footnotetext{
* Numbers in brackets denote references listed at the end of each paper.
} 

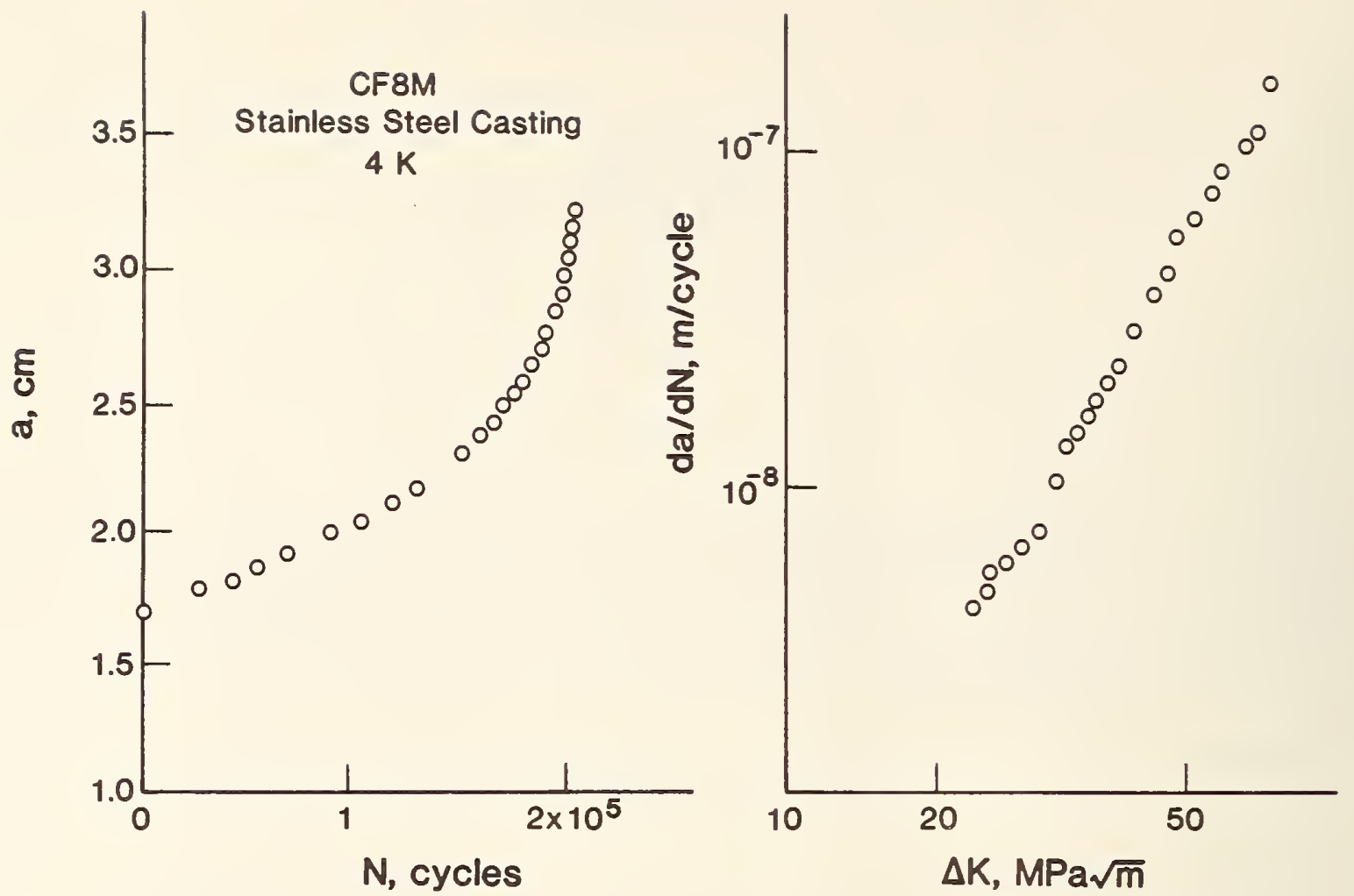

Figure 1. Data outputs from the automated FCGR test.

The machine control unit, which is included in the hydraulic mechanical test machine, includes a servo-control system, a feedback system, two dc conditioners, and a valve drive. A nonprogrammable function generator with an electronic pulse counter is usually built into the machine control unit of a commercially available mechanical testing machine. Signal amplifiers and a load cell are also included in the mechanical testing machine.

The programmable digital oscilloscope contains two 15-bit 100-kHz digitizers, and it serves as an analog-to-digital (A/D) converter. In addition to its high speed A/D conversion rate, this oscilloscope features the ability to instantaneously freeze and hold data in memory. These features eliminate the problems encountered with slower A/D converters, such as interruptions during the test [7] and low test frequencies [8]. For the near-threshold and the variable-load-amplitude FCGR tests, load levels vary with time and a programmable function generator is needed. For these tests, a programmable arbitrary waveform generator is used. At present, this programmable waveform generator is not connected to a cycle-counting device, and the fatigue cycle counts are inferred from the cyclic frequency ${ }^{*}$ and elapsed time, as given by the computer. For the constant-loadamplitude FCGR test, a built-in function generator is used.

Included in the minicomputer are a cathode-ray-tube (CRT) terminal, a line printer, a dual

\footnotetext{
* The frequency used for cycle calculation is checked with a frequency meter; the typical error in frequency is $50 \mathrm{ppm}$.
} 


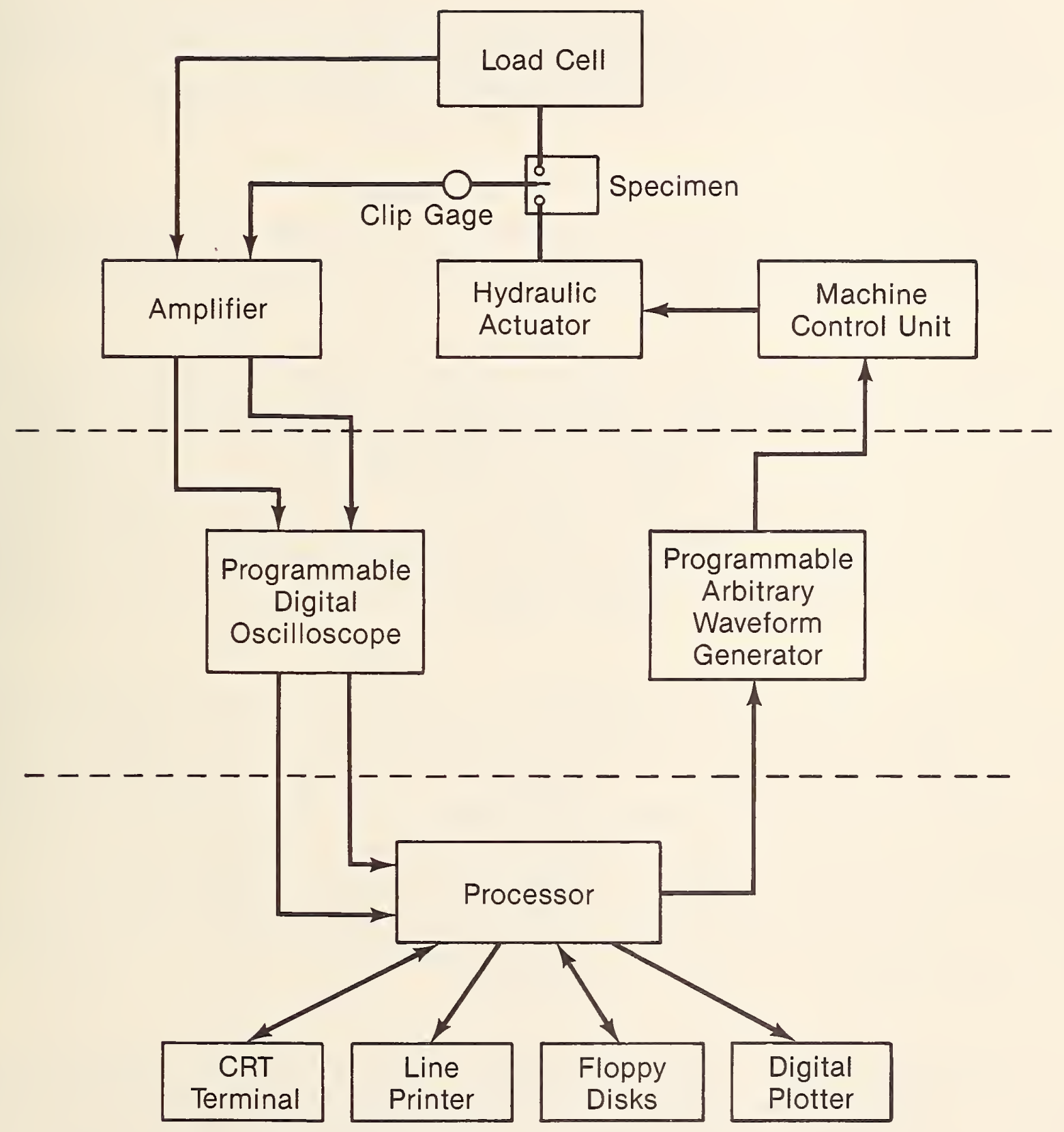

Figure 2. Schematic of the automated FCGR test system. 
floppy disk storage unit, and a digital plotter. The minicomputer uses the 16-bit word and has $128 \mathrm{~K}$ words of memory. The minicomputer also contains an internal clock that reads to $1 / 60 \mathrm{~s}$. The IEEE-488/GPIB is used for the interface between the computer and the programmable digital oscilloscope and between the computer and the programmable arbitrary waveform generator.

Applications

In the following discussion, we describe how this test system is used to conduct the FCGR tests. Requirements on grips, fixtures, specimen design, and specimen preparation are detailed in ASTM E647-83 and other proposed standards $[3,9]$ and are not discussed in this paper.

Constant-Load-Amplitude FCGR Test

The test system described in the previous section can be programmed to run the constant-loadamplitude FCGR test. The operational details below implement the procedures set forth by ASTM E647-83.

As shown in figure 3, the operator feeds the input parameters into the computer through the CRT terminal. The input parameters include specimen identification, specimen dimensions, Young's modulus, selected time interval for measuring crack length, minimum load level for compliance measurement, load levels, and test frequency. The time interval for measuring crack length must be kept small enough so that every increment of crack growth will not exceed the recommended values prescribed in ASTM E647-83. The minimum load level for compliance measurement is used to eliminate possible crack closure effects [10], which have a significant effect on the accuracy of crack length measurement.

The precracked specimen is fatigue cycled under the prescribed loading conditions and cyclic frequency. A typical frequency is $10 \mathrm{~Hz}$. When the preselected time interval (typical value is 1 min) for crack length measurement is reached, the computer requests the load-versus-deflection data from the programmable digital oscilloscope, which freezes the load-deflection data in the memory instantaneously and correlates the data to a straight line using a linear least-squares fit. A linear correlation coefficient of 0.999 or better is usually obtained. From the resulting compliance, the instantaneous crack length is computed by using the appropriate expression for the compliance calibration of the specimen [11]. The precision of the crack length measurement is typically within $0.04 \mathrm{~mm}$.

The inferred crack length, which is obtained from the measured compliance, published compliance calibrations, and published Young's modulus, usually does not agree exactly with the actual crack length for a given material and specimen geometry. The exact reasons for the discrepancy between the inferred and the actual crack lengths are not clear and have been discussed in references 12 and 13. Correction factors to the compliance calibrations have been used to obtain more accurate physical crack length predictions.

Another way of correcting the mismatch between the inferred and the actual crack lengths is to adopt an "effective modulus" for the material. The effective modulus, E eff, is deduced from a known 


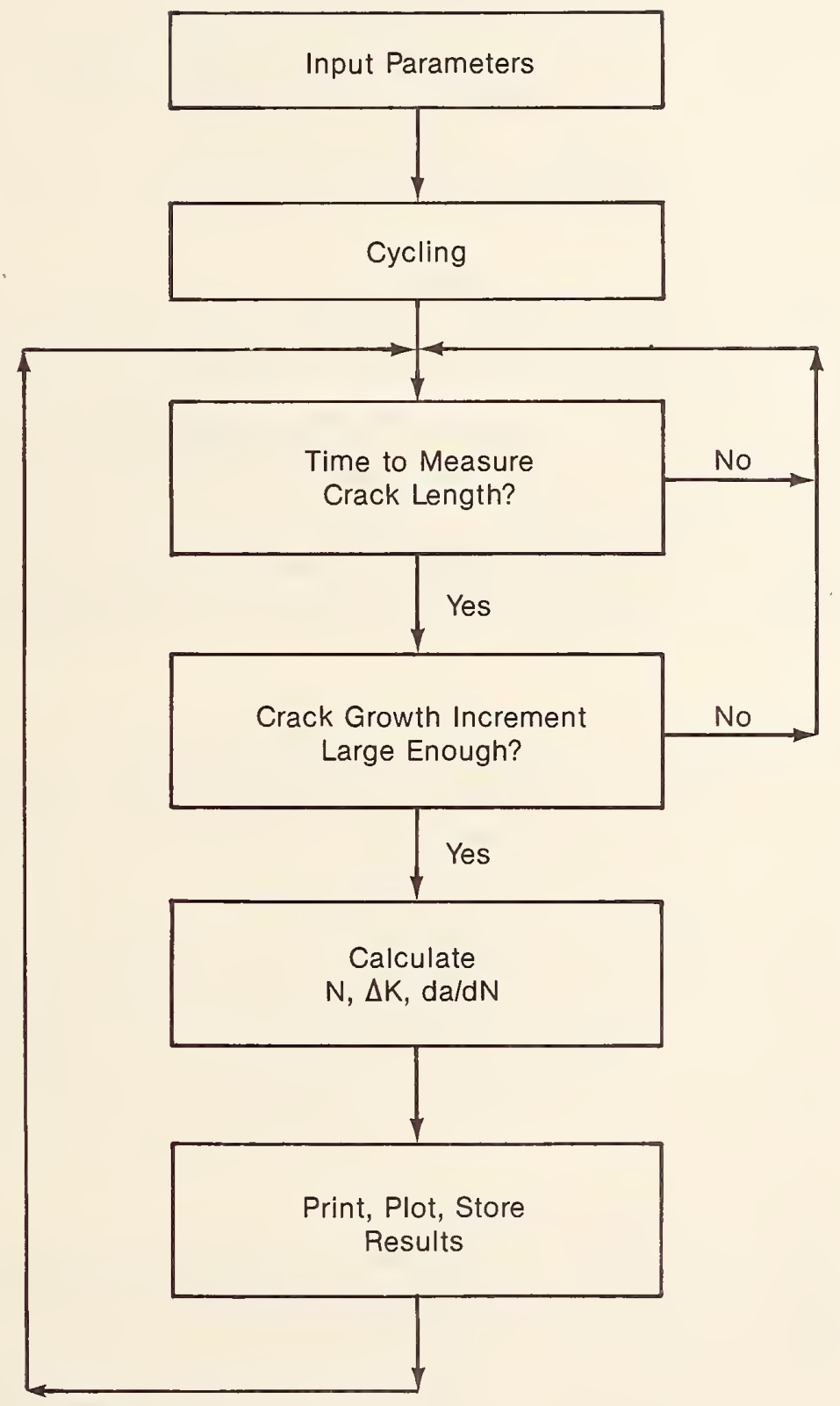

Figure 3. Summary flow chart of the automated constant-load-amplitude FCGR test. 
crack length in a given specimen geometry and compliance calibration. Typically, Eeff is deduced from one well-defined crack front that is visible on a posttest fracture surface. The crack front at the end of fatigue precracking or at the final fatigue crack length is generally used. The effective modulus approach, which is used in our labaratory, thus forces agreement between the inferred and the actual crack lengths and compensates for any errors regardless of source [13].

The portion of the load-versus-deflection curve used for compliance calculation is from the specified minimum load level to a value corresponding to 95 percent of the maximum load. The typical minimum load level used for compliance calculation is the mean load (load signal midpoint). Note, however, that the specific value of the minimum load level used for a given material, specimen geometry, and load ratio must be larger than crack closure loads. The reason for excluding the upper 5 percent of the load for calculation is that the clip gage tends to vibrate, and noise in the clip-gage signal increases at the maximum load during the high-frequency test.

The increment of crack length (the difference between the current measured crack length and the last recorded crack length) is checked against specified values, which are within the recommended values of ASTM E647-83. A value of $0.5 \mathrm{~mm}$ is typically specified for a 25.4-mm-thick standard compact-type specimen. If the increment of crack growth is equal to or greater than the specified value, the computer calculates $N, \Delta K$, and da/dN; the digital plotter plots the data points (a, $N$ ) and $(\mathrm{da} / \mathrm{dN}, \Delta \mathrm{K}$ ) on the a-versus $-\mathrm{N}$ and $\mathrm{da} / \mathrm{dN}$-versus- $\Delta \mathrm{K}$ graphs, such as those shown in figure 1 ; the 1 ine printer prints the value of calculated compliance, the linear least-squares correlation coefficient, a, $N, d a / d N$, and $\Delta K$ results. All the resulting data are stored on floppy disks for posttest analyses.

During the test, the point-to-point data reduction technique is used to calculate $\Delta \mathrm{K}$ and da/dN from a and N. Usually the results are consistent with minimum scatter, such as those shown in figure 1. If the results of $\Delta \mathrm{K}$ versus $\mathrm{da} / \mathrm{dN}$ scatter, the seven-point incremental polynomial method is used to smooth the results after the test is completed.

The computer programs for posttest analyses include the following capabilities:

1. Reducing a-versus $-\mathrm{N}$ data to $\Delta \mathrm{K}$-versus-da/dN by seven-point incremental polynomial method

2. Converting units

3. Plotting data in desired units

4. Plotting data in desired coordinate ranges

5 Plotting data for several different specimens on one graph (for comparison)

6. Calculating the material constants $C$ and $n$ in the Paris equation $[14], d a / d N=C(\Delta K)^{n}, a n d$ drawing the regression line through the data

All computer programs, including the data acquisition routines, were written in the Fortran IV language.

Near-Threshold FCGR Test

The computer programs used in the constant-load-amplitude FCGR test, with some modifications, can be used for near-threshold FCGR tests. The major difference in test procedures is that the load 
levels in the near-threshold FCGR test decrease according to the initial $\Delta K$ value (in the Kdecreasing test technique). The load levels are calculated from the following equations [9]:

$$
\begin{aligned}
& \Delta K \quad=\Delta K_{0} \exp \left[C^{\prime}\left(a-a_{0}\right)\right] \\
& \Delta P \quad=B W^{0.5} \Delta K / f_{1}(a / W) \quad \text { for compact-type specimens } \\
& \Delta P \quad \text { for center-cracked-tension specimens } \\
& P_{\max }=\Delta P /(1-R) ; \quad P_{\min }=P_{\max } R
\end{aligned}
$$

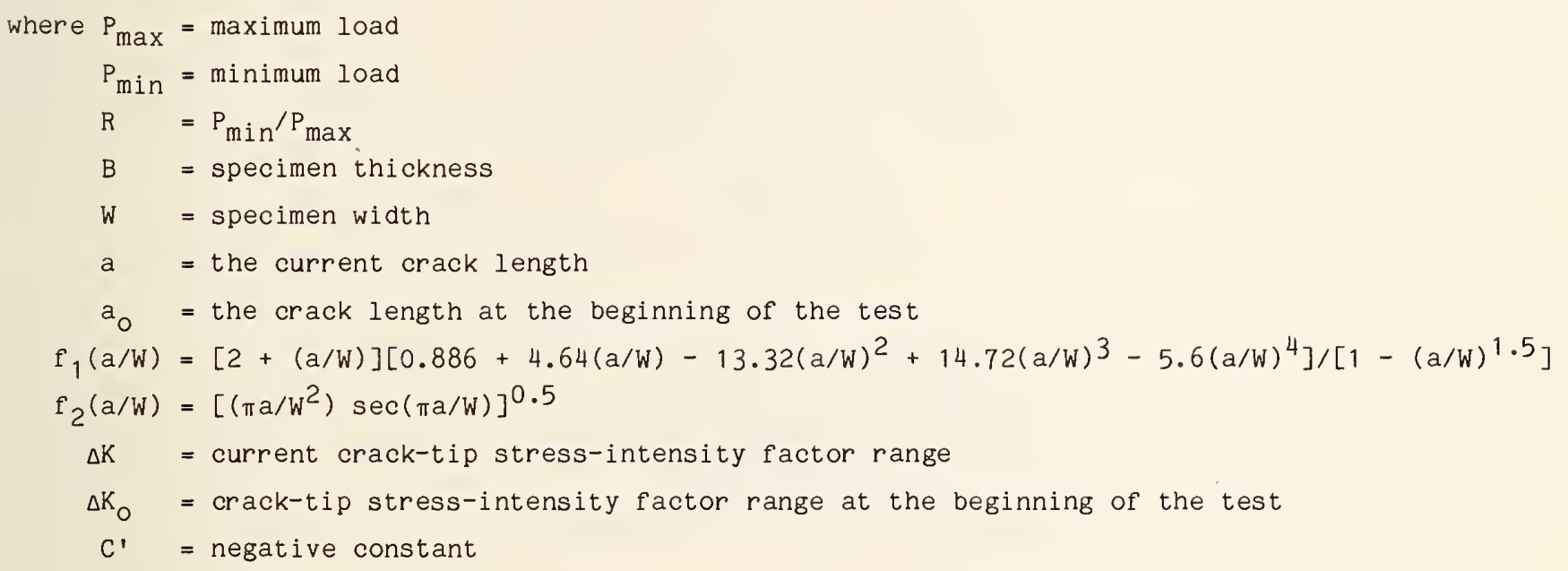

A typical value of $C^{\prime}$ is $-0.08 \mathrm{~mm}^{-1}$, which gives satisfactory results with no apparent anomalous crack growth for AISI 300-series stainless steels.

The flow chart describing the automated near-threshold FCGR test is summarized in figure 4. After each crack length measurement, the crack length is compared with the last stored crack length to ensure that a specified measurable small amount of crack growth has occurred. If this is not done, then some unnecessary load level adjustments will take place because of scatter in the crack length measurement. After the crack length has increased a certain amount (for example, $0.13 \mathrm{~mm}$ ), the new $\Delta K$ is calculated from equation (1) and the new crack length is stored. The load levels are then adjusted using equations (2), (3), and (4).

In high-frequency fatigue testing, which is desirable in the near-threshold FCGR test, hydraulic lag might be a problem. As a result the specimen is not actually subjected to the load range commanded by the computer (or waveform generator). The problem is usually corrected by using proper signal conditioners and gain settings. However, overprogramming is sometimes necessary to overcome the persistent hydraulic lag. During the overprogramming process, which is done by a trial-and-error method, the computer monitors the values of $\mathrm{P}_{\max }$ and $\mathrm{P}_{\min }$ through the programmable digital oscilloscope and makes necessary changes to achieve the desired values of $P_{\max }$ and $P_{\min }$.

If the measured crack-growth increment, which is the difference between the current measured crack length and the last recorded crack length, is equal to or greater than specified values, which 


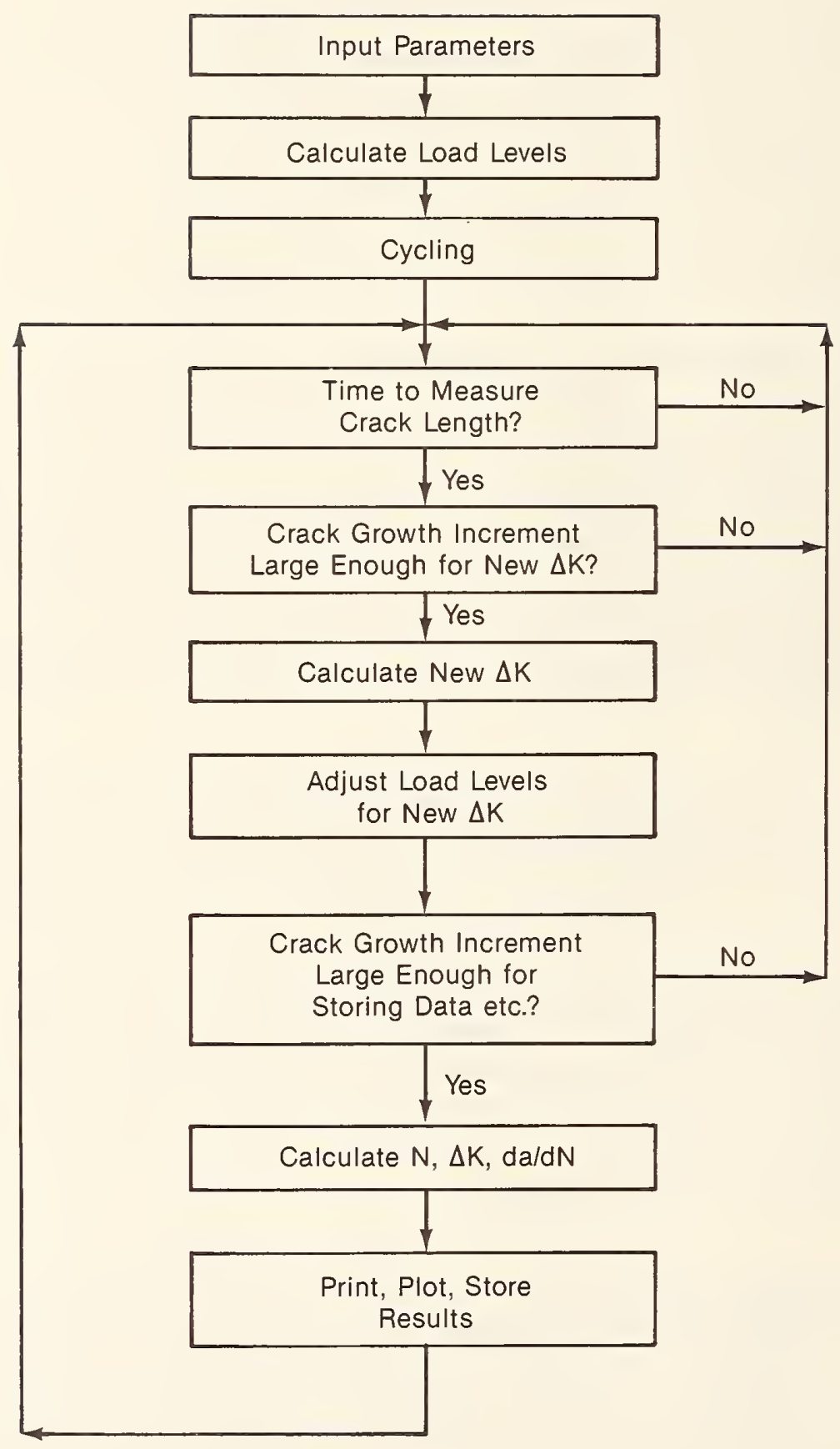

Figure 4. Summary flow chart of the automated near-threshold FCGR test. 
are within the recommended values [8], the values of $\mathrm{N}, \Delta \mathrm{K}$, and $\mathrm{da} / \mathrm{dN}$ are calculated and the results are printed, plotted, and stored. A value of $0.5 \mathrm{~mm}$ is typically specified for a $25.4-\mathrm{mm}-\mathrm{thick}$ standard compact-type specimen. The previously mentioned computer programs for posttest analyses are also applicable for analyzing the data obtained in the near-threshold FCGR test.

Variable-Load-Amplitude FCGR Test

The automated FCGR test system is also used in the variable-load-amplitude FCGR test. The procedures used in this application are similar to those described in the previous two sections.

The computer reads the prerecorded load-time history from the floppy disks and controls the hydraulic machine through the programmable waveform generator. At a preselected time interval, the crack length is measured. A typical interval is $30 \mathrm{~min}$ for an average test frequency of $0.1 \mathrm{~Hz}$. The desired output in the variable-load-amplitude test is time versus crack length. The results are printed, plotted, and stored for posttest analyses.

The present system has two limitations in the application of variable-load-amplitude FCGR testing. One is that the waveform generator needs about $0.1 \mathrm{~s}$ for changing one commamd to another, and this limits the average frequency to about $1 \mathrm{~Hz}$. The needed $0.1 \mathrm{~s}$ for changing commands results in a holding situation of about $0.1 \mathrm{~s}$ at the peak loads when higher test frequencies are used. In a corrosive or a high temperature environment, in which the hold time at peak load is important, this might introduce anomalous fatigue crack growth. The other is limited storage capacity of the floppy disks, which can only store a certain amount of load-time pairs. The present system uses soft disks, which can store about 18,000 load-time pairs. If longer load-time histories are desired, other means of storage, such as hard disks, must be used.

\section{Summary}

An automated FCGR test system has been developed that can be used for tests of constant-loadamplitude FCGR above $10^{-8} \mathrm{~m} / \mathrm{cycle}$ (ASTM E647-83), near-threshold FCGR, and variable-load-amplitude FCGR. The test system saves considerable time in data acquisition and data reduction. The test procedure is relatively easy to follow and enables technicians to produce data with less scatter (with respect to the non-computer-aided technique), because higher precision in crack length measurement and better control in data point spacing are obtained, while manual data interpretation and data fitting are eliminated.

Acknowledgments

Mr. J. C. Moulder of NBS is acknowledged for helpful discussions on the interface between the computer and the instruments. The work was supported by the Department of Interior, Minerals Management Service, and the Department of Energy, office of Fusion Energy.

References

[1] Fatigue Thresholds: Fundamentals and Engineering Applications, J. Backlund, A. F. Blour, and C. J. Beevers, eds., Engineering Materials Advisory Services, Chameleon Prêss, London (1982). 
[2] R. J. Bucci, "Development of a Proposed ASTM Standard Test Method for Near-Threshold Fatigue Crack Growth Rate Measurement," in: Fatigue Crack Growth Measurement and Data Analysis, ASTM STP 738, S. J. Hudak, Jr. and R. J. Bucci, eds., American Society for Testing and Materials, Philadelphia (1981), pp. 5-28.

[3] T. W. Crooker, F. D. Bogar, and G. R. Yoder, "Standard Method of Test for Constant-LoadAmplitude Fatigue Crack Growth Rates in Marine Environments," NRL Memorandum Report 4594 , Naval Research Laboratory, Washington, DC (August 1981).

[4] R. P. Wei, W. Wei, and G. A. Miller, "Effect of Measurement Precision and Data-Processing Procedure on Variability in Fatigue Crack Growth-Rate Data," Journal of Testing and Evaluation, Vol. 7, No. 2 (March 1979), pp. 90-95.

[5] The Measurement of Crack Length and Shape During Fracture and Fatigue, C. J. Beevers, ed., Engineering Materials Advisory Services, Chameleon Press, London (1980).

[6] Advances in Crack Length Measurement, C. J. Beevers, ed., Engineering Materials Advisory Services, Chameleon Press, London (1981).

[7] Y. W. Cheng, "A Computer-Interactive Fatigue Crack Growth Rate Test Procedure," in: Materials Studies for Magnetic Fusion Energy Applications at Low Temperatures--VI, R. P. Reed and N. J. Simon, eds., NBSIR 83-1690, National Bureau of Standards, Boulder, Colorado (1983), pp. $4 \uparrow-5 \uparrow$.

[8] J. J. Ruschau, "Fatigue Crack Growth Rate Data Acquisition System for Linear and Nonlinear Fracture Mechanics Applications," Journal of Testing and Evaluation, Vol. 9, No. 6 (Nov. 1981), pp. $317-323$.

[9] "Proposed ASTM Test Method for Measurement of Fatigue Crack Growth Rates," in: Fatigue Crack Growth Measurement and Data Analysis, ASTM STP 738, S. J. Hudak, Jr. and R. J. Bucci, eds., American Society for Testing and Materials, Philadelphia (1981), pp. 340-356.

[10] W. Elber, "The Significance of Fatigue Crack Closure," in: Damage Tolerance in Aircraft Structures, ASTM STP 486, M. S. Rosenfeld, ed., American Society for Testing and Materials, Philadelphia (1971), pp. 230-242.

[11] S. J. Hudak, Jr., A. Saxena, R. J. Bucci, and R. C. Malcolm, "Development of Standards of Testing and Analyzing Fatigue Crack Growth Rate Data," AFML-TR-78-40, Air Force Materials Laboratory, Wright-Patterson Air Force Base, Ohio (May 1978).

[12] T. Nicholas, N. E. Ashbaugh, and T. Weerasooriya, "On the Use of Compliance for Determining Crack Length in the Inelastic Range," to be published in ASTM STP 833.

[13] R. L. Tobler and W. C. Carpenter, "A Numerical and Experimental Verification of Compliance Functions for Compact Specimens," to be published in Engineering Fracture Mechanics.

[14] P. C. Paris and F. Erdogan, "A Critical Analysis of Crack Propagation Laws," Journal of Basic Engineering, Trans. ASME, series D, Vol. 85, No. 3 (1963), pp. 528-534. 
THE FATIGUE CRACK GROWTH OF A SHIP STEEL

IN SALTWATER UNDER SPECTRUM LOADING ${ }^{+}$

\author{
Yi-Wen Cheng \\ Fracture and Deformation Division \\ National Bureau of Standards \\ Boulder, Colorado
}

Abstract

Fatigue crack growth under spectrum loading intended to simulate sea loading of offshore structures in the North sea was studied using the fracture mechanics approach. A digital simulation technique was used to generate samples of load-time histories from a power spectrum characteristic of the North Sea environment. In the constant-load-amplitude tests, the effects of specimen orientation and stress ratio on fatigue crack growth rates were negligible in the range $2 x 10^{-5}$ to $10^{-3} \mathrm{~mm} /$ cycle. Fatigue crack growth rates in a 3.5 percent $\mathrm{NaCl}$ solution were two to five times higher than those observed in air in the stress intensity factor range 25 to $60 \mathrm{MPa} / \mathrm{m}$. The average fatigue crack growth rates under spectrum loading and under constant-amplitude loading were in excellent agreement when fatigue crack growth rate was plotted as a function of the appropriately defined equivalent-stress-intensity range. This procedure is equivalent to applying Miner's summation rule in fatigue life calculations.

Key words: corrosion fatigue; fatigue crack growth; fracture mechanics; seawater environment; spectrum loading; structural steel.

+ Published in the International Journal of Fatigue, Vol. 7 (April 1985), pp. 95-100. 
In recent years the petroleum industry has built offshore drilling and production platforms in deeper waters and more hostile climates. As the offshore platforms encounter more severe weather and rougher sea-state conditions, fatigue becomes a more important factor in consideration of structural integrity. In treating the fatigue problem, it is usual to separate the fatigue life into two separate stages: (1) crack initiation and (2) crack growth. For welded structures, such as offshore platforms, crack initiation, during which microcracks form, grow, and coalesce to become a macrocrack, is less important than crack growth because fabrication imperfections are always present. Most of the fatigue life is spent in the crack growth stage.

Analysis of fatigue crack growth under spectrum loading, which is usually irregular in nature, is complicated because of load-sequence interaction effects. A cycle-by-cycle approach, taking into account overload effects, has been used in the aerospace industry $[1,2]^{*}$. Other empirical approaches, such as root mean square (RMS) [3] or root mean cube (RMC) [4], have also been successfully used to correlate experimental results of spectrum loading of bridges with those of constant-amplitude loading. Use of the latter approaches is empirical and implementation of the former is time-consuming. A more efficient approach has been proposed [5,6], which will be discussed later. This paper describes the work carried out at the National Bureau of Standards over the past two years on the investigation of fatigue crack growth in ABS grade EH36 steel under simulated off shore platform service conditions.

\section{Load Spectrum}

Service loads acting on offshore structures are random in nature. The main source of cyclic loading derives from wave action, which excites a vibration at approximately the wave frequency. The magnitude of the vibration depends mainly on wave height and direction, size of the component and its location in a structure. Besides those due to wave action, additional vibrations are induced from structural responses to the wave action. The magnitude and frequency of the structural resonance depend on local structural characteristics. Thus, the precise definition of load-time history is extremely complex and would be expected to vary between locations on the same structure.

Because of complexity in and lack of information on the precise load-time history experienced by offshore structures, no standard load-time history exists for purposes of analysis and experiment. Numerous load-time histories, including Rayleigh peak distribution [7,8], Gaussian peak distribution [7-9], Gassner blocked program [10], and others [11], have been used to evaluate fatigue performance of weldments. The load spectrum selected for the present investigation was realistic for offshore structures in the North Sea environment [12], as shown in figure 1. The principal loads in this spectrum, those with a frequency of about $0.1 \mathrm{~Hz}$, are due to wave action. The higher frequency (about $0.35 \mathrm{~Hz}$ ) loads are due to structural resonance.

*Numbers in brackets denote references listed at the end of each paper. 


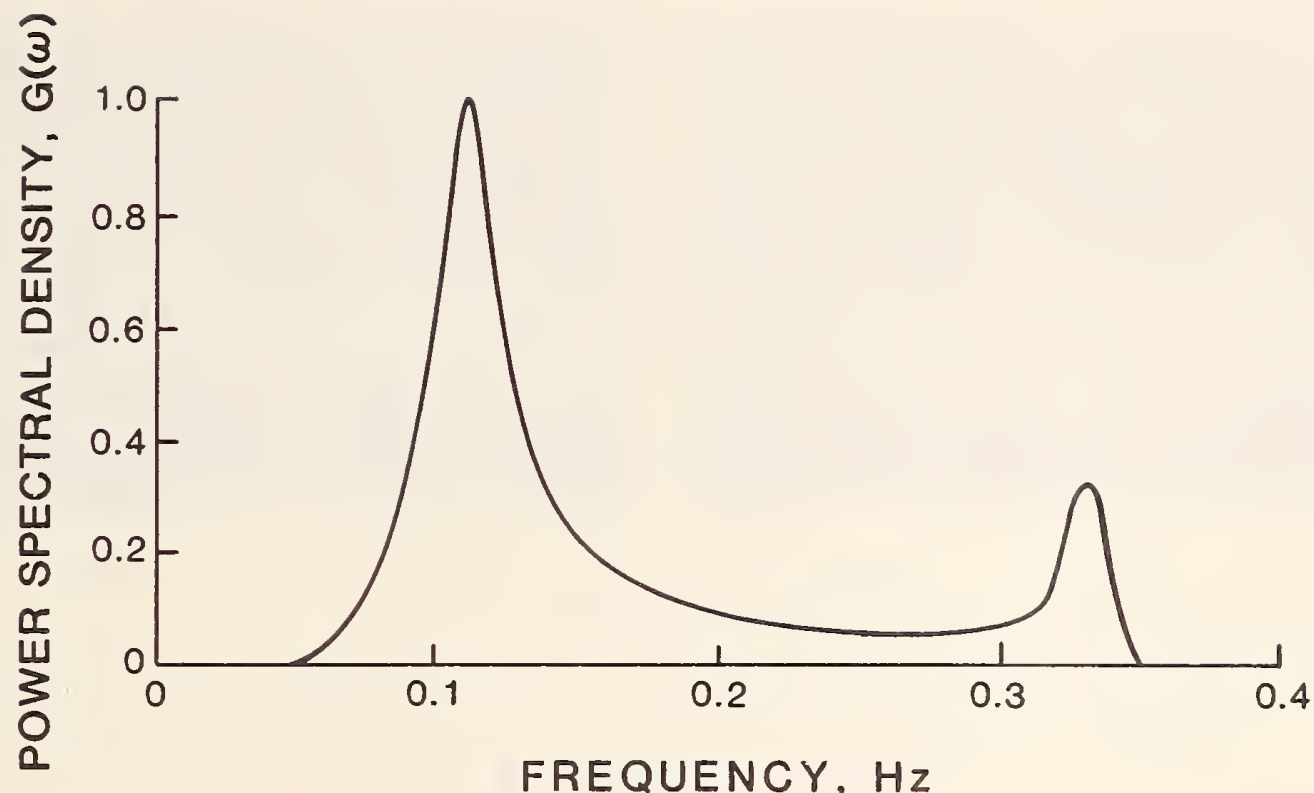

Figure 1. Characteristic power spectrum for offshore structures in the North Sea.

\section{Simulation of Load-Time Histories}

For purpose of experiment, the power spectral density function, $S(\omega)$, is not sufficient; load-time history, $X(t)$, has to be used. In this investigation, the following expression [13,14] was used to reconstruct $X(t)$ from $S(\omega)$ :

$$
X(t)=\sum_{k=1}^{J}\left[2 G\left(\omega_{k}\right) \Delta \omega_{k}\right]^{0.5} \cos \left(\omega_{k} t+\Phi_{k}\right)
$$

where $G(\omega)$, as shown in figure 1, is the one-sided power spectral density function in terms of frequency, $\omega[G(\omega)=2 S(\omega)$ for $\omega>0] . \Phi_{k}$ is a random phase angle uniformiy distributed between 0 and $2 \pi$; and $\omega_{k}$ is the midpoint of $\Delta \omega_{k}$. The number of harmonic functions, $J$, is arbitrary; in this investigation it was taken to be 50 . Frequency is defined over the interval [0, $\left.\omega_{u}\right]$ with partitions of length such that

$$
\omega_{u}=\sum_{k=1}^{J} \Delta \omega_{k}
$$

An $X(t)$ with an undesired short period occurs if the minimum common divider for all the $\Delta \omega_{k}$ is large. This problem is avoided by using random intervals for $\Delta \omega_{k}$. In this investigation, $\Delta \omega_{k}$ was taken from a normal distribution with a mean equal to the average of $\Delta \omega_{k}$ and a standard deviation equal to one-tenth the average of $\Delta \omega_{k}$. 
A computer program written in Fortran IV has been developed to simulate X( $t$ ) from equation ( 1 ). Newton's method was then used to locate peaks and troughs with respect to time in the simulated load-time history.

Two load spectra were used in this study. One contains only the wave-loading portion of the power spectral density function with frequencies up to $0.2 \mathrm{~Hz}$ (case I), as shown in figure 1 . The other reproduces the whole curve (case II). Typical simulated load-time histories, X( $t$ ), from the power spectral density function are shown in figure 2.

Values of the irregularity factor (number of mean crossings/number of peaks plus troughs) calculated from the power spectra are 0.90 and 0.69 for case I and case II, respectively; they are 0.90 and 0.68 , as determined from the simulated load-time histories. The excellent agreement between the values obtained from the power spectra and the simulated load-time histories indicates that use of equation (1) is satisfactory. Values of the clipping ratio are 3.84 and 3.91 for case I and case II, respectively. Clipping ratio is defined as the ratio of the maximum load amplitude, which is the difference between the maximum peak and the mean load, to the root-mean-square value of load amplitude.*

Experimental Procedures

Test Material and Specimens

The test material was a 25.4-mm-thick plate of ABS grade EH36 steel, a 350-MPa-yield-strength C-Mn steel. The chemical composition is given in table 1. The steel was in the normalized condition and had particularly uniform properties due to sulfide shape control.

Fatigue crack growth rate (FCGR) tests under constant-amplitude loading and spectrum loading were conducted using standard (25.4-mm-thick) and modified [15] compact specimens. The modified compact specimen was a lengthened and side-grooved (with a net thickness of $3.18 \mathrm{~mm}$ ) version of the standard compact specimen. The deep side grooves determine the plane of crack growth and provide a strip of material that undergoes large cyclic plasticity during fatigue. Specimens were in LT and TL orientations.

Test Apparatus and Environment

Fatigue crack growth rate tests were conducted with a fully automated test system, which was described in a previous paper [16]. Briefly, the fully automated test system consists of a closed-loop, servo-controlled, hydraulic mechanical test machine, a programmable digital oscilloscope serving as an analog-to-digital converter, a programmable arbitrary waveform generator, and a minicomputer.

Tests were performed in laboratory air and in 3.5 percent $\mathrm{NaCl}$ solution with a free corroding

*This should not be confused with the root-mean-square value of load range which was used in reference 3 . 

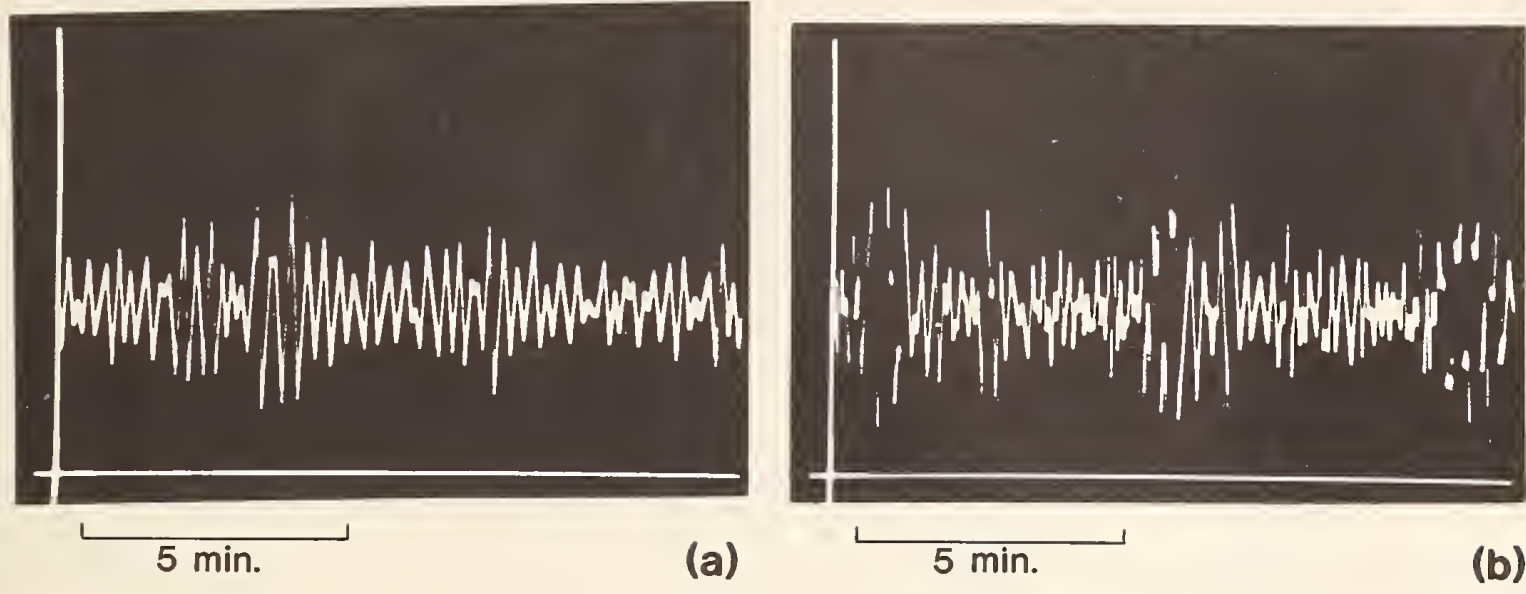

Figure 2. Samples of load-time histories: (a) case I, (b) case II.

Table 1. Chemical composition of ABS grade EH36 steel.

\begin{tabular}{lllllllllll}
\hline C & Mn & P & S & Si & Cu & Ni & Cr & Mo & Fe \\
\hline 0.12 & 1.39 & 0.015 & 0.006 & 0.380 & 0.05 & 0.03 & 0.05 & 0.007 & bal. \\
\hline
\end{tabular}

condition (no cathodic protection). Crack lengths were measured by the compliance technique. The crack-length measurement technique was accurate at least to $0.1 \mathrm{~mm}$. In the saltwater tests, the clip-gage used for displacement measurements was mounted on a scissors-like extension to avoid immersion in the saltwater. The environmental chamber was a 19-l-capacity plastic container in which the saltwater was continuously circulated at a rate of $26 \mathrm{l} / \mathrm{min}$ through a diatomaceous-earth filter. The $\mathrm{NaCl}$ concentration, temperature, and $\mathrm{pH}$ value of the saltwater were monitored periodically.

\section{Loading Conditions}

In the constant-load-amplitude tests, the stress ratio $R$ (i.e., the ratio of minimum to maximum stress) was kept constant at 0.1 or 0.5 . Tests in air were conducted at $10 \mathrm{~Hz}$ and tests in 3.5 percent $\mathrm{NaCl}$ solution were conducted at $0.1 \mathrm{~Hz}$. A sinusoidal load-time history was used.

In the spectrum-loading tests, the simulated load-time histories were recorded on floppy disks, which were read by a minicomputer. The minicomputer then sent the signals to the hydraulic mechanical test machine through a programmable arbitrary waveform generator. The loads were periodically monitored with an oscilloscope to ensure that the input values to the hydraulic mechanical test machine and the output values from the load cell agreed. No modifications, such as truncation, were made to the simulated load-time histories with the exception of the levels of mean loads. The mean loads were increased so that the minimum loads were slightly-above zero because the 
apparatus was limited to tension-tension loading. The stress ratio, therefore, varied from about 0 (usually for large load ranges) to about 1 (usually for very small load ranges).

Because of the limited capacity of the floppy disk, the total recorded lengths of load-time histories were $18.0 \mathrm{~h}$ for case I and $9.3 \mathrm{~h}$ for case II. The recorded lengths corresponded to return periods of 15,773 and 11,890 mean-load crossings for case I and case II, respectively. The wave shape was triangular. It has been shown [17] that there are no differences in FCGR between tests conducted with sinusoidal and triangular waveforms. Both tests in air and in saltwater were conducted at ambient temperature.

Experimental Results and Discussion

Constant-Load-Amplitude Tests

Fatigue crack growth rates were calculated using the linear-elastic fracture mechanics approach; the experimental results are shown in figures 3 through 6 . As shown in figure 3 , specimen orientation, TL versus LT, had little influence on FCGR in air and in saltwater. The FCGRs in air and in saltwater are compared in figures 4 and 5 . For stress intensity factor range, $\Delta K$, between 30 and $40 \mathrm{MPa} / \mathrm{m}$, the FCGRs in saltwater were up to five times higher than those in air. A summary of all results in figure 6 indicated that stress ratio had little influence on FCGR in air. Below $4 \times 10^{-5} \mathrm{~mm} /$ cycle the FCGRs in air and in saltwater were about the same.

The minimal influence of stress ratio and specimen orientation observed is consistent with that of other investigators [18] in the FCGR range $2 \times 10^{-5}$ to $10^{-3} \mathrm{~mm} / \mathrm{cycle}$. The effects of stress ratio and specimen orientation are expected to be more pronounced at higher and lower FCGRs [18].

Note that in each of the FCGR curves the high values were obtained with the modified compact specimen. These data follow the same trend line as the data obtained with the standard compact specimen. Thus, it appears that the linear-elastic fracture mechanics approach can be applied to fatigue crack growth in conditions of contained large cyclic plasticity.

Spectrum-Loading Tests

Fatigue crack growth rates under spectrum loading were analyzed using the equivalent-stressrange approach $[5,6]$, which is described in the following. For simplicity the paris equation, $\mathrm{da} / \mathrm{dN}=\mathrm{C}(\Delta \mathrm{K})^{\mathrm{n}}$, is used for discussion. Here, da/dN is crack growth increment per load cycle, $\Delta \mathrm{K}$ is stress intensity factor range, and $C$ and $n$ are constants. $\Delta K$ is defined as

$$
\Delta K=h(\pi a)^{0.5} Y
$$

where $\mathrm{h}=$ stress range

$\mathrm{a}=$ crack length

$Y=$ geometry factor

If $\mathrm{da} / \mathrm{dN} \ll$ crack length, a, and there are no load-sequence interaction effects, then 


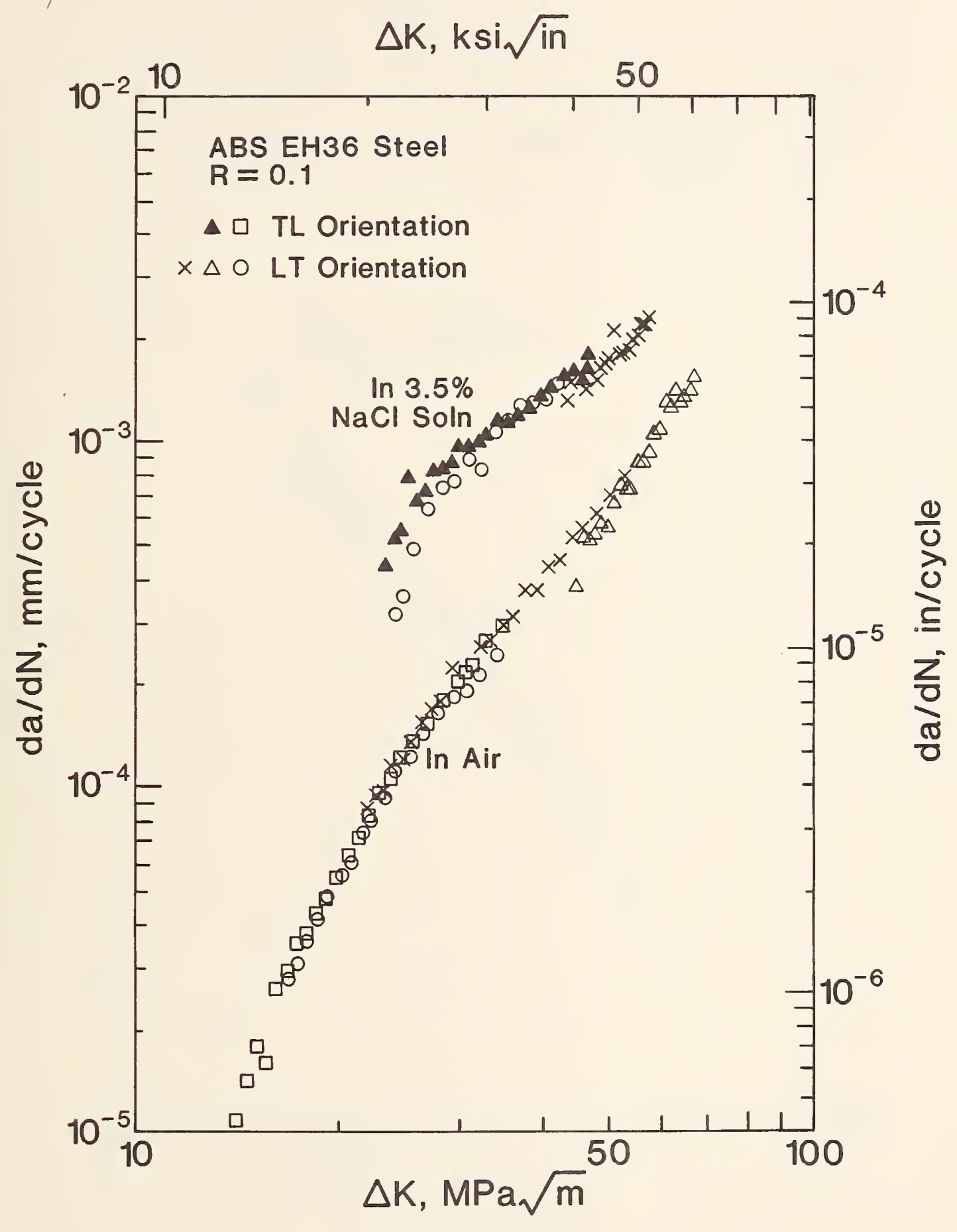

Figure 3. Fatigue crack growth rates in EH36 steel: effect of specimen orientation. Different symbols represent results obtained from different specimens. 


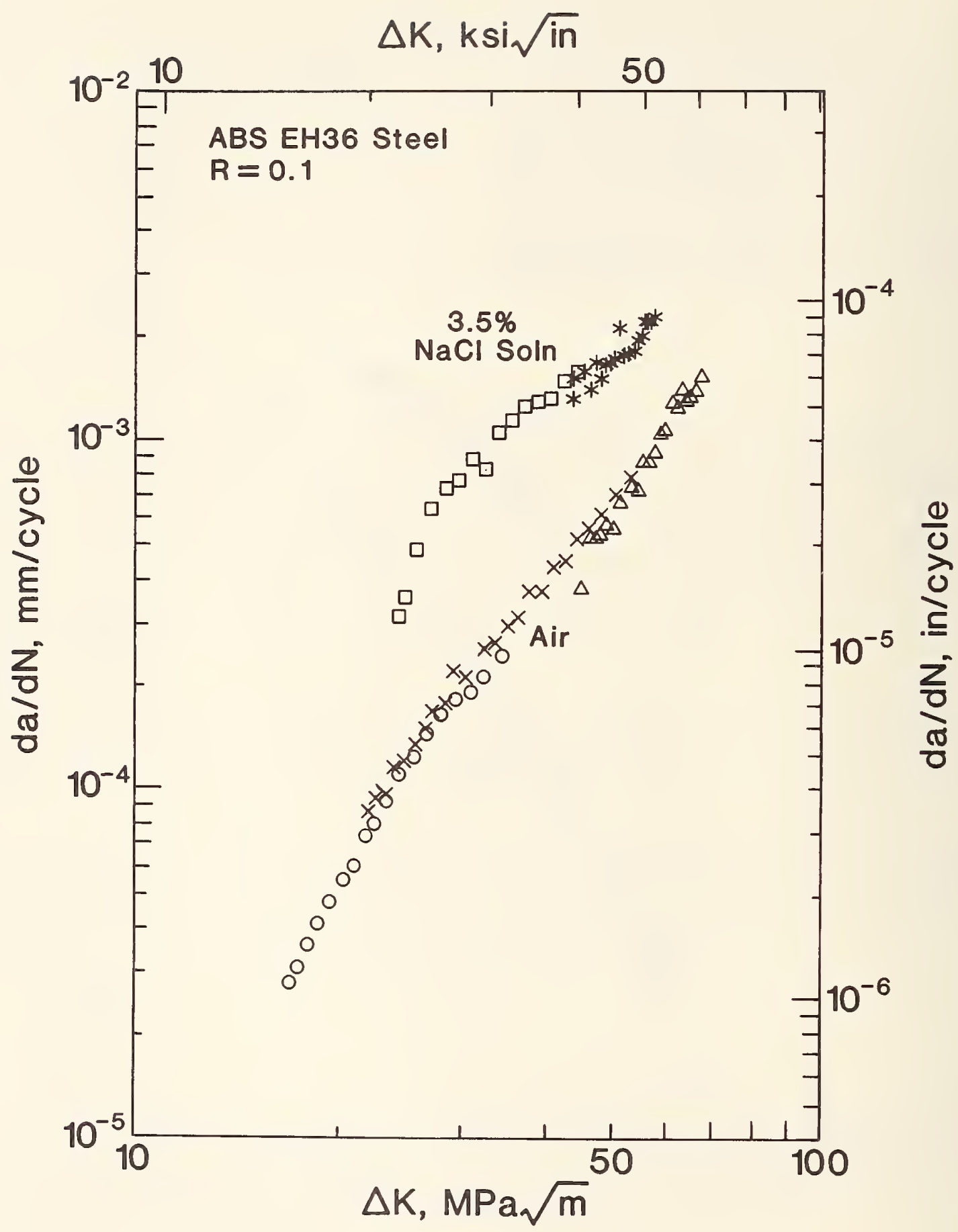

Figure 4. Fatigue crack growth rates in EH36 steel: saltwater versus air at stress ratio equal to 0.1 . Different symbols represent results obtained from different specimens. 


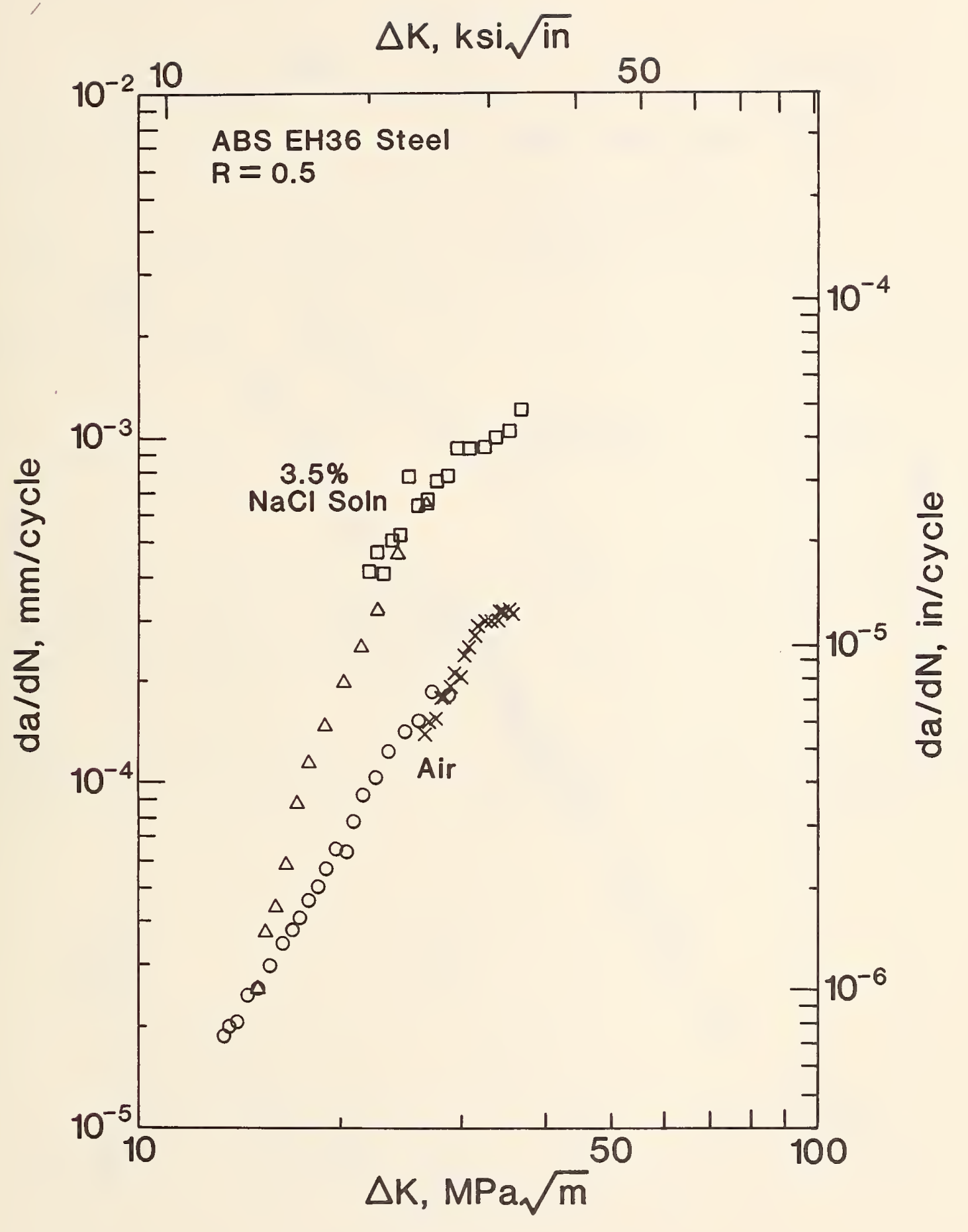

Figure 5. Fatigue crack growth rates in EH36 steel: saltwater versus air at stress ratio equal to 0.5 . Different symbols represent results obtained from different specimens. 


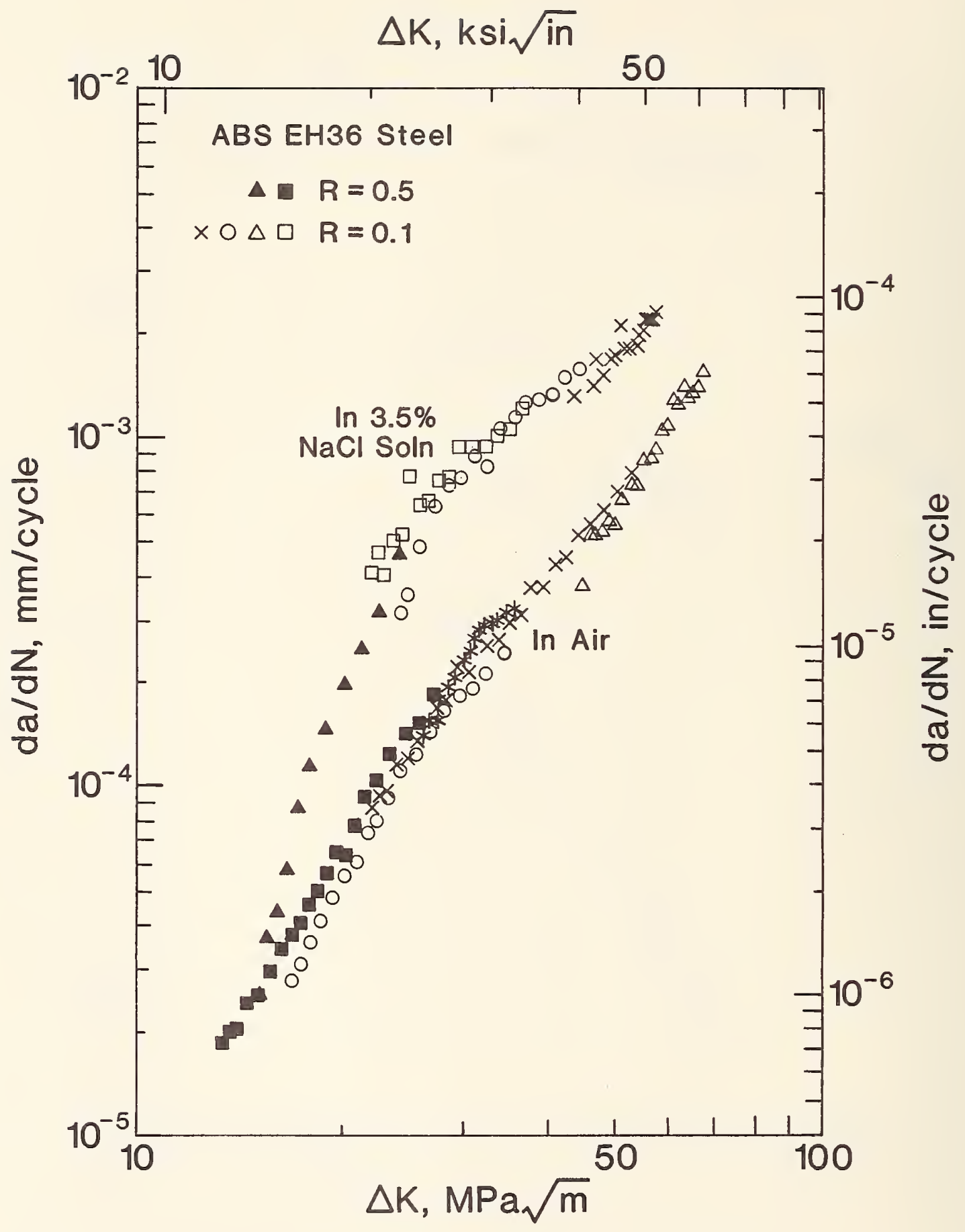

Figure 6. Fatigue crack growth rates in EH36 steel: summary. Different symbols represent results obtained from different specimens. 


$$
\begin{aligned}
& \Delta a_{1}=c h_{1}{ }^{n}\left[(\pi a)^{0.5} Y\right]^{n} \\
& \Delta a_{2}=c h_{2}{ }^{n}\left[(\pi a)^{0.5} Y\right]^{n} \\
& \cdots \\
& \cdots \\
& \cdots \\
& \Delta a_{N}=c h_{N}^{n}\left[(\pi a)^{0.5} Y\right]^{n}
\end{aligned}
$$

Summing equations (4) through (6) gives

$$
\left(\Delta a_{1}+\Delta a_{2}+\ldots+\Delta a_{N}\right)=c\left(h_{1}{ }^{n}+h_{2}^{n}+\ldots+h_{N}^{n}\right)\left[(\pi a)^{0.5} Y\right]^{n}
$$

The left-hand side of equation (7) is the increment of crack growth in $\mathrm{N}$ successive cycles; the average FCGR per cycle is then

$$
\begin{aligned}
\mathrm{da} / \mathrm{dN} & =c\left[\left(\mathrm{~h}_{1}{ }^{\mathrm{n}}+\mathrm{h}_{2}{ }^{\mathrm{n}}+\ldots+\mathrm{h}_{N}{ }^{\mathrm{n}}\right) / N\right]\left[(\pi a)^{0.5} Y\right]^{\mathrm{n}} \\
& =c\left[\left(\mathrm{~h}^{\mathrm{n}}\right)^{1 / n}(\pi a)^{0.5} Y\right]^{\mathrm{n}} \\
& =c\left[\mathrm{~h}_{\text {eq }}(\pi a)^{0.5} Y\right]^{\mathrm{n}}
\end{aligned}
$$

Here $N$ should be large in order for the equivalent-stress range, $h_{\text {eq }}$, to be representative of a load spectrum. The definitions of stress range and cycle used in this investigation are given in figure 7. The value of $\mathrm{n}$ in 3.5 percent $\mathrm{NaCl}$ solution test is 5.5 , which is derived from the results of constant-load-amplitude test in the $\Delta \mathrm{K}$ range of interest.

The results for FCGR under spectrum loading in 3.5 percent NaCl solution are given in figures 8 and 9 for case I and case II, respectively. Excellent agreement between spectrum and sinusoidal loading is observed. This suggests that load-sequence interaction effects are effectively

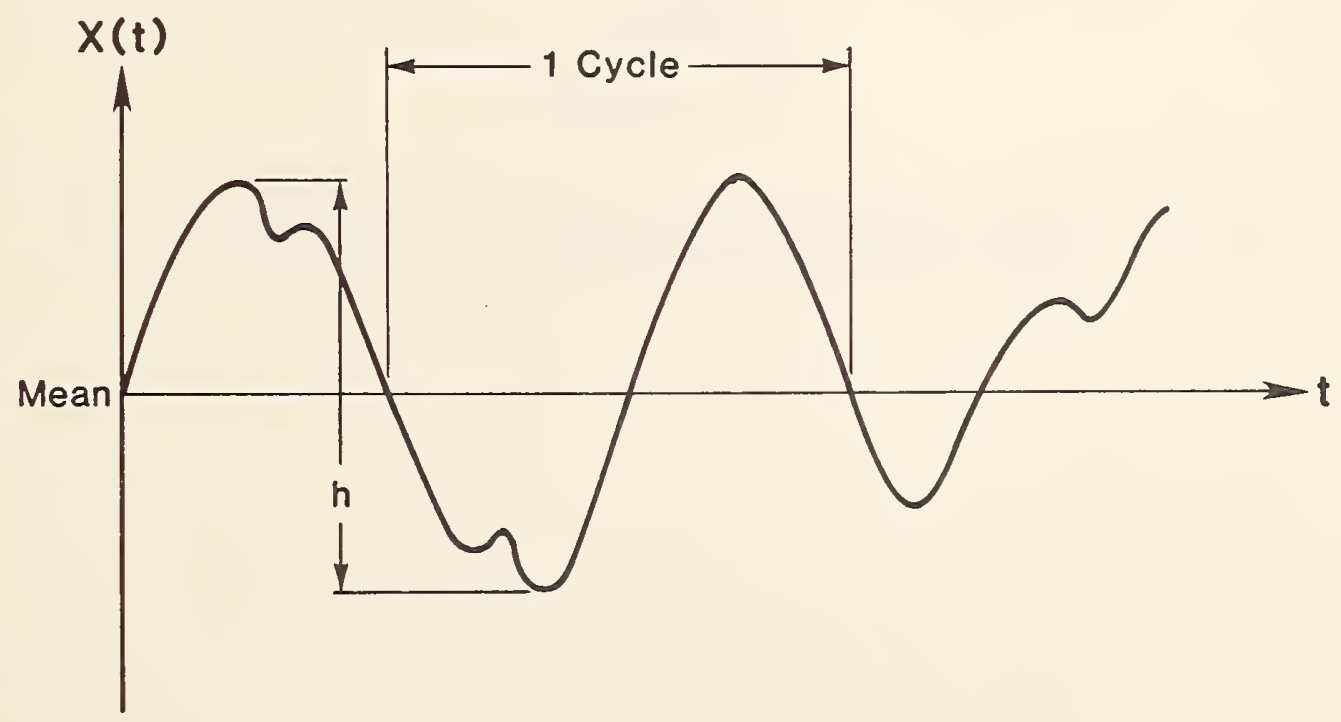

Figure 7. Definitions of stress range and cycle. 


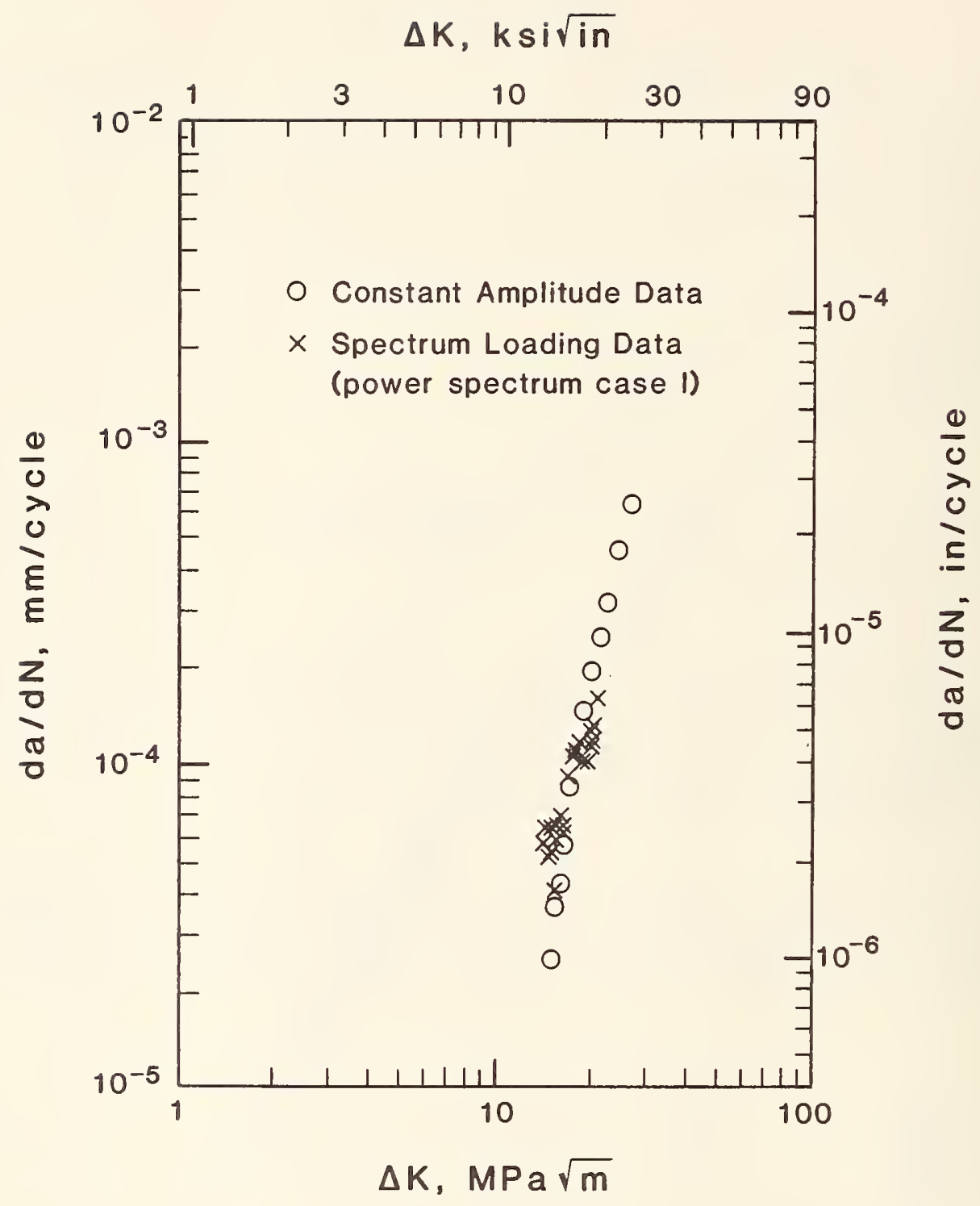

Figure 8. Fatigue crack growth rates in EH36 steel in saltwater: constant-amplitude loading versus spectrum loading (case I). 


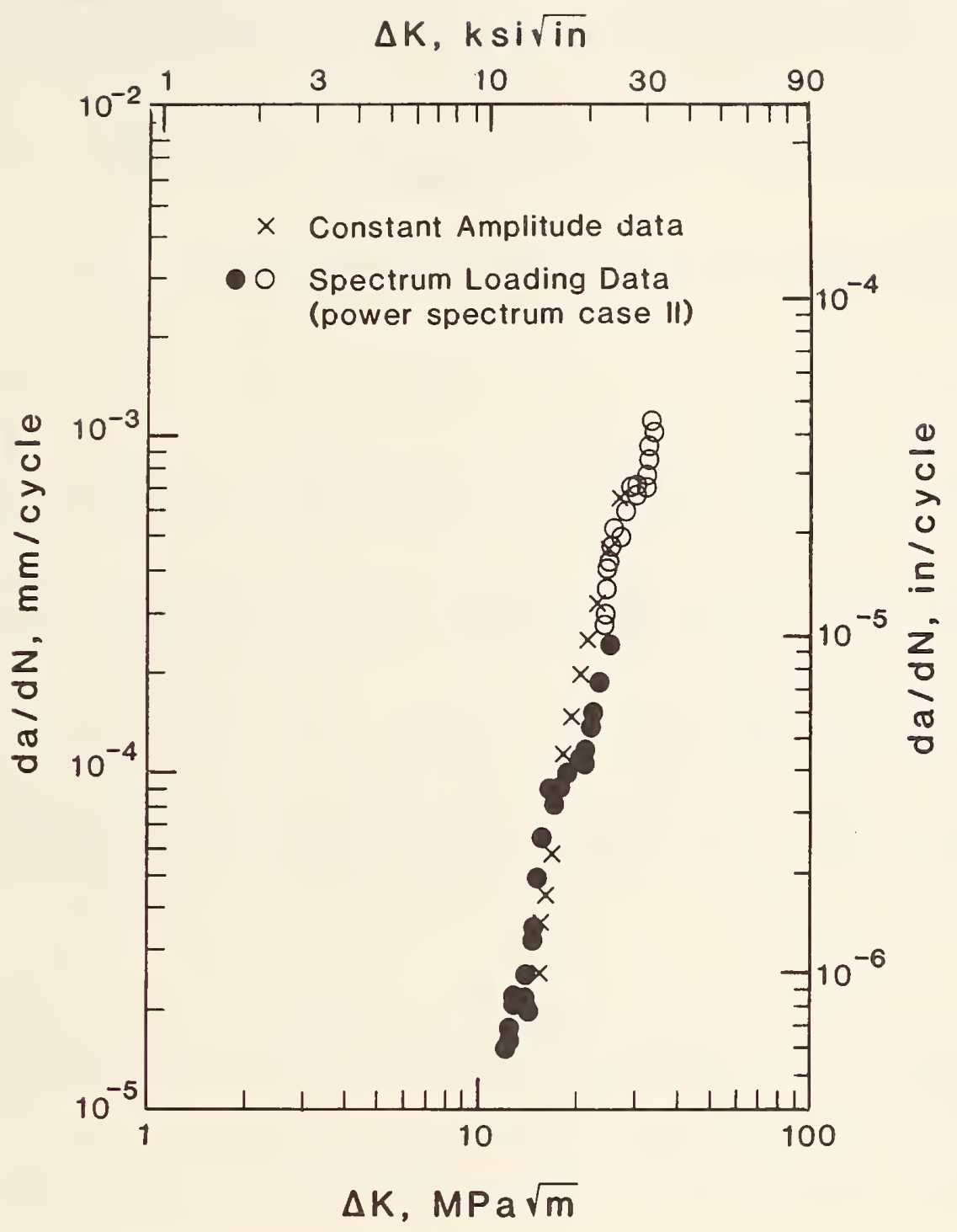

Figure 9. Fatigue crack growth rates in EH36 steel in saltwater: constantamplitude loading versus spectrum loading (case II). 
negligible. The lack of observed load-sequence interaction effects is probably due to low clipping ratio of 3.84 (case I) and 3.91 (case II). The results also imply that under spectrum loading at a given $\mathrm{da} / \mathrm{dN}$, value of $\Delta \mathrm{K}$ is smaller if RMS $(n=2)$ or RMC $(n=3)$ is used because heq decreases with decreasing $n$. This shifts the spectrum-loading results to the left of those of constant-amplitude loading (figures 8 and 9), resulting in a higher FCGR in spectrum loading than in constant-amplitude loading at a given value of $\Delta K$. Conversely, a lower FCGR will result if either RMS or RMC is used to predict FCGR in a region where $\mathrm{n}$ is larger than 3 , such as in the present investigation.

Miner's rule [19] states that a component (or specimen) will fail if

$\sum\left(\mathrm{f}_{i} / \mathrm{F}_{\mathrm{if}}\right) \geqq 1$

where $\mathrm{f}_{i}$ is the number of fatigue cycles applied at stress range $\Delta S_{i}$ and $F_{i f}$ is the number of fatigue cycles to failure at stress range $\Delta S_{i}$. This rule implies that there are no load-sequence interaction effects. Miner's rule, as originally stated, applied to fatigue failure rather than fatigue crack growth. Terms such as "Miner's rule of fatigue crack growth" are often used to mean fatigue crack growth with no load-sequence interaction effects. Such statements represent a generalization of the original Miner's rule. The data of this study, along with others [5], support such a generalization for a clipping ratio less than 4 and constant mean stress, which might be stated as follows: Load-sequence interactions are small, or they tend to cancel, such that overall effect on fatigue life is small. For such a rule to be applicable to random or quasi-random load-time histories, a definition of a cycle is needed. In this study, the load amplitude of one cycle has been defined as the maximum load difference among three successive mean crossings (figure 7).

The value of $h_{\text {eq }}$ can be obtained in a closed-form expression from the power spectrum if the loading is a narrow-band random process $[6,20]$. However, no closed-form solutions are available for wide-band random processes.

\section{Conclusions}

The following conclusions were drawn from this investigation:

1. The digital simulation technique is adequate to generate samples of load-time histories from a given power spectrum.

2. In constant-load-amplitude tests, the influence of specimen orientation and stress ratio on fatigue crack growth rate were negligible in the fatigue crack growth rate range $2 \mathrm{x} 10^{-5}$ to $10^{-3} \mathrm{~mm} /$ cycle. Fatigue crack growth rates in a 3.5 percent Nacl solution were two to five times higher than those observed in air in the stress intensity factor range 25 to $60 \mathrm{MPa} / \mathrm{m}$.

3. The average fatigue crack growth rates under spectrum loading and under constant-amplitude loading were in excellent agreement when fatigue crack growth rate was plotted as a function of the appropriately defined equivalent-stress-intensity range. This procedure is equivalent to applying Miner's summation rule in fatigue life calculations. 
Helpful discussions with Drs. H. I. McHenry and D. T. Read, and Professors S. Berge and P. N. Li are appreciated. This work was supported by the Department of Interior, Minerals Management Service.

References

[1] 0. E. Wheeler, "Spectrum Loading and Crack Growth," Journal of Basic Engineering, Trans. ASME, Vol. 94 (March 1972), pp. 181-186.

[2] J. Willenborg, R. M. Engle, and H. A. Wood, "A Crack Growth Retardation Model Using an Effective Stress Concept," AFFDL-TM-71-FBR, Air Force Flight Dynamics Laboratory, Dayton, Ohio (January 1971).

[3] J. M. Barsom, "Fatigue Crack Growth under Variable-Amplitude Loading in Various Bridge Steels," in: Fatigue Crack Growth under Spectrum Loads, ASTM STP 595, American Society for Testing and Materials, Philadelphia (1976), pp. 217-235.

[4] P. Albrecht and K. Yamada, "Simulation of Service Fatigue Loads for Short-Span Highway Bridges," in: Service Fatigue Loads Monitoring, Simulation, and Analysis, ASTM STP 671, American Society for Testing and Materials, Philadelphia (1979), pp. 255-277.

[5] W. D. Dover, S. J. Holbrook, and R. D. Hibberd, "Fatigue Life Estimates for Tubular Welded T Joints Using Fracture Mechanics," in: Proceedings of European Offshore Steels Research Seminar, The Welding Institute, Cambridge, UK (November 27-29, 1978), pp. V/PD-1 - V/PD-11.

[6] F. A. McKee and J. W. Hancock, "Fatigue Crack Growth and Failure in Spectrum Loading," in: Proceedings of European Offshore Steels Research Seminar, The Welding Institute, Cambridge, UK (November 27-29, 1978), pp. V/PC-1 - V/PC-10.

[7] L. P. Pook, "Proposed Standard Load Histories for Fatigue Testing Relevant to offshore Structures," NEL Report No. 624, National Engineering Laboratory, Glasgow, UK (October 1976).

[8] M. H. J. M. Zwaans, P. A. M. Jonkers, and J. L. Overbeeke, "Random Load Tests on Plate Specimens," Eindhoven University of Technology, The Netherlands (December 1980).

[9] P. J. Haagensen and V. Dagestad, "Corrosion Fatigue Crack Propagation in Structural Steel Under Stationary Random Loading," SINTEF Report No. 18 A 78017, The Foundation of Scientific and Industrial Research at the Norwegian Institute of Technology, Trondhein, Norway (October 2, 1978).

[10] H. P. Lieurade, J. P. Gerald, and C. J. Putot, "Fatigue Life Prediction of Tubular Joints," in: Proceedings of the Offshore Technology Conference, OTC Paper No. 3699, Houston, Texas (May 1980).

[11] R. M. Olivier, M. Greif, W. Oberparleiter, and W. Schutz, "Corrosion Fatigue Behavior of Offshore Steel Structures under Variable Amplitude Loading," in: Proceedings of International Conference on Steel in Marine Structures, Paper 7.1, Paris, France (October 5-8, 1981).

[12] R. M. Kenley, "Measurement of Fatigue Performance of Forties Bravo," in: Proceedings of the Offshore Technology Conference, OTC Paper No, 4402, Houston, Texas (May 1982).

[13] J. N. Yang, "Simulation of Random Envelop Processes," Journal of Sound and Vibration, Vol. 21, No. 1 (1972), pp. 73-85.

[14] P. H. Wirsching and A. M. Shehata, "Fatigue under Wide Band Random Stresses Using the Rainflow Method," Journal of Engineering Materials and Technology, Trans. ASME, Vol. 99, No. 3 (July 1977), pp. 205-211.

[15] H. I. McHenry and G. R. Irwin, "A Plastic-Strip Specimen for Fatigue Crack Propagation Studies in Low Yield Strength Alloys," Journal of Materials, JMLSA, Vol. 7, No. 4 (December 1972), pp. $455-459$. 
[16] Y. W. Cheng and D. T. Read, "An Automated Fatigue Crack Growth Rate Test System," to be published in ASTM STP 377.

[17] J. M. Barsom, "Effect of Cyclic Stress Form on Corrosion Fatigue Crack Propagation below K in a High Yield Strength Steel," in: Corrosion Fatigue: Chemistry, Mechanics, and Microstructure, National Association for Corrosion Engineers, NACE-2, Houston, Texas (1972), pp. 424-435.

[18] R. O. Ritchie, "Influence of Microstructure on Near-Threshold Fatigue-Crack Propagation in Ultra-high Strength Steel," Metal Science, Vol. II (1977), pp. 368-381.

[19] M. A. Miner, "Cumulative Damage in Fatigue," Journal of Applied Mechanics, Trans. ASME, Vol. 12 (September 1945), pp. A159-A164.

[20] J. N. Yang, "Statistics of Random Loading Relevant to Fatigue," Journal of the Engineering Mechnaics Division, Proceedings of the American Society of Civil Engineers, Vol. 100, No. EM3 (June 1974), pp. 469-475. 


\author{
Pei-Ning $\mathrm{Li}^{+}$ \\ Yi-Wen Cheng \\ Fracture and Deformation Division \\ National Bureau of Standards \\ Boulder, Colorado 80303
}

Abstract

This paper presents several simplified methods of evaluating the irregularity factor of a power spectrum. The irregularity factor can be computed either from integration of the power spectrum or from the characteristic bandwidth and the center frequency of the power spectrum. The characteristic bandwidths and the center frequencies of power spectra with irregular shapes are defined in this paper. Estimated errors associated with the simplified methods in the cases of practical interest are given.

Key words: bandwidth; irregularity factor; power spectrum; random loading fatigue.

${ }^{+}$Guest worker, on leave from East-China Institute of Chemical Technology, Shanghai, China. 
In many structural applications, such as offshore platforms in the North Sea environment, fatigue under random loading is a major problem. Load-time histories under random loading are usually difficult to predict and can only be treated in a statistical manner. If the random loading is a stationary Gaussian process, as is commonly assumed, then there exists a power spectrum, G(f), which possesses all the statistical properties of the original load-time history [1]* . Therefore, the power spectrum is conveniently used to represent the random load-time history.

Several important parameters in the random-loading fatigue analysis can be derived from the power spectrum. These parameters include root-mean-square (RMS) value of the load amplitude, average rises and falls, and the irregularity factor, $\alpha[2,3]$. The RMS value equals the square root of the area under the power spectrum-versus-frequency curve. The average rises and falls, which are related to the RMS value and the irregularity factor of the power spectrum, have been analytically and numerically studied [4]. The irregularity factor has been used as a parameter to normalize the fatigue damage caused by narrow-band and broad-band loadings [5]. The irregularity factor of a power spectrum is usually computed from the integration of the power spectrum, which can become tedious and time-consuming if the shape of $G(f)$ is irregular. This paper presents simplified techniques for estimating $\alpha$ from a power spectrum.

\section{Irregularity Factor}

The irregularity factor, $\alpha$, is defined as the ratio of the number of positive-slope zero crossings, $N_{O}$, to the number of peaks per unit time in a load-time history, $F_{0}$ :

$$
\alpha=\frac{\mathrm{N}_{0}}{F_{0}}
$$

The exact value of $\mathrm{N}_{\mathrm{O}}$ and $\mathrm{F}_{\mathrm{O}}$ carı be evaluated from $\mathrm{G}(\mathrm{f})$ as follows:

$$
\begin{aligned}
& N_{0}=\left(\frac{M_{2}}{M_{0}}\right) 0.5 \\
& F_{0}=\left(\frac{M_{4}}{M_{2}}\right) 0.5
\end{aligned}
$$

where $M_{0}, M_{2}$, and $M_{4}$ are the zeroth, second, and fourth moments of $G(f)$ about the origin (zero frequency) and are defined as:

$$
M_{0}=\int_{0}^{\infty} G(f) d f
$$

\footnotetext{
* Numbers in brackets denote references listed at the end of each paper.
} 
where $f$ is frequency. Thus,

$$
\alpha=\frac{M_{2}}{\left(M_{0} M_{4}\right)^{0.5}}
$$

The irregularity factor, $\alpha$, not only describes the irregularity of the random load-time history but also is a measure of the bandwidth of $G(f)$. As $\alpha$ approaches unity, the distribution of the loading peaks approximates to the Rayleigh distribution [1], and the shape of $G(f)$ is sharply peaked at the center frequency or far away from the origin. This is called narrow-band power spectrum. A single-frequency sine-wave loading can be described as a Dirac-Delta function power spectrum; it has $\alpha=1$. The value of $\alpha$ decreases with increasing width of the power spectrum.

Evaluation of Irregularity Factor from Power Spectra

Direct Integration of Power Spectral Density Function

The value of $\alpha$ can be evaluated from equation (4) by integrating equations (3a), (3b), and (3c). The integrations can become tedious and time-consuming if the shape of $G(f)$ is irregular. One simplified way of evaluating $\alpha$ is to break $G(f)$ into $n$ simpler geometries, such as those shown in figure $1(n=5)$, and then to evaluate the moments according to the following equation :

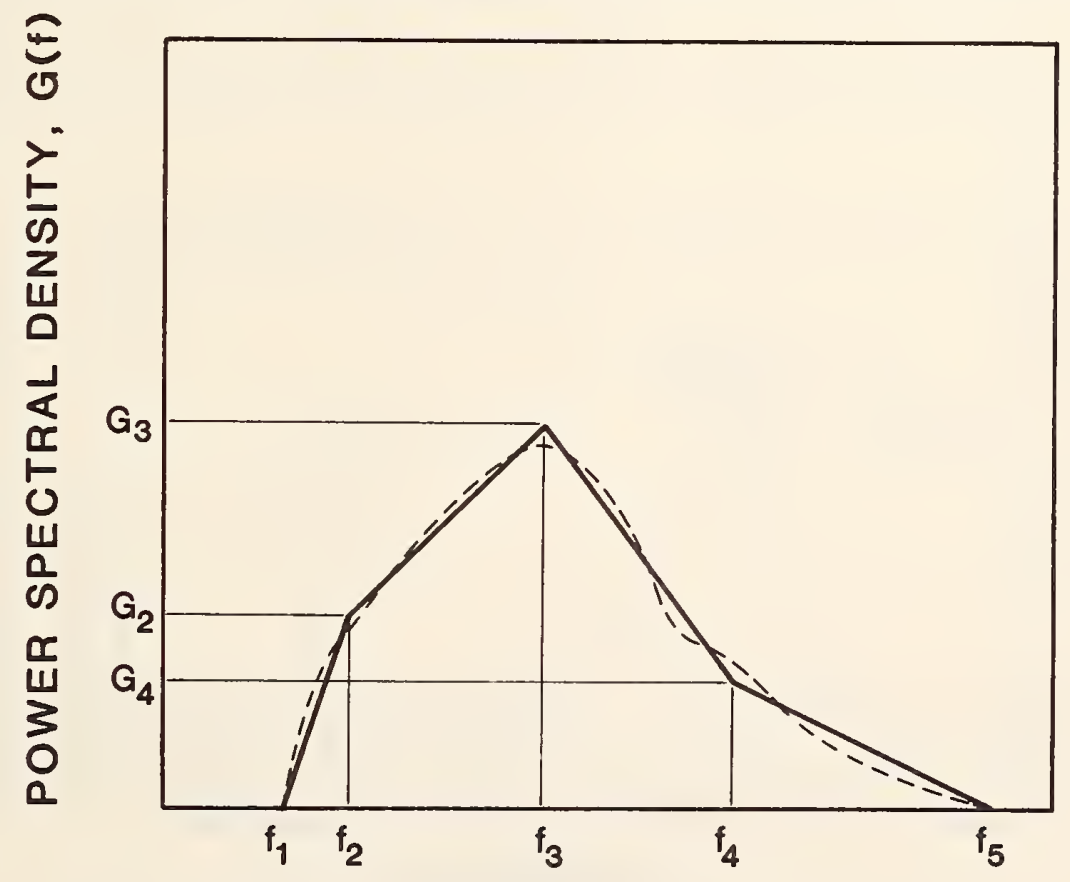

FREQUENCY, $\mathrm{Hz}$

Figure 1. Power spectrum: dashed line represents the original spectrum, and solid lines are a simplified diagram. 


$$
M_{j}=\frac{1}{(j+1)(j+2)} \sum_{i=1}^{n}\left(G_{i}-G_{i+1}\right) \frac{f_{i+1}^{(j+2)}-f_{i}^{(j+2)}}{f_{i+1}-f_{i}}, \quad j=0,2,4
$$

where $G_{i}$ 's and $f_{i}$ 's are power spectral densities and frequencies respectively, as shown in figure 1. (The derivation of equation (5) is given in the appendix.) For example, from equation (5) and the smplified diagram shown in figure $2(n=9)$, the value of $\alpha$ was calculated to be 0.699 . Using integration technique of equation (4), the value of a was 0.697 . The error of using equation (5) was 0.14 percent.

Estimation from Characteristic Width and Center Frequency of the Power Spectrum

The irregularity factor can also be estimated from the characteristic width and the center frequency of a power spectrum. For the case of rectangular power spectra, $\alpha$ can be obtained from the following expression [6].

$$
\alpha=\left[\frac{5\left(9+6 B^{2}+B^{4}\right)}{9\left(5+10 B^{2}+B^{4}\right)}\right] 0.5
$$

where $B=W / 2 f_{C}, W$ is the width, and $f_{c}$ is the center frequency of the rectangle (power spectrum). Here, $B$ is the geometric dimensionless bandwidth of the power spectrum. Different power spectra with same values of $B$ have the same values of $\alpha$, regardless of their shapes and positions with respect to the origin (zero frequency). The definitions of $W$ and $f_{c}$ are obvious in this case, and both are determined in a straightforward manner. For irregular spectra, the determination of $W$ and

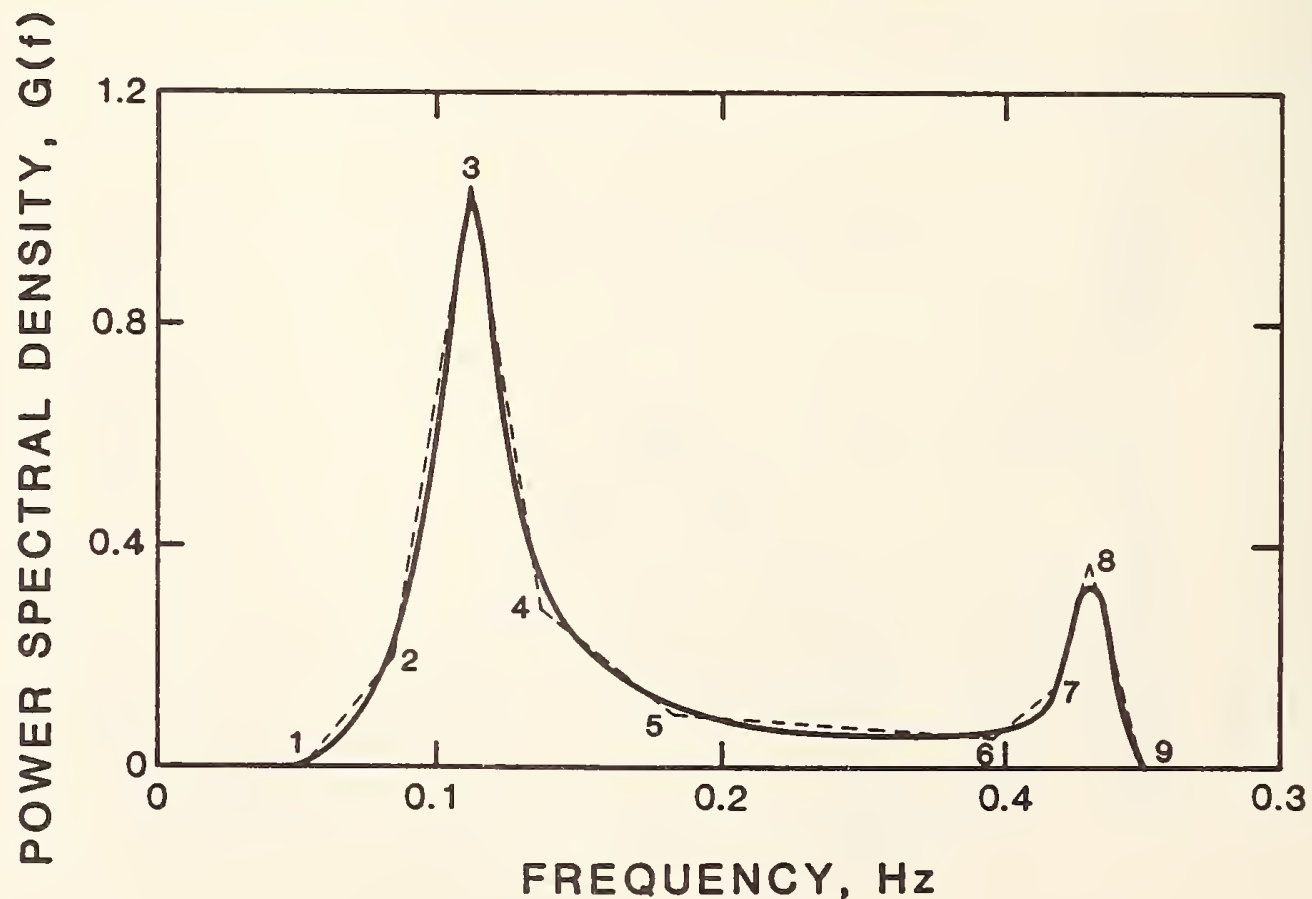

Figure 2. Example of computing the irregularity factor from a simplified diagram of a power spectrum. 
"f can be difficult; it is discussed in the following sections.

From geometric analysis of rectangular power spectra, it was noted that the values of $B$ were bounded by 0 and 1 . Accordingly, $\alpha$ was within 1 and 0.745 .

Determination of characteristic width. In the case of symmetric, single-peak power spectra, the center frequency is at the center of the frequency range. However, the determination of the characteristic width, $W$, is not obvious and the following empirical equation has been used to evaluate it:

$$
W=W^{\prime}\left(\frac{A_{r e c}}{A_{p s}}\right)^{0.5}
$$

where $W^{\prime}$ is the arithmetic average width of the power spectrum, $A_{\text {rec }}$ is the area of a rectangle enveloping the power spectrum, and $A_{p s}$ is the area of the power spectrum. For example, the value of $W^{\prime}$ is half of its base width for an isosceles triangular power spectrum and the ratio of $A_{r e c}{ }^{A}{ }_{p s}$ is 2 .

Results for several symmetric, single-peak power spectra with various shapes, including isosceles triangles, rectangles, isosceles trapezoids and pagodas, are plotted in figure 3 in the form of $\alpha$ versus B. All values of $\alpha$ in figure 3 and other figures in this paper were calculated from equation (4), if not otherwise specified. The value of a obtained from equation (6) coincides with those of the rectangles in figure 3. It can be seen that $\alpha$-versus-B curves for four different shapes of power spectra were in reasonable agreement, demonstrating that estimates of $W$ from equation (7) combined with equation (6), provide good estimates of $\alpha$. The errors in $\alpha$ at $B=1$ were less than \pm 5 percent.

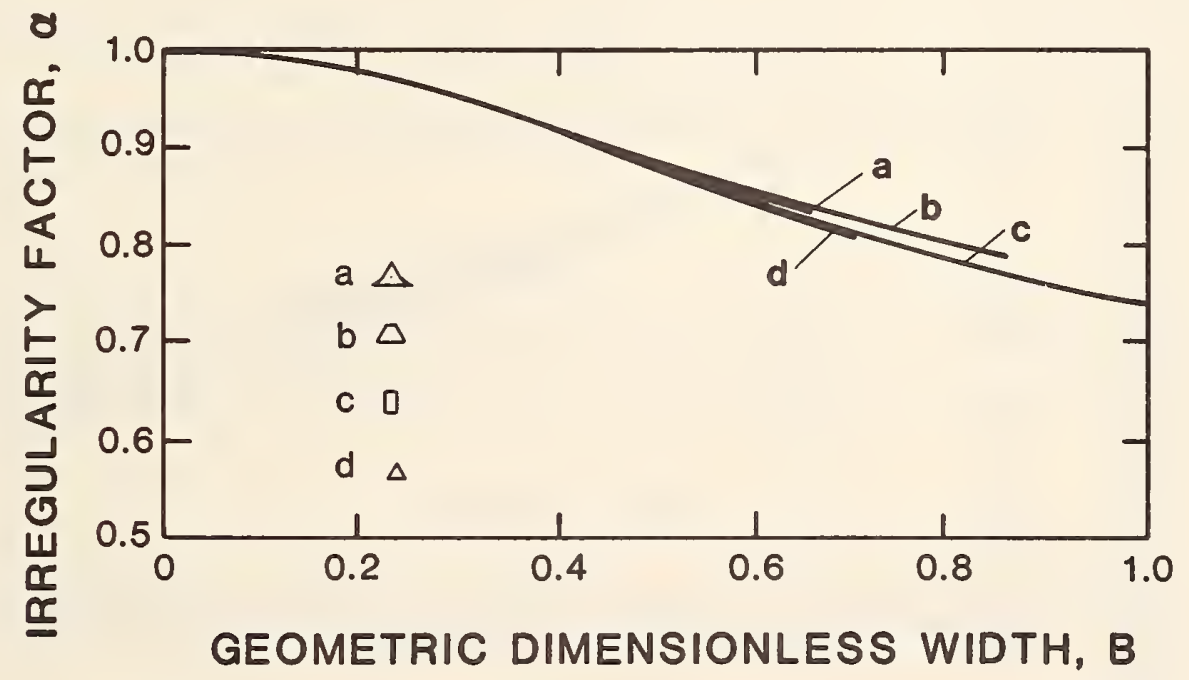

Figure 3. Irregularity factor-versus-geometric dimensionless width for four different symmetric, single-peak power spectra. 
Determination of center frequency. The value of $\alpha$ of an arbitrary triangular power spectrum with a fixed base (i.e., with a constant characteristic width) varies with the location of the peak within the width, because the center frequency varies. Several candidates for the operational definition of center frequency, $f_{c}$, including the frequency at the peak of the power spectrum, the frequency at the center of gravity of the power spectrum, the frequency at the middle of the frequency range, and the frequency at the middle of the half-height width, were studied. The frequency at the middle of the half-height width of the power spectrum gave the least scatter in the $\alpha$-versus$B$ curves of several asymmetrical single-peak power spectra. The $\alpha$-versus- $B$ curves of right triangular power spectra with the right angle to the left or to the right are compared with those of rectangular power spectra in figure 4. The figure shows that at a given value of $B$, the values of all the triangles studied are slightly smaller than those of rectangles. The largest error at $B=1$ was about 10 percent. This means that use of the frequency at the middle of half-height width of a triangular power spectrum slightly overestimates the value of $\alpha$.

Behavior of double-peak power spectra. The irregularity factor of a double-peak power spectrum was estimated from the following equations:

$$
\begin{aligned}
& \alpha=\frac{1+A F^{2}}{\left[(1+A)\left(1+A F^{4}\right)\right]^{0.5}} \\
& A=\frac{A_{2}}{A_{1}} \\
& F=\frac{f_{C 2}}{f_{C 1}}
\end{aligned}
$$

where $\mathrm{A}_{1}, \mathrm{~A}_{2}, \mathrm{f}_{\mathrm{C} 1}$, and $\mathrm{f}_{\mathrm{c} 2}$ are the areas and center frequencies of each peak, respectively, with $\mathrm{A}_{1}$ and $\mathrm{f}_{\mathrm{c} 1}$ being closer to the zero frequency (see table 1). As shown in table 1 , the error of using

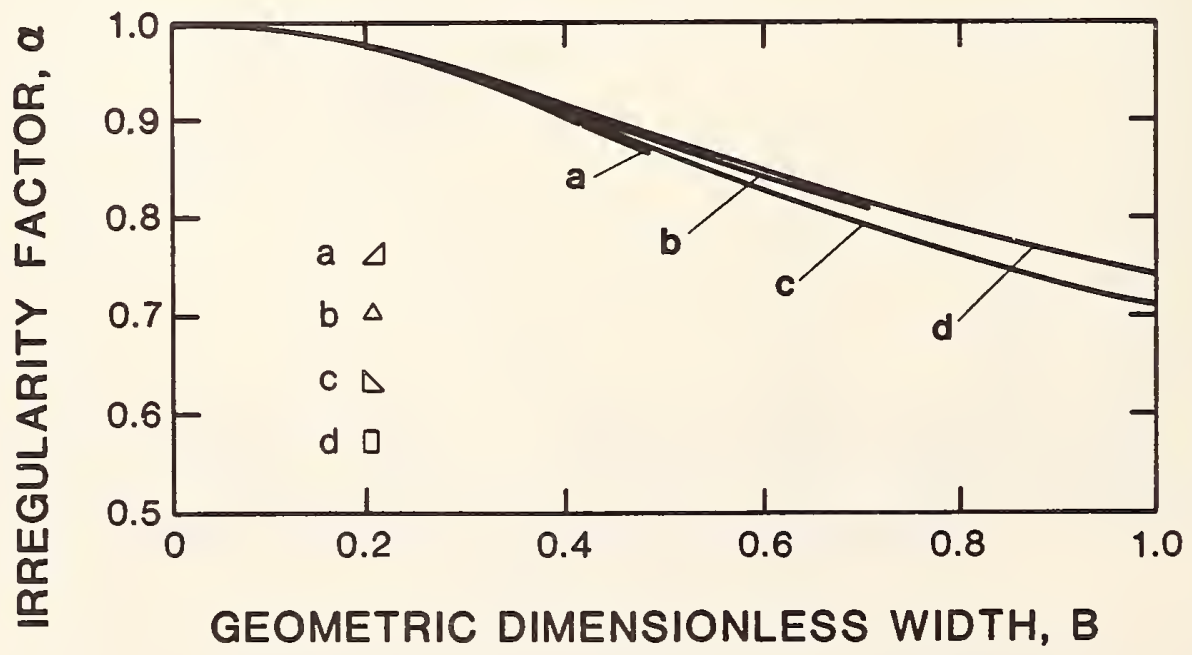

Figure 4. Irregularity factor-versus-geometric dimensionless width for four different asymmetric, single-peak power spectra. 
equation ( 8 ) is within \pm 5 percent for a wide range of two-peak power spectra. Table 1 contains results ranging $A$ from 0.1 to $10, F$ from 2.333 to $7, G_{2} / G_{1}$ (see table 1 for definition of $G_{i}$ ) from 0.1 to 10 , and $\alpha$ from 0.56 to 0.96 .

Figure 5 presents results from equation (8) in graphic form. It shows that the larger the value of $F$ and the smaller the value of $A$ are, the smaller the irregularity factor is. From equations (3) and (4), one would expect that the higher frequency peak dominates the determination of $\alpha$ because of the second and the fourth power of frequency in $M_{2}$ and $M_{4}$. In the case of $A_{2} \gg A_{1}$, the lower frequency peak can be neglected in the determination of $\alpha$. The smaller the value of $F$ is, the closer the two peaks are, and vice versa. Figure 5 shows that, at a given value of A, $\alpha$ decreases with increasing $\mathrm{F}$.

The two peaks in a double-peak power spectrum of practical interest usually connect to each other at their bases. In this case, the double-peak power spectrum was divided into two parts. Their center frequencies and areas were estimated; then the value of $\alpha$ was estimated from equation (8). For example, the power spectrum characteristic of the North Sea environment, as shown in figure 6 , was divided at $0.3 \mathrm{~Hz}, 0.25 \mathrm{~Hz}$, or $0.2 \mathrm{~Hz}$ and represented by two triangles, $\triangle A B C$ and $\triangle \mathrm{DEF}, \triangle \mathrm{ABC}$ ' and $\triangle \mathrm{D}^{\prime} \mathrm{EF}$, or $\triangle \mathrm{ABC} "$ and $\triangle \mathrm{D}^{\prime \prime E F}$. All triangles had the same areas as the original curves that they represented. The values of $\mathrm{F}$ and $\mathrm{A}$ obtained were 2.70 and $0.1514,2.71$ and $0.2278,0 \mathrm{or}$ 2.74 and 0.3165 , respectively. The estimated value of $\alpha$ using equation (8) was $0.6520,0.6616,0$, 0.6785 . The errors were $-6.5,-5.08$, and -2.65 percent, respectively.

\section{Summary}

Several simplified methods for evaluating the irregularity factor of a power spectrum have been derived. The irregularity factor was computed either from integration of the power spectrum or from the characteristic bandwidth and the center frequency of the power spectrum.

For idealized shapes of power spectra, such as rectangles and isosceles triangles, the characteristic bandwidth and the center frequency were readily obtained. For irregular shapes, the power spectra were represented by simplified geometries from which the characteristic bandwidths and the center frequencies were estimated.

For all the cases studied in this paper, the largest errors introduced by using the simplified methods was about 10 percent, but the majority were within 5 percent. Therefore, use of the simplified methods is recommended where approximation is allowable and as a check on more exact methods.

Acknowledgments

This work was supported by the Department of Interior, Minerals Management Service. 


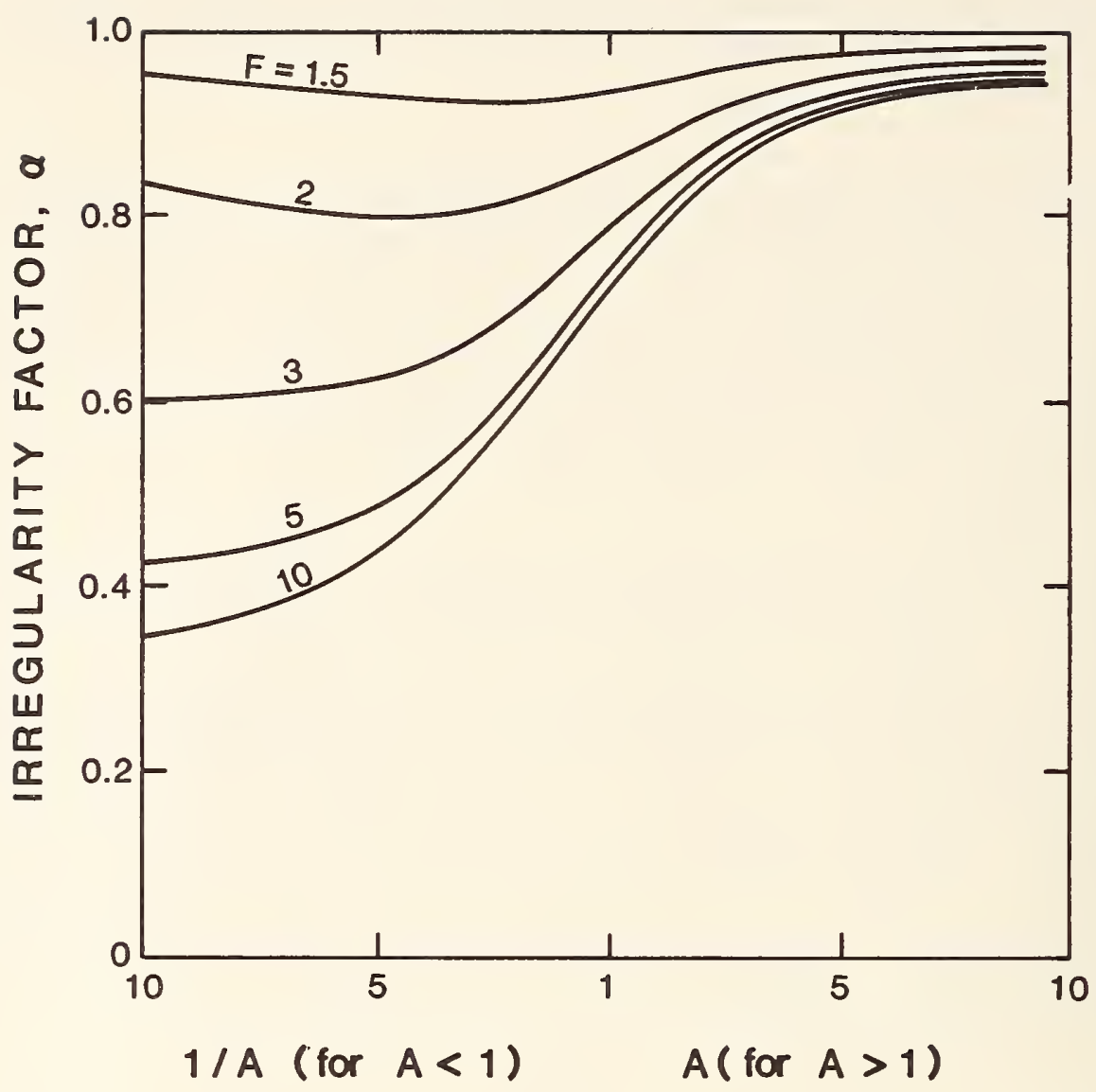

Figure 5. Irregularity factor as a function of the ratio of area and frequency of each peak for double-peak power spectra.

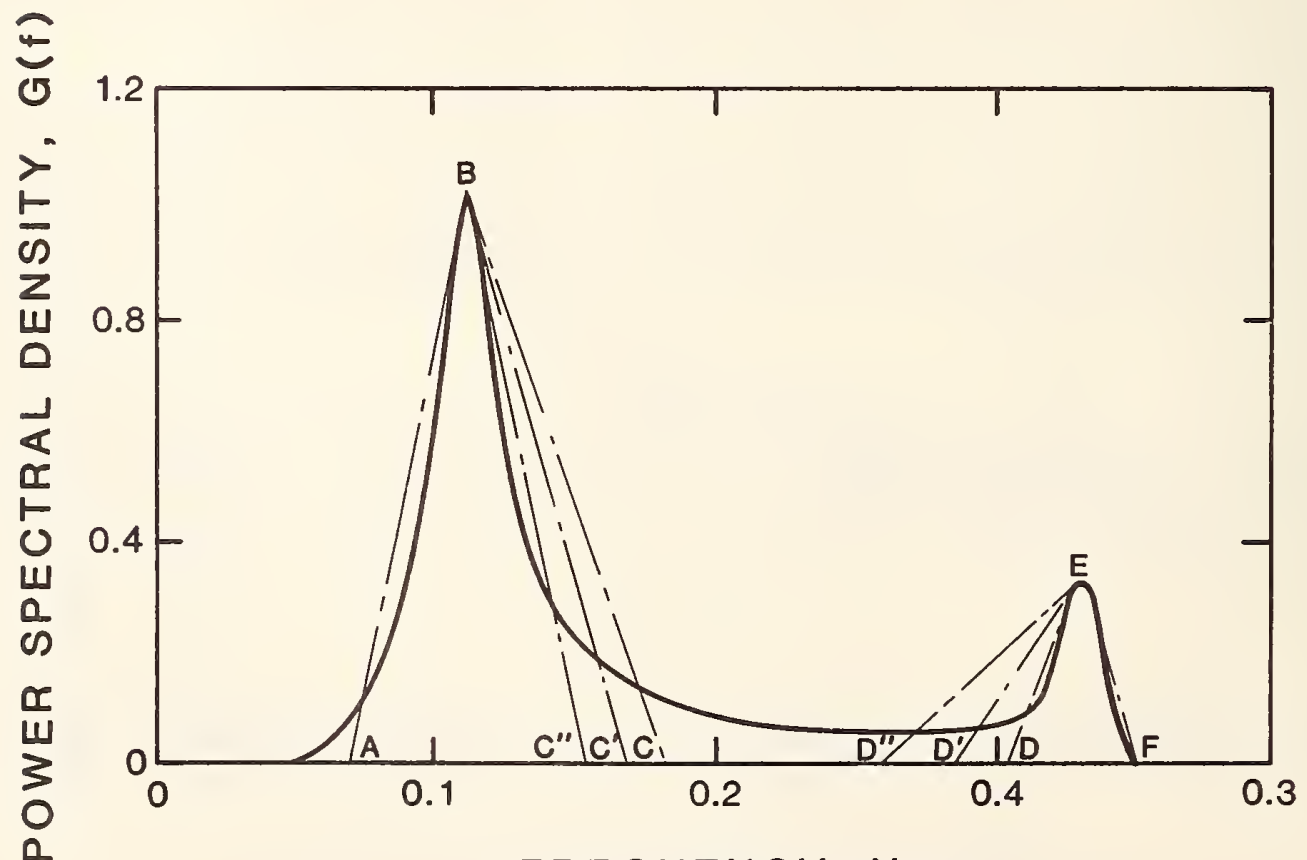

FREQUENCY, Hz

Figure 6. Example of calculating the irregularity factor of a double-peak power spectrum of practical interest by dividing the two connected peaks into two separate triangles. 
Table 1. Estimated errors in irregularity factor of double-peak power spectra determined by simplified method.

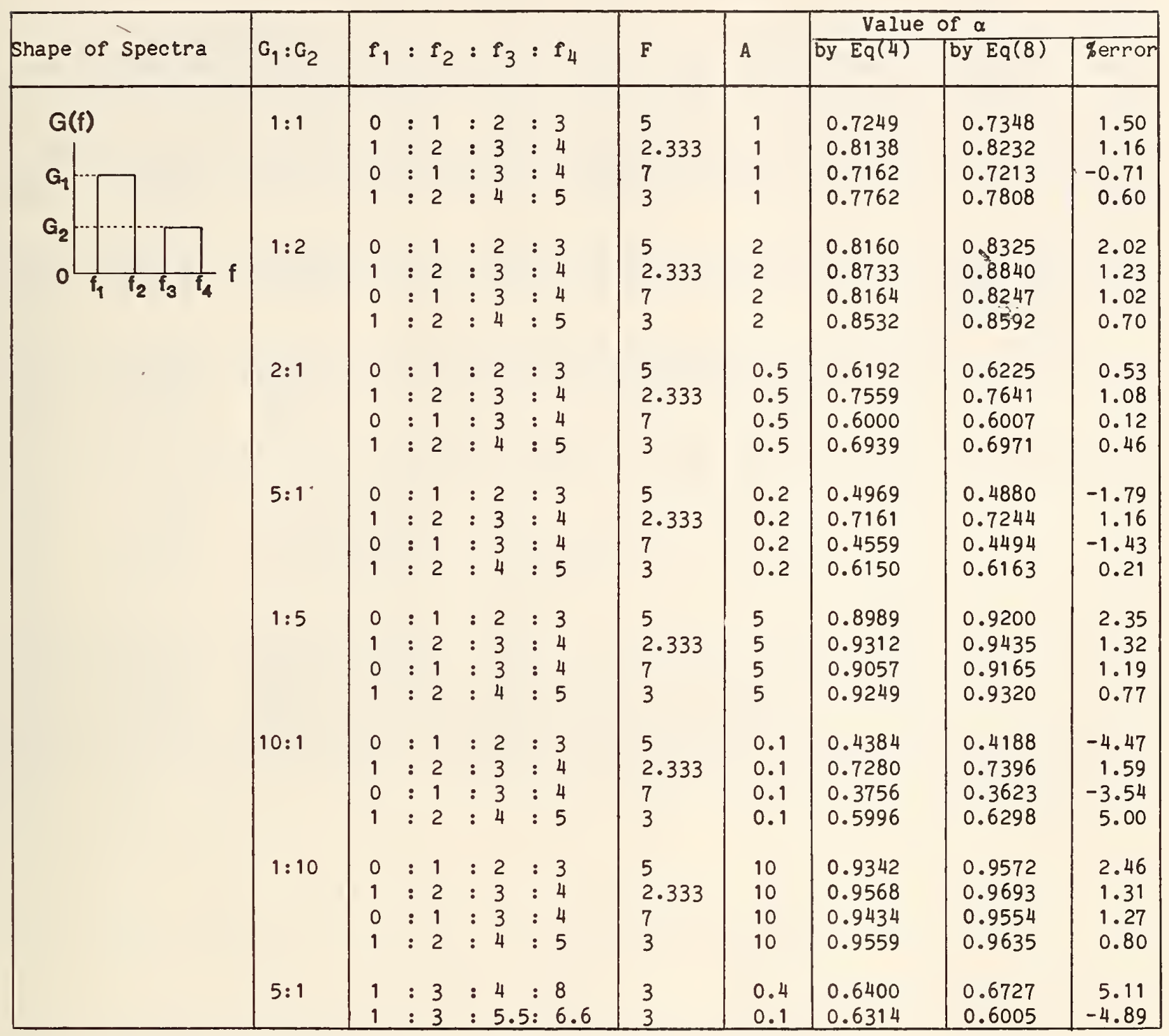


Table 1. (cont.)

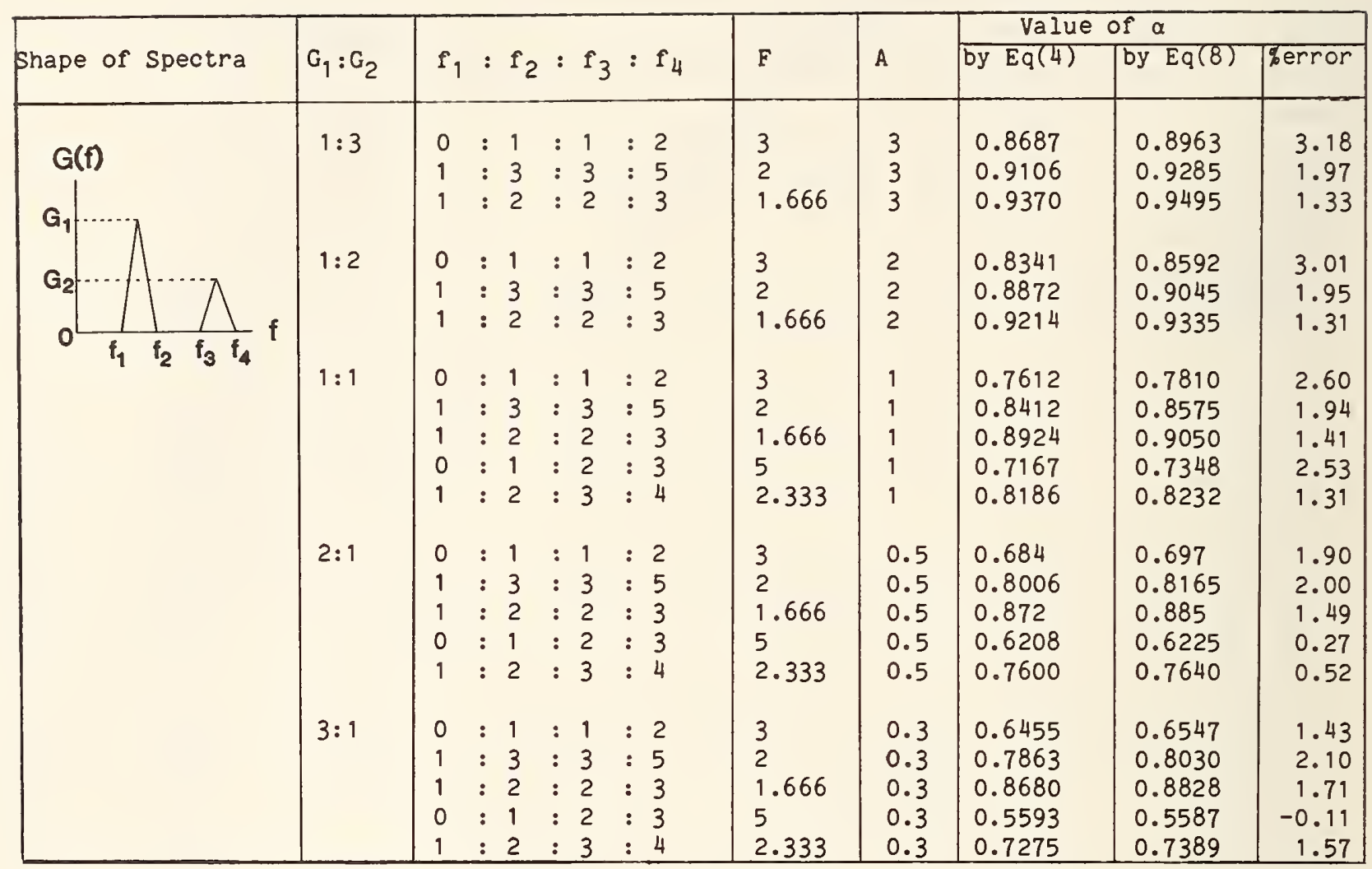


[1] J. S. Bendat, Principles and Application of Random Noise Theory, John Wiley \& Sons, New York (1958).

[2] S. H. Smith, "Fatigue Crack Growth under Axial Narrow and Broad Band Random Loading," in: Acoustical Fatigue in Aerospace Structure, Syracuse, New York (1964), pp. 331-360.

[3] F. Beer, R. Wagner, L. Bahar, and R. Ravera, "On the Statistical Distribution of Rises and Falls in a Stochastic Process," Lehigh Institute of Research Progress Report, Lehigh University, Bethlehem, Pennsylvania (1961). (Fracture Mechanics Research for the Boeing Airplane Company).

[4] J. R. Rice, "Theoretical Prediction of Some Statistical Characteristics of Random Loadings Relevant to Fatigue and Fracture," Ph.D. Thesis, Lehigh University, Bethlehem, Pennsylvania (1964).

[5] P. H. Wirsching and M. C. Light, "Probability Based Fatigue Design Criteria for Ocean Structures," API-PRAC Project No. 15, Final Report, American Petroleum Institute, Dallas, Texas (1979).

[6] L. P. Pook, "Proposed Standard Load Histories for Fatigue Testing Relevant to Offshore Structures," NEL Report No. 624, National Engineering Laboratory, Glasgow, UK (October 1976).

\section{Appendix}

Straight lines can be used to approximate the original curves of any kind of power spectra. For example, figure 1 shows a single-peak power spectrum (dashed line), approximated by four straight lines (solid line). The important consideration in choosing the straight lines is that the area under the straight line should be the same (or close to) that of the original curve it represents. Taking $G_{1}$ and $G_{5}$ equal to 0 , the four straight lines in figure 1 are expressed by the following linear equations:

$$
\begin{array}{ll}
G(f)=\left(G_{2}-0\right) \frac{f-f_{1}}{f_{2}-f_{1}} & \text { for the first segment } \\
G(f)=\left(G_{3}-G_{2}\right) \frac{f-f_{2}}{f_{3}-f_{2}}+G_{2} & \text { for the second segment } \\
G(f)=\left(G_{4}-G_{3}\right) \frac{f-f_{4}}{f_{4}-f_{3}}+G_{4} & \text { for the third segment } \\
G(f)=\left(0-G_{4}\right) \frac{f-f_{5}}{f_{5}-f_{4}} & \text { for the fourth segment }
\end{array}
$$

After integration of equations $(3 a),(3 b)$, and $(3 c)$ and some manipulation, one $f$ inds, 


$$
\begin{aligned}
M_{0}= & \frac{1}{2}\left[\left(0-G_{2}\right) \frac{f_{2}^{2}-f_{1}^{2}}{f_{2}-f_{1}}+\left(G_{2}-G_{3}\right) \frac{f_{3}^{2}-f_{2}^{2}}{f_{3}-f_{2}}+\left(G_{3}-G_{4}\right) \frac{f_{4}^{2}-f_{3}^{2}}{f_{4}-f_{3}}\right. \\
& \left.+\left(G_{4}-0\right) \frac{f_{5}^{2}-f_{4}^{2}}{f_{5}-f_{4}}\right] \\
M_{2}= & \frac{1}{12}\left[\left(0-G_{2}\right) \frac{f_{2}^{4}-f_{1}^{4}}{f_{2}-f_{1}}+\left(G_{2}-G_{3}\right) \frac{f_{3}^{4}-f_{2}^{4}}{f_{3}-f_{2}}+\left(G_{3}-G_{4}\right) \frac{f_{4}^{4}-f_{3}^{4}}{f_{4}-f_{3}}\right. \\
& \left.+\left(G_{4}-0\right) \frac{f_{5}^{4}-f_{4}^{4}}{f_{5}-f_{4}}\right] \\
M_{4}= & \frac{1}{30}\left[\left(0-G_{2}\right) \frac{f_{2}^{6}-f_{1}^{6}}{f_{2}-f_{1}}+\left(G_{2}-G_{3}\right) \frac{f_{3}^{6}-f_{2}^{6}}{f_{3}-f_{2}}+\left(G_{3}-G_{4}\right) \frac{f_{4}^{6}}{f_{4}-f_{3}^{6}}\right. \\
& \left.+\left(G_{4}-0\right) \frac{f_{5}^{6}-f_{4}^{6}}{f_{5}-f_{4}}\right]
\end{aligned}
$$

Equations (A1), (A2), and (A3) can be written in a general form:

$$
M_{j}=\frac{1}{(j+1)(j+2)} \sum_{i=1}^{n}\left(G_{i}-G_{i+1}\right) \frac{f_{i+1}^{(j+2)}-f_{i}^{(j+2)}}{f_{i+1}-f_{i}} ; \quad j=0,2,4
$$

which can be used for single-peak as well as double-peak power spectra. 


\author{
Pei-Ning $\mathrm{Li}^{+}$ \\ Yi-Wen Cheng \\ Fracture and Deformation Division \\ National Bureau of Standards \\ Boulder, Colorado 80303
}

Abstract

Hole-in-plate specimens, made of ABS EH36 steel, were tested in air and in 3.5 percent $\mathrm{NaCl}$ solution to measure fatigue crack growth rates in areas of stress concentration at the edges of circular holes. The linear-elastic fracture mechanics analysis of fatigue crack growth appears to be adequate in yielded regions that are caused by monotonic loading but which have a linear stressstrain relation under cyclic loading. Small-crack behavior, in which cracks grow at higher rates than predictions from the long cracks, was observed when the crack length was less than $1.5 \mathrm{~mm}$ in air and less than $3 \mathrm{~mm}$ in 3.5 percent $\mathrm{NaCl}$ solution. The problem of small-crack behavior was accounted for by adding an intrinsic crack length to the physical crack length, as suggested by El Haddad.

Key words: C-Mn steel; environmental effects; fatigue crack growth; small cracks; yielding effects.

${ }^{+}$Guest worker, on leave from East-China Institute of Chemical Technology, Shanghai, China. 
The fatigue life of a structural component is determined by the sum of the applied load cycles required to initiate a crack and to propagate the crack from subcritical to critical size. Because welded structures, such as offshore structures, usually contain weld defects at areas of stress concentrations, the fatigue life depends mainly on the time required for crack propagation: a fatigue fracture mechanics analysis, therefore, is appropriate. The initial weld defects are small and will propagate in the plastically deformed regions near stress concentrators.

Fatigue crack propagation in plastically deformed regions of structural stress concentrators, such as at weld toes and notch roots, has been studied by many investigators $[1-5]^{*}$. They observed that the linear-elastic fracture mechanics (LEFM) method was inadequate for predicting the fatigue crack growth rate (FCGR) in this area. Some parameters have been proposed for correlation with FCGR. Solomon [1] suggested that the plastic strain range, $\Delta \varepsilon_{p}$, could be used to predict the crack propagation rate, but this worked only for large plastic deformations. El Haddad et al. [2-4] used the strain intensity factor range instead of the stress intensity factor range as the driving force for fatigue crack propagation. Dowling [5] proposed that for several kinds of specimens the Jintegral was an adequate parameter for correlation with FCGR. These proposed parameters and subsequent correlations with FCGR are empirical or semiempirical in nature. Their ranges and conditions of applicability need to be defined.

Another problem associated with the fatigue crack propagation in plastically deformed regions of structural stress concentrators is the unexpected rapid growth of small cracks. Fatigue crack growth rates of small cracks are higher than those predicted by the results from long cracks. The use of existing long-crack results for defect-tolerance fatigue-life calculations in components, where the growth of a small crack represents a large portion of the fatigue life, leads to nonconservative life predictions. To account for the higher crack growth of small cracks, El Haddad et al. [2] introduced the notion of an intrinsic crack length, $a_{0}$, which is added to the physical crack length. The value of $a_{0}$ is constant for a given material condition and environment. The term $\left(a+a_{0}\right)$ is viewed as an effective crack length and the effective stress intensity factor range is

$$
\Delta K=\Delta S\left[\pi\left(a+a_{0}\right)\right]^{0.5} \mathrm{~F}_{0}
$$

where $\Delta \mathrm{K}$ is the stress intensity factor range, $\Delta \mathrm{S}$ is the nominal stress range, and $\mathrm{F}_{0}$ is a geometrical factor. The value of $a_{0}$ can be evaluated from the limiting condition of a smooth specimen, where the physical crack length, $a$, approaches zero. When $F_{0}$ is unity and $\Delta K$ becomes the threshold stress intensity factor range, $\Delta K_{t h}$, then $\Delta S$ approaches the fatigue limit of the material, $\Delta \sigma e^{\cdot}$ Therefore, from equation (1)

$$
a_{0}=\left(\frac{1}{\pi}\right)\left(\frac{\Delta K_{t h}}{\Delta \sigma_{e}}\right)^{2}
$$

\footnotetext{
* Numbers in brackets denote references listed at the end of each paper.
} 
In this paper, we report FCGRs in areas of stress concentrations and of small cracks, using the hole-in-plate specimens in air and in 3.5 percent NaCl solution (saltwater).

Experimental Procedures

Test Material

The test material was a 12.7-mm-thick plate of ABS grade EH36 steel, a 350-MPa-yield-strength C-Mn steel. The chemical composition of the steel was given in reference 6 . The steel was in the normalized condition and had particularly uniform properties owing to sulfide shape control. Tensile, fracture [7], and fatigue crack growth [6] properties of the steel have been studied extensively (reference 6 is in this report). The tensile and fracture properties at ambient temperature are listed in table 1.

Specimen Preparation

The test specimens were 12.7-mm-thick hole-in-plate tensile panels. The test matrix and specimen dimensions are given in table 2. The specimen configuration is shown in figure 1 . A circular hole was drilled at the center of the plate and a fatigue crack was initiated at the edge of the hole so that fatigue crack growth behavior in areas of stress concentration could be studied. Pin-loading holes at the ends of the specimen were reinforced by welding on a doubler plate.

Except for specimen 1, which did not have notches, sharp notches about 0.5 to $1 \mathrm{~mm}$ in length were machined from the edge(s) of the hole normal to the loading direction with a slitting saw. The sharp notches were used as crack starters to facilitate fatigue precracking.

Table 1. Tensile and fracture properties of ABS grade EH36 steel at ambient temperature [7].

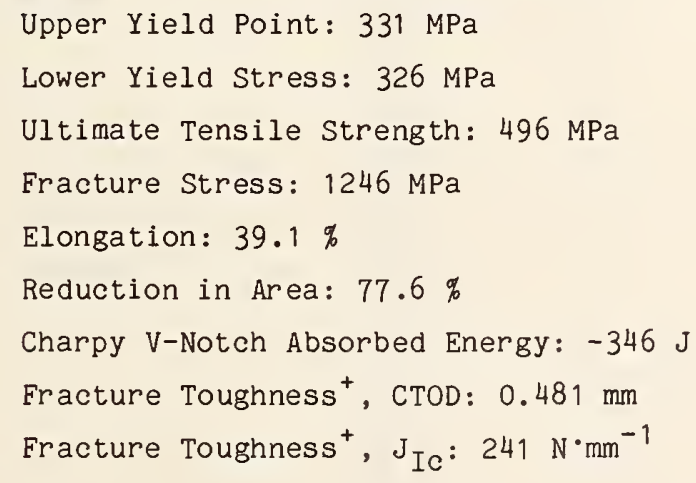

${ }^{+}$-point bend specimen with thickness $=25.4 \mathrm{~mm}$.

Solutions for the stress intensity factor, $K$, of the specimen are available in reference 8 . The stress intensity factor is given as 
Table 2. Test matrix and specimen dimensions.

\begin{tabular}{|c|c|c|c|c|c|}
\hline $\begin{array}{c}\text { Specimen } \\
\text { No. }\end{array}$ & $\begin{array}{r}\text { Specimen } \\
\text { Width, mm }\end{array}$ & $\begin{array}{l}\text { Center Hole } \\
\text { Diameter, mm }\end{array}$ & Crack & $\begin{array}{c}\text { Test } \\
\text { Environment }\end{array}$ & $\begin{array}{l}\text { Test } \\
\text { Erequency, } \mathrm{Hz}\end{array}$ \\
\hline 1 & 203 & 50.8 & No & Air & --- \\
\hline 2 & 254 & 50.8 & $\begin{array}{l}\text { Asymmetric } \\
\text { (One Crack) }\end{array}$ & Air & 3 \\
\hline 3 & 254 & 50.8 & $\begin{array}{l}\text { Asymmetric } \\
\text { (One Crack) }\end{array}$ & Saltwater & 0.1 \\
\hline 4 & 254 & 50.8 & $\begin{array}{l}\text { Symmetric } \\
\text { (Two Cracks) }\end{array}$ & Air & 3 \\
\hline
\end{tabular}
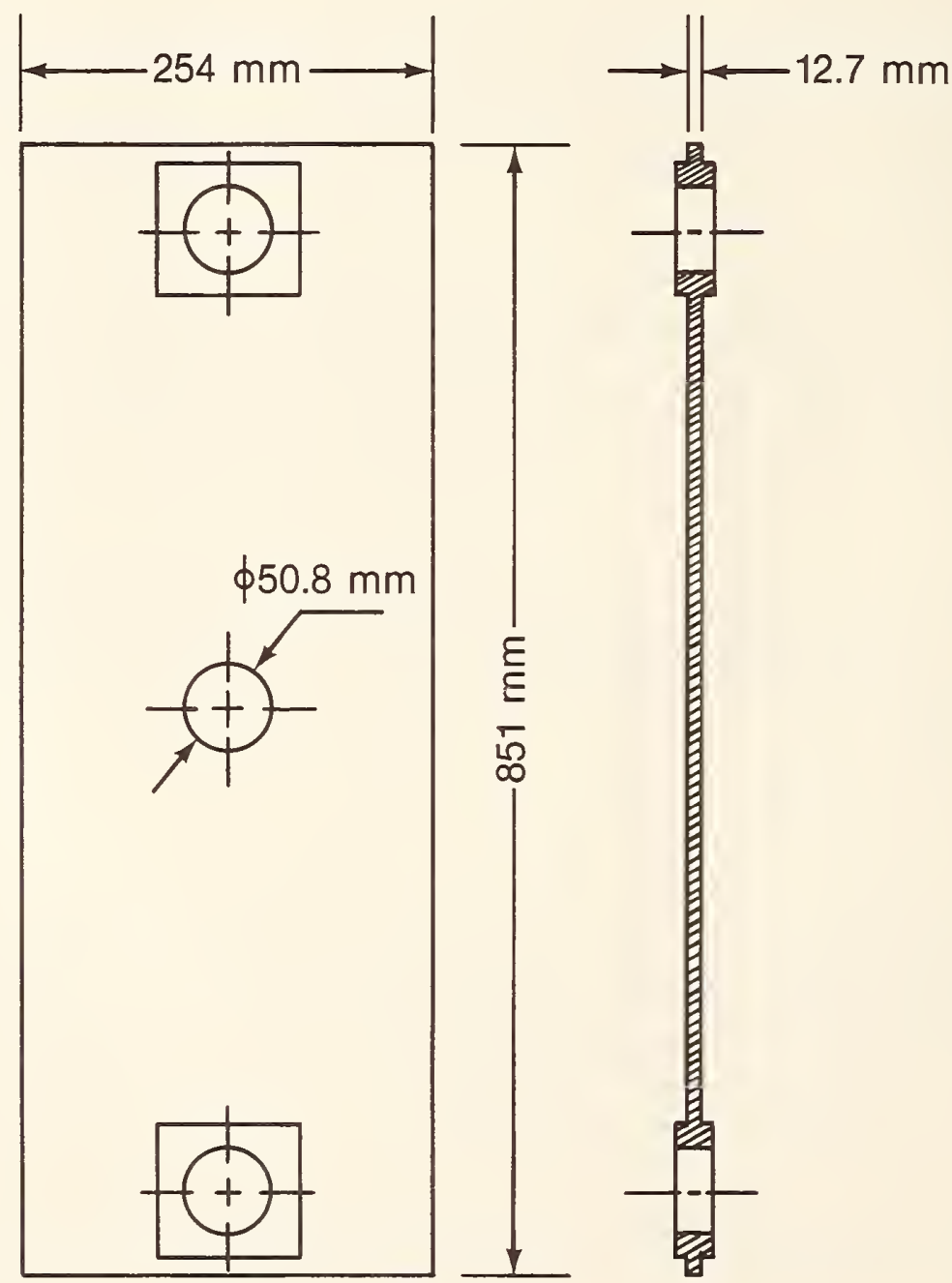

Figure 1. Schematic of hole-in-plate specimen. 
$=K=S(\pi a)^{0.5} F(a / D)$

where the crack length, a, is measured from the edge of the hole, $D$ is the hole diameter, $S$ is the remote tensile stress, and $F(a / D)$ is a function of crack length and hole diameter.

Loading Conditions

Except for specimen 1, specimens were cyclically loaded at ambient temperature with frequencies of $3 \mathrm{~Hz}$ in air and $0.1 \mathrm{~Hz}$ in saltwater using load control with a 1-MN-capacity servo-controlled hydraulic testing machine. The stress ratio (i.e., the ratio of minimum to maximum stress) was kept constant at 0.3 .

Specimen 1, which had no crack, was instrumented with eight electrical-resistance strain gages extending from the edge of the hole to the edge of the test plate perpendicular to the loading direction. The gages were spaced $2.5 \mathrm{~mm}$ near the edge and $25.4 \mathrm{~mm}$ away from the hole. The purpose of testing specimen 1 was to study the strain distribution at the stress concentration under loading-unloading-reloading sequence. The loading and unloading were controlled manually under displacement control.

Test Environments and Crack-Length Measurements

Tests were conducted in air and in saltwater at ambient temperature. Crack-length measurements were made with a 30-power traveling microscope at various time intervals, depending upon crack propagation rates. For tests in saltwater, a transparent plastic container was used to contain the saltwater, which was continuously circulated at a rate of $26 \mathrm{l} / \mathrm{min}$ through a diatomaceous-earth filter. The NaCl concentration, temperature, and $\mathrm{pH}$ value of the saltwater were monitored periodically.

For tests in saltwater, crack lengths were measured with the traveling microscope through the transparent container. The rust around the crack tips was scrubbed from the specimen surface with sandpaper and cotton swabs before measurements.

Crack closure was monitored through the load-displacement curves with an $\mathrm{x}-\mathrm{y}$ recorder or an oscilloscope. Displacements were measured at the crack mouth. To facilitate the displacement measurements, razor blades, spot welded at the crack mouth and extending out of the specimen plane, were used for attachment of the clip-on gage.

Experimental Results and Discussion

Strain Survey

Specimen 1, which had no crack, was monotonically loaded from zero to $220.4 \mathrm{MPa}$ (nominal gross-section stress) and then unloaded to zero nominal stress. The measured local strains along the direction of the hole diameter normal to the loading direction are plotted in $f$ igure 2 .

In the elastic range, that is, for nominal stress less than one-third the yield strength, the 
strain distribution in the vicinity of a circular hole can be calculated accurately [9]. The edge of the hole begins to deform plastically when the nominal stress is higher than one-third the yield strength. If the extent of plastic deformation is small, the stress redistribution owing to the plastic deformation is negligible, and the elastic solutions [9] are still adequate for regions that do not yield. The results of the present investigation indicate that elastic solutions are adequate (the error is within 3 percent) for areas $2 \mathrm{~mm}$ or farther from the hole edge at a nominal stress of 155.1 $\mathrm{MPa}$, which is much higher than one-third the yield strength ( $117 \mathrm{MPa}$ ).

The strain increases rapidly after the material has yielded. Strain distributions in the elastic-plastic case can be estimated from Neuber's rule [10]. To obtain accurate results, numerical methods, such as finite element analysis, must be performed.

After the specimen was unloaded to zero nominal stress, as shown in figure 2 , residual strains existed over a large region $(>50 \mathrm{~mm})$. The specimen was reloaded and strain increments, $\Delta \varepsilon$, were recorded. A strain increment is the difference between the current measured strain and the residual strain, $\Delta \varepsilon=\varepsilon_{\text {current }}-\varepsilon_{\text {residual }}$. As shown in figure 3 , as nominal stress increased from 116.3 to $220.4 \mathrm{MPa}$ (about double) at a point $2 \mathrm{~mm}$ from the hole edge, $\Delta \varepsilon$ increased from $1.52 \mathrm{x} 10^{-3}$ to $3.12 \times 10^{-3}$ (about double). The relation between nominal stress and local strain increment is 1 inear owing to strain hardening of the material in the plastically deformed region. Because of the linear relation between stress and strain at stress levels above monotonic yield strength, LEFM analysis of FCGR in this region should be adequate. However, the residual stress associated with the residual strain might influence FCGR. The residual stress is in compression and effectively reduces the minimum-to-maximum stress ratio; this usually lowers FCGR, especially at higher and near-threshold growth rate regions.

FCGR at Edges of a Yielded Hole in Air

Specimen 4, which had two symmetric cracks emanating from opposite edges of the hole, was fatigue tested with a maximum stress, $S_{\max }$, of $207 \mathrm{MPa}$ and a minimum stress, $\mathrm{S}_{\mathrm{min}}$, of $62.1 \mathrm{MPa}$ in air. With a stress concentration factor of 3.14, the maximum and minimum local stresses at the edge of the hole were 650 and $195 \mathrm{MPa}$, respectively. Fatigue crack growth rates were measured as the cracks propagated from 0.5 to $9 \mathrm{~mm}$, which was within the yielded region caused by the application of a nominal stress of $207 \mathrm{MPa}$ (figure 2).

The FCGR results, plotted in figure 4, show good agreement between the hole-in-plate specimen and compact-type (CT) specimens [6] at $\Delta \mathrm{K}$ higher than $30 \mathrm{MPa} / \mathrm{m}$. Below $30 \mathrm{MPa} / \mathrm{m}$, the FCGRs of the hole-in-plate specimen are higher than those obtained from CT specimens, which is not unexpected. Usually, the length of the existing crack is larger than $15 \mathrm{~mm}$ for a $25.4-\mathrm{mm}-\mathrm{thick}$ CT specimen, which was used in reference 6 and the crack behaves like a normal or long crack. In the hole-inplate specimen, the crack length was about $1.5 \mathrm{~mm}$ when $\Delta \mathrm{K}$ was $30 \mathrm{MPa} / \mathrm{m}$, and the crack behaves 1 ike a small crack. As mentioned previously, FCGRs of small cracks are higher than those predicted by results from long cracks.

Using the approach of El Haddad et al. [2-4], we found the value of $a_{0}$ in equation (1) to be $0.35 \mathrm{~mm}$. Then the whole da/dN-versus- $\Delta K$ curve of the hole-in-plate specimen agreed well with the results from CT specimens. 


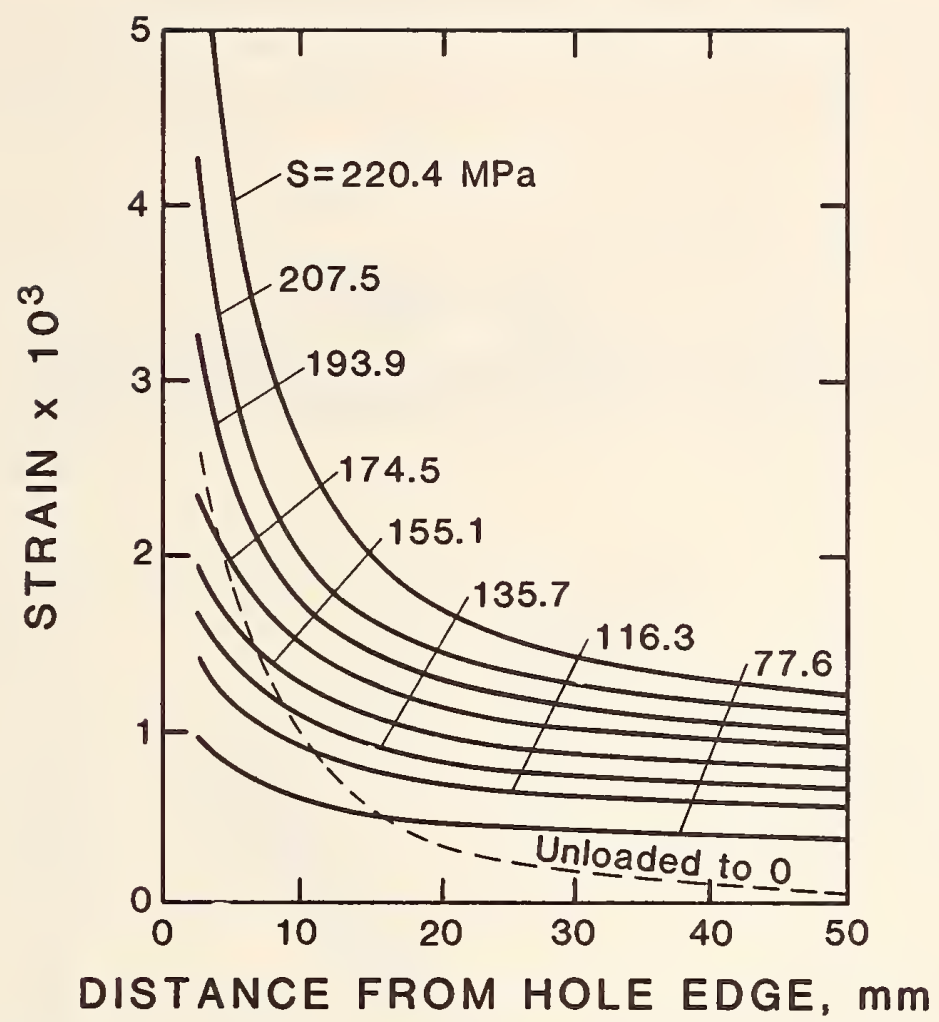

Figure 2. Measured strain distribution in the vicinity of a circular hole at various nominal stress levels.

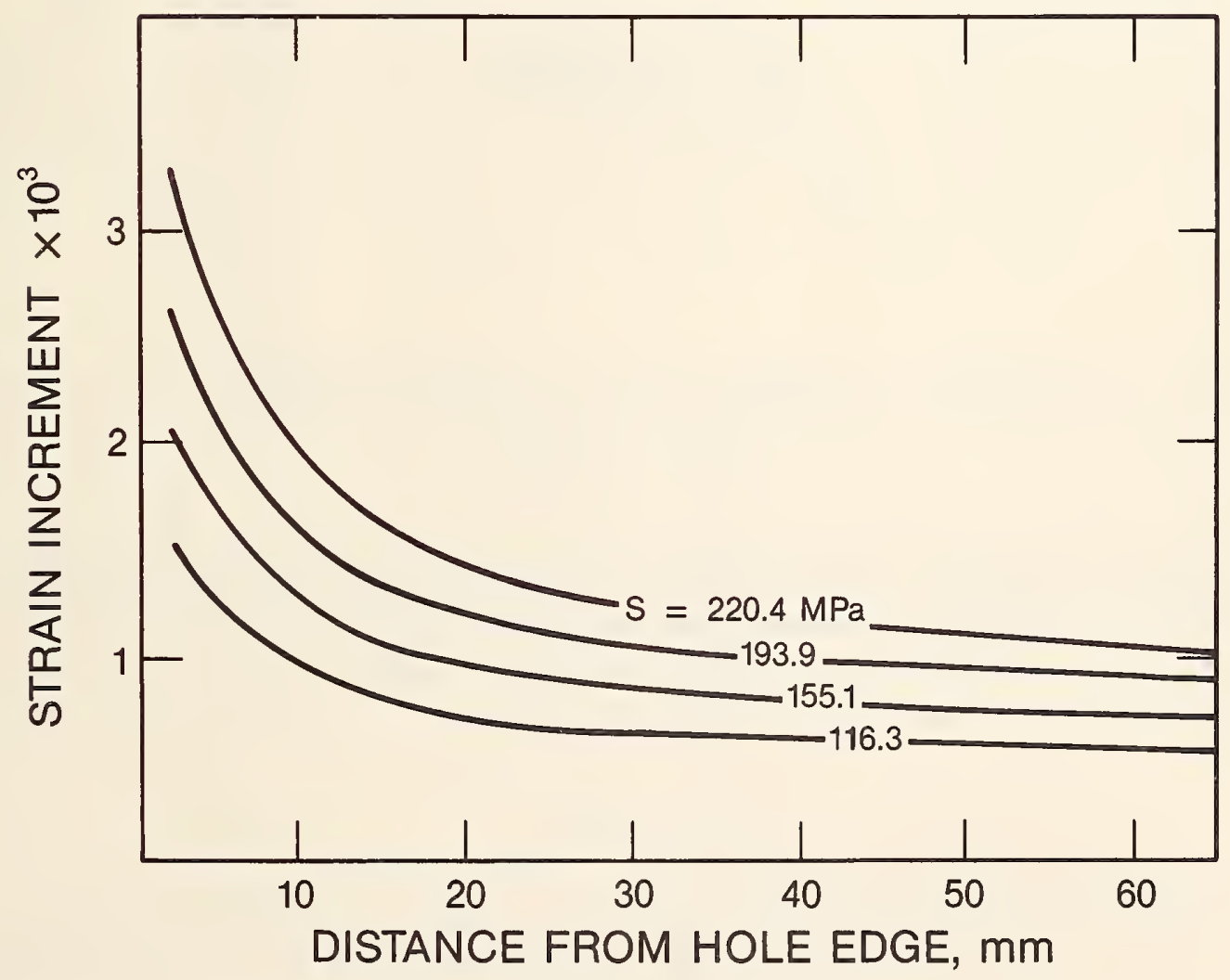

Figure 3. Measured strain distribution in the vicinity of a circular hole at various nominal stress levels after one loading-unloading sequence. 


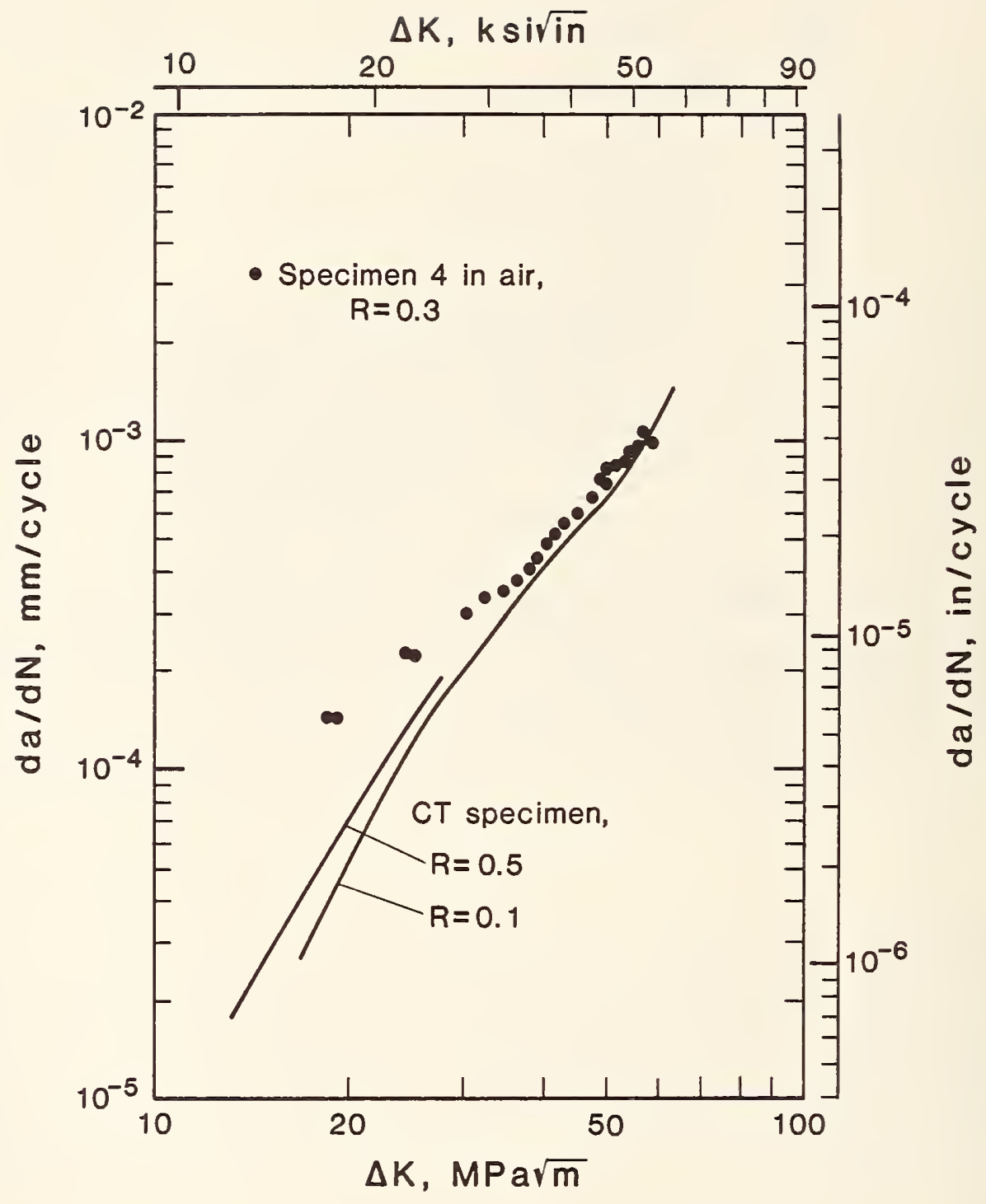

Figure 4. Comparison of fatigue crack growth rates in plastically deformed regions and compact-type specimens in air. 
Specimen 2, which had only one crack emanating from one edge of the hole, was fatigue tested with a loading condition identical to that applied to specimen 4. The FCGR results are shown in figure 5, which show reasonable agreement between the hole-in-plate specimen and CT specimens [6].

The results of this investigation show that the LEFM analysis of fatigue crack growth is adequate in yielding conditions under monotonic loading. This observation is consistent with one other study [6] in which a deeply-grooved CT specimen was tested. However, it should be cautioned that the applicability of the LEFM analysis of fatigue crack growth in yielding conditions (under monotonic loading) is probably limited to conditions where the local stress-strain relation under cyclic loading remains linear.

FCGR at Edges of a Yielded Hole in Saltwater

Specimen 3, which had one crack emanating from one edge of the hole, was fatigue tested with a loading history identical to that applied to specimen 4 in saltwater. The FCGR results are shown in figure 6. Reasonable agreement between results from CT specimens [6] and the present study is observed, indicating that in saltwater as well as in air the LEFM analysis of fatigue crack growth is adequate in yielding conditions under monotonic loading.

As shown in figure 6 , the small-crack behavior occurs at a $\Delta \mathrm{K}$ level of about $45 \mathrm{MPa} / \mathrm{m}$, which corresponds to a crack length of $3 \mathrm{~mm}$, twice as long as that observed in air ( $1.5 \mathrm{~mm}$ ). The reason for this is not clear and further study is needed.

The FCGRs of hole-in-plate specimens are slightly lower than those of CT specimens because the $K$ solutions [8] for a crack at the edge of a hole were larger than the experimental data [11,12]. Consequently, the FCGR is lower when a calculated $\mathrm{K}$ is used. In the case where there are two cracks at the edge of a hole, results obtained with a calculated $\mathrm{K}$ agree with experimental results.

\section{Summary and Conclusions}

Even though significant plastic deformation exists in areas of stress concentration in structural components, the fatigue crack growth rates in those areas can be predicted very well using the LEFM analysis, provided that the local stress-strain relation is linear under cyclic loading and the crack is long enough that the small-crack behavior is absent. Small cracks grow at higher rates than those predicted from da/dN-versus- $\Delta K$ results for long cracks. The problem of small-crack behavior can be accounted for by adding an intrinsic crack length to the physical crack length, as suggested by El Haddad. The intrinsic crack length appears to be dependent upon environmental conditions for a given material. It is longer in saltwater ( $3 \mathrm{~mm}$ ) than in air ( $1.5 \mathrm{~mm}$ )

\section{Acknowledgments}

This worked was supported by the Department of Interior, Minerals Management Service. Drs. H. I. McHenry and D. T. Read provided helpful discussions. 


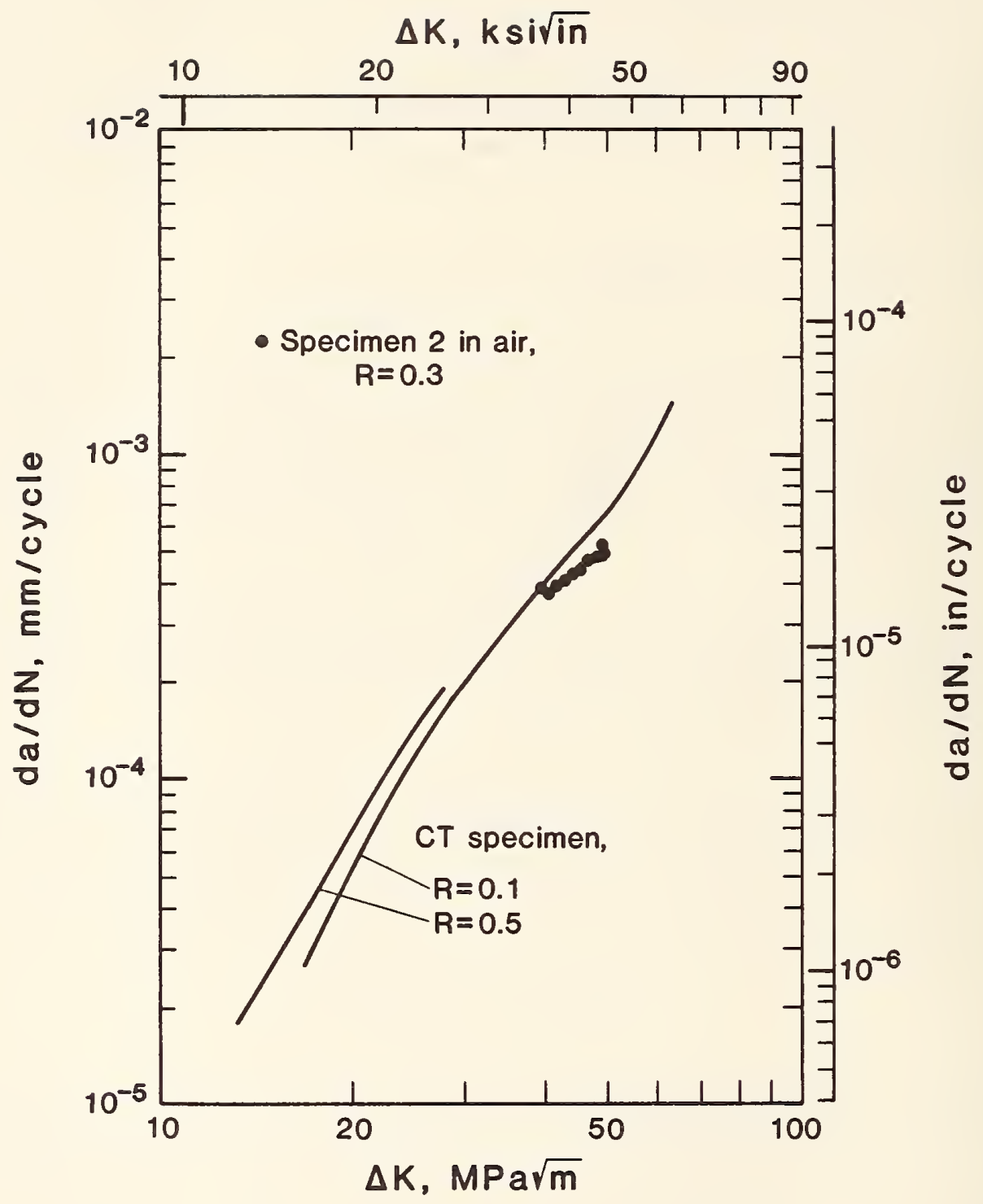

Figure 5. Comparison of fatigue crack growth rates in plastically deformed regions and compact-type specimens in air. 


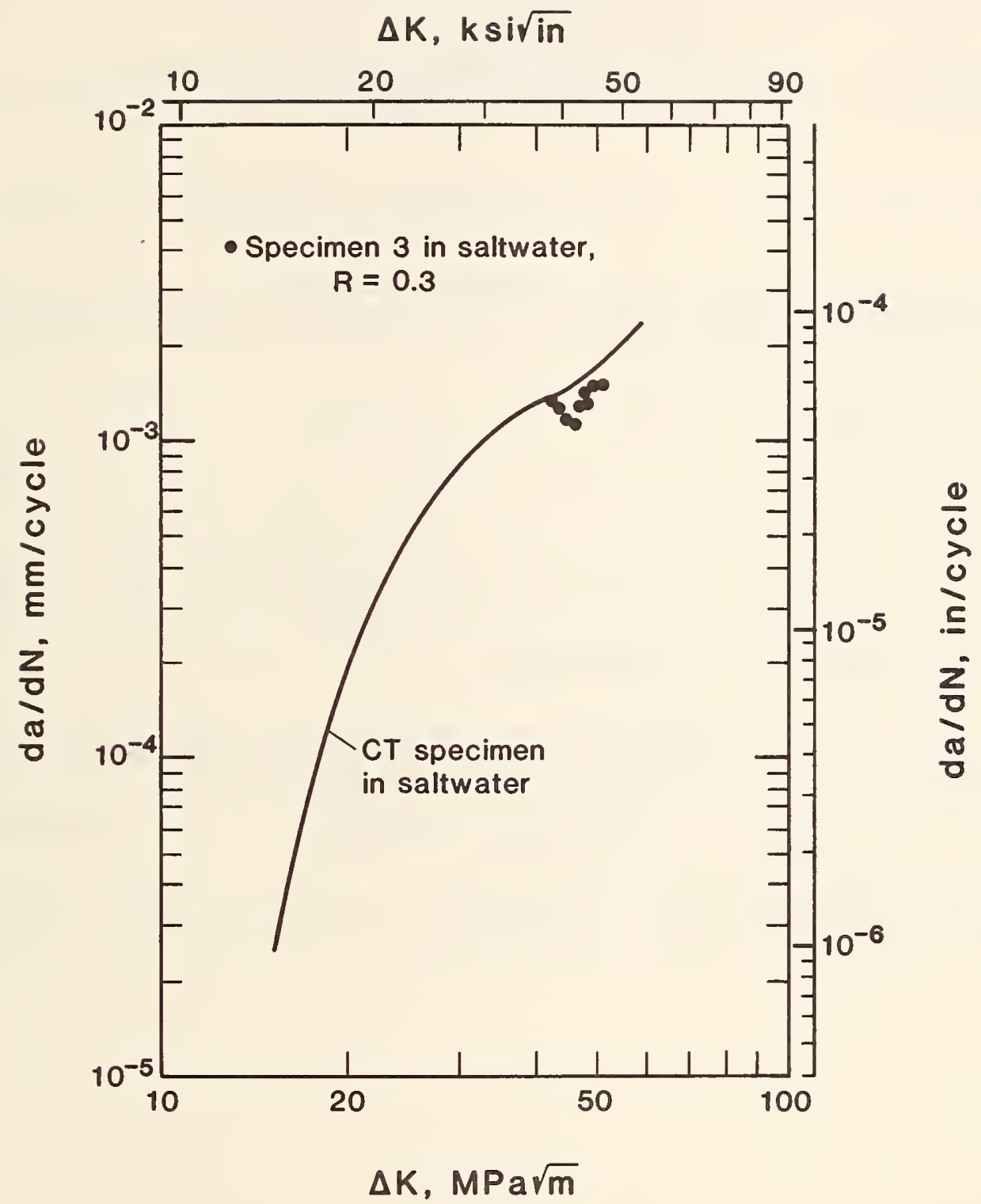

Figure 6. Comparison of fatigue crack growth rates in plastically déformed regions and compact-type specimens in saltwater. 
[1] H. D. Solomon, "Low Cycle Fatigue Crack Propagation in 1018 Steel," Journal of Materials, Vol. 7, No. 3 (1972), pp. 299-306.

[2] M. H. El Haddad, K. N. Smith, and T. H. Topper, "Fatigue Crack Propagation of Short Cracks," Journal of Engineering Materials and Technology, Vol. 102 (1979), pp. 42-46.

[3] M. H. El Haddad, K. N. Smith, and T. H. Topper, "A Strain Based Intensity Factor Solution for Short Fatigue Cracks from Notches," in: Fracture Mechanics, ASTM STP 677, American Society for Testing and Materials, Philadelphia (1979), pp. 274-284.

[4] M. H. El Haddad, N. E. Dowling, T. H. Topper, and K. N. Smith, "J-Integral Applications for Short Fatigue Cracks at Notches," International Journal of Fracture, Vol. 16, No: 1 (1980), pp. $15-30$.

[5] N. E. Dowling, "Geometry Effects and the J-Integral Approach to Elastic-Plastic Fatigue Crack Growth," in: Crack and Fracture, ASTM STP 601, American Society for Testing and Materials, Philadelphia (1977), pp. 19-32.

[6] Y. W. Cheng, "The Fatigue Crack Growth of a Ship Steel in Saltwater under Spectrum Loading ," in this report, pp. 15-30.

[7] T. L. Anderson, "The Effect of Crack-Tip Region Constraint on Fracture in the Ductile-toBrittle Region," Ph.D. thesis, Colorado School of Mines, Golden, Colorado (1983).

[8] H. Tada, P. C. Paris, and G. R. Irwin, The Stress Analysis of Cracks Handbook, Del Research Corp.. Hellerton, Pennsylvania (1973), pp. 19.2, 19.4, and 19.9.

[9] G. N. Savin, Stress Concentration Around Holes, translated from the Russian by E. Gros, Pergamon Press, New York (1961), pp. 104-113.

[10] H. Neuber, "Theory of Stress Concentration for Shear-Strained Prismatical Bodies with Arbitrary Nonlinear Stress-Strain Law," Journal of Applied Mechanics, Vol. 28 (1961), pp. 544-550.

[11] P. N. Li and Y. W. Cheng, "High/Low Stress Amplitude Effects on Fatigue Crack Growth of a Ship Steel in Air and in Saltwater," in this report, pp. 55-65.

[12] J. S. Cargill, J. K. Malpani, and Y. W. Cheng, "Disk Residual Life Studies," AFML-TR-79-4173, Air Force Materials Laboratory, Dayton, Ohio (1979). 


\author{
Pei-Ning $\mathrm{Li}^{+}$ \\ Yi-Wen Cheng \\ Fracture and Deformation Division \\ National Bureau of Standards \\ Boulder, Colorado 80303
}

\begin{abstract}
Hole-in-plate specimens, made of ABS grade EH36 steel, were tested in air and in 3.5 percent $\mathrm{NaCl}$ solution (saltwater) to study the high/low stress amplitude effects on fatigue crack growth rates (FCGRs) in an elastic stress field and at the edge of a yielded hole. Effects of tensile overload prior to crack initiation on subsequent FCGR at the edge of a yielded hole were also investigated. The results are summarized as follows:
\end{abstract}

1. The tensile overload retardation effects were similar in an elastic stress field and at the edge of a yielded hole.

2. The tensile overload retardation effects were similar in air and in saltwater.

3. The Bowie analysis overestimated the stress intensity factors when compared with experimental results.

4. The simple engineering approach gave accurate stress intensity factors when compared with experimental results, except in areas close to the edge of a hole. In the latter case, the simple engineering approach overestimated the stress intensity factors owing to overestimation of crack length.

5. Tensile overload prior to crack initiation appeared to retard the subsequent FCGR at the edge of a yielded hole. The retardation was explained by the presence of beneficial residual stresses and crack closure.

Key words: C-Mn steel; environmental effects; fatigue crack growth; load-sequence interaction effects; yielding effects.

${ }^{+}$Guest worker, on leave from East-China Institute of Chemical Technology, Shanghai, China. 
The fracture mechanics approach has been successfully applied to describe fatigue crack growth under constant-amplitude loading. However, fatigue life predictions of structural components remain complicated and imprecise owing to lack of methodologies that accurately account for the irregular nature of service loading. Load-sequence interaction effects have been qualitatively recognized for a long time, but because of numerous factors involved, detailed quantitative characterization has not well been established. Significant effects observed by many investigators can be summarized as follows :

1. Tensile overloads cause retardation of fatigue crack growth. A sufficiently high tensile overload may stop the growth of a fatigue crack completely [1].*

2. Preceding lower cyclic loads cause a slight acceleration of fatigue crack growth [2].

3. A compressive overload preceding a tensile overload reduces the retardation caused by the tensile overload [3].

4. A compressive overload following a tensile overload significantly reduces the retardation effects caused by the tensile overload [3].

5. Compressive overloads slightly accelerate fatigue crack growth [3].

For sea loading on offshore structures, all the aforementioned load-sequence interaction effects occur. In the case of offshore structures, one has to consider the possibility of additional interactions between load sequence and strong environmental effects due to saltwater. The investigation reported in this paper pursued the following objectives: (1) to compare the high/low stress amplitude effects on fatigue crack growth rates (FCGRs) in air and in 3.5 percent NaCl solution (saltwater), (2) to compare the high/low stress amplitude effects on FCGRs in an elastic stress field and at the edge of a yielded hole, and (3) to study the effects of tensile overload prior to crack initiation on subsequent FCGR.

Experimental Procedures

This investigation was a continuation of that reported in reference 4 (reference 4 is in this report). The test material, specimen preparation, test environment and crack length measurement technique of this investigation were identical to those described in reference 4 . The test variables, which were different from reference 4, are described in the following.

The maximum and minimum loads were step decreased during the test, while the minimum-to-maximum stress ratio was kept constant at 0.3 , to study the high/low stress amplitude effects. The initial maximum and minimum nominal stresses, $\mathrm{S}_{\max }$ and $\mathrm{S}_{\min }$, were 207 and $62.1 \mathrm{MPa}$. The stresses were step decreased to 147.9 and $44.36 \mathrm{MPa}$, and then to 105.6 and $31.69 \mathrm{MPa}$.

In addition to the test matrix given in table 2 of reference 4 , specimen 5 was used to study the influence of tensile overload which was applied before crack initiation on the subsequent fatigue crack propagation at stress concentrations. Specimen 5, which had no crack initially with a

\footnotetext{
*Numbers in brackets denote references listed at the end of each paper.
} 
hole diameter of $44.45 \mathrm{~mm}$, was monotonically loaded to a nominal stress of $242 \mathrm{MPa}$. After being unloaded, two small notches of $0.5 \mathrm{~mm}$ in length were introduced with a jeweler's saw on opposite edge of the hole normal to the loading direction. The specimen was fatigue cycled at stress levels of $\mathrm{S}_{\max }=207 \mathrm{MPa}$ and $\mathrm{S}_{\min }=62.1 \mathrm{MPa}$. After each crack had grown $3.2 \mathrm{~mm}$, the specimen was remachined to enlarge the hole diameter to $50.8 \mathrm{~mm}$. The specimen was then fatigue cycled again at the same cyclic stress levels $\left(S_{\max }=207 \mathrm{MPa}\right.$ and $\left.S_{\min }=62.1 \mathrm{MPa}\right)$.

Experimental Results and Discussion

Effects of High/Low Stress Amplitude on FCGR in Air

Specimens 2 and 4 (in reference to table 2 of reference 4 ) were tested to study the effects of high/low stress amplitude on FCGR in air in the plastically deformed regions. The results, along with the detailed loading histories, are given in figures 1 and 2 for specimens 2 and 4 , respectively. At the beginning of testing specimen 2, which had a single crack emanating from the edge of the hole, the maximum nominal stress, $S_{\max }$, and the minimum nominal stress, $S_{m i n}$, were first decreased from 207 and $62.1 \mathrm{MPa}$ to 115 and $34.5 \mathrm{MPa}$, a load reduction ratio of 1.8 . The overload effect was so strong that there was no observed crack growth in 90.9 kilocycles. Subsequently, $S_{\text {max }}$ and $\mathrm{S}_{\mathrm{min}}$ were increased to 147.9 and $44.36 \mathrm{MPa}$, respectively.

The values of $\Delta \mathrm{K}$, as shown in figure 1, were calculated using the Bowie analysis [5], the simple engineering approach [6] (which considers the hole as a portion of the crack), and the experimental method. In the experimental method, values of $\Delta K$ were inferred, using the da/dN-versus$\triangle K$ results of $C T$ specimens [7], from the measured da/dN of the hole-in-plate specimen.

As shown in figure 1, the trend of experimental $\Delta \mathrm{K}$ without considering crack closure or retardation effects is lower than predictions of both the Bowie analysis and the simple engineering approach. However, if crack closure is considered, the apparent stress intensity factor range $\left(\Delta \mathrm{K}_{\mathrm{app}}\right)$, plotted as crosses in figure 1 , increases and agrees very well with predictions from the simple engineering approach.

At crack lengths less than $5 \mathrm{~mm}$, the simple engineering approach overestimates $\Delta \mathrm{K}$ because it overestimates the crack length by considering the hole as a portion of the crack. The Bowie analysis overestimates $\Delta K$ in the whole range studied. The present results are consistent with those of another study [8] in which a single fatigue crack propagated from the bolt hole of a compressor disk. The crack length at which the simple engineering solution crosses over the Bowie analysis depends on the size of the hole; it increases with increasing hole diameter.

As expected, immediately after the load reduction the FCGRs were lower than the trend line, indicating that the fatigue crack growth was retarded (figure 1). There was no observed crack growth in 90.9 kilocycles after a load reduction ratio of 1.8 .

The measured widths of retardation effect were in reasonable agreement with predictions by Willenborg model [9]: 4.5 and $6.5 \mathrm{~mm}$ versus $4.9 \mathrm{~mm}$. The Willenborg model assumes that, as long as the instantaneous plastic zone is within the prior high-load-affected plastic zone, crack growth retardation will be present. The retardation decays to zero when the instantaneous plastic zone 


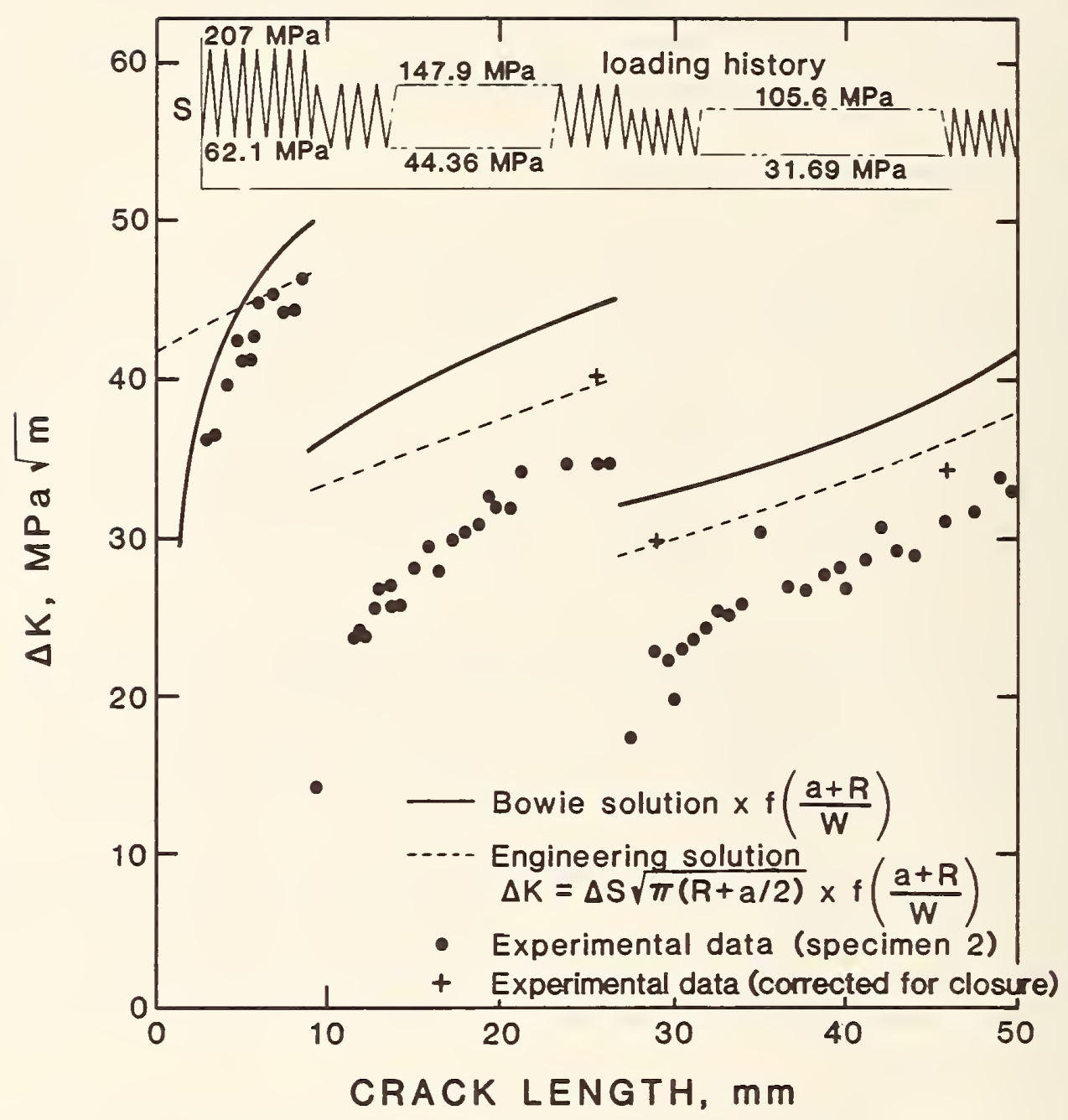

Figure 1. Theoretical and experimental stress intensity factor ranges as a function of crack length: in air. 


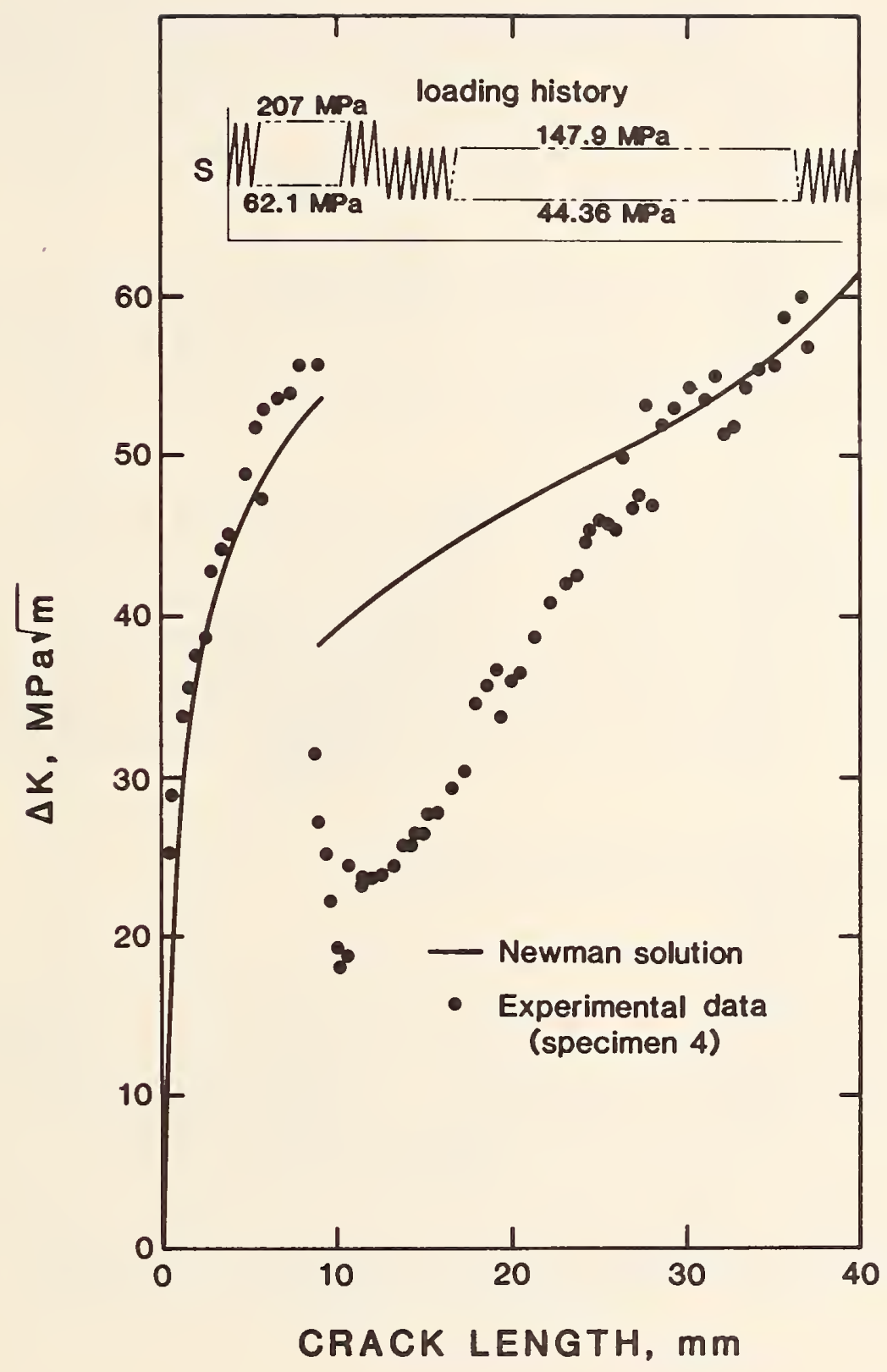

Figure 2. Theoretical and experimental stress intensity factor ranges as a function of crack length: in air. 
passes beyond the prior high-load-affected plastic zone.

As indicated in figure 2 of reference 4, at a nominal stress of $207.5 \mathrm{MPa}$ the yielded region extended from the hole edge to about $19 \mathrm{~mm}$ away from the hole edge. Thus, at the first load reduction, the crack tip with a crack length of $9 \mathrm{~mm}$ was within the yielded region. At the second load reduction, the crack tip with a crack length of $26 \mathrm{~mm}$ was outside the yielded region. The $\Delta \mathrm{K}-$ versus-a trends (figure 1) of the first and the second load reductions are similar, indicating that the high/low stress amplitude effects on FCGR are similar in the elastic and in the yielded regions. However, note that LEFM analysis of ECGR in the yielded region is probably limited to conditions where the stress-strain relation remains linear under cyclic loading. If it is cyclically yielded, the analysis will probably not be valid.

The test results for specimen 4, which had two symetrical cracks emanating from opposite edge of the hole, are shown in figure 2. The available $\mathrm{K}$ solution is from an analysis by Newman [5]. As shown in figure 2, the experimental $\Delta K$ values are in excellent agreement with those of analytical predictions except in the areas affected by the load reduction.

The test results of specimen 4 differed from those of specimen 2 in three ways: First, no apparent crack closure was observed. Second, the measured width of retardation effect (17 mm) was much larger in specimen 4 than in specimen 2. Third, the delayed retardation effect was more pronounced. The only difference between specimens 2 and 4 is that specimen 2 had a single crack emanating from one edge of the hole and specimen 4 had two symmetrical cracks emanating from opposite edges of the hole. To conform that these differences are geometry dependent, additional tests are needed.

Effects of High/Low Stress Amplitude on FCGR in Saltwater

Specimen 3, which had one crack emanating from one edge of the hole (identical to specimen 2), was fatigue tested with a loading history identical to that applied to specimen 4 in saltwater. The results obtained in saltwater, as shown in figure 3, are similar to those of specimen 2 in air (figure 1): (1) The experimental $\Delta K$ values, without considering crack closure, were smaller than those predicted by the Bowie analysis and by the simple engineering approach. (2) Overloading effects were observed, and the width of the retardation effect was in good agreement with that predicted by the willenborg model. This indicates that the high/low stress amplitude effects are practically the same in saltwater as in air.

Effects of Overload Prior to Crack Initiation on FCGR

Specimen 5, containing a 44.5-mm-diameter center hole without a notch, was preloaded to a remote stress of $242 \mathrm{MPa}$. After being unloaded, two small notches of $0.5 \mathrm{~mm}$ in length were introduced by a jeweler's saw on opposite edges of the hole. Then the specimen was fatigue cycled at stress levels of $\mathrm{S}_{\max }=207 \mathrm{MPa}$ and $\mathrm{S}_{\min }=62.1 \mathrm{MPa}$, identical to that applied to specimen 4 . As the distance between the two crack tips increased beyond $50.8 \mathrm{~mm}$, the specimen was remachined to enlarge the hole diameter to $50.8 \mathrm{~mm}$, while the center of the hole was adjusted such that lengths of the remaining small cracks were identical. Finally, the specimen was cycled again at the same cyclic stress levels $\left(S_{\max }=207\right.$ and $S_{\min }=62.1 \mathrm{MPa}$ ). 


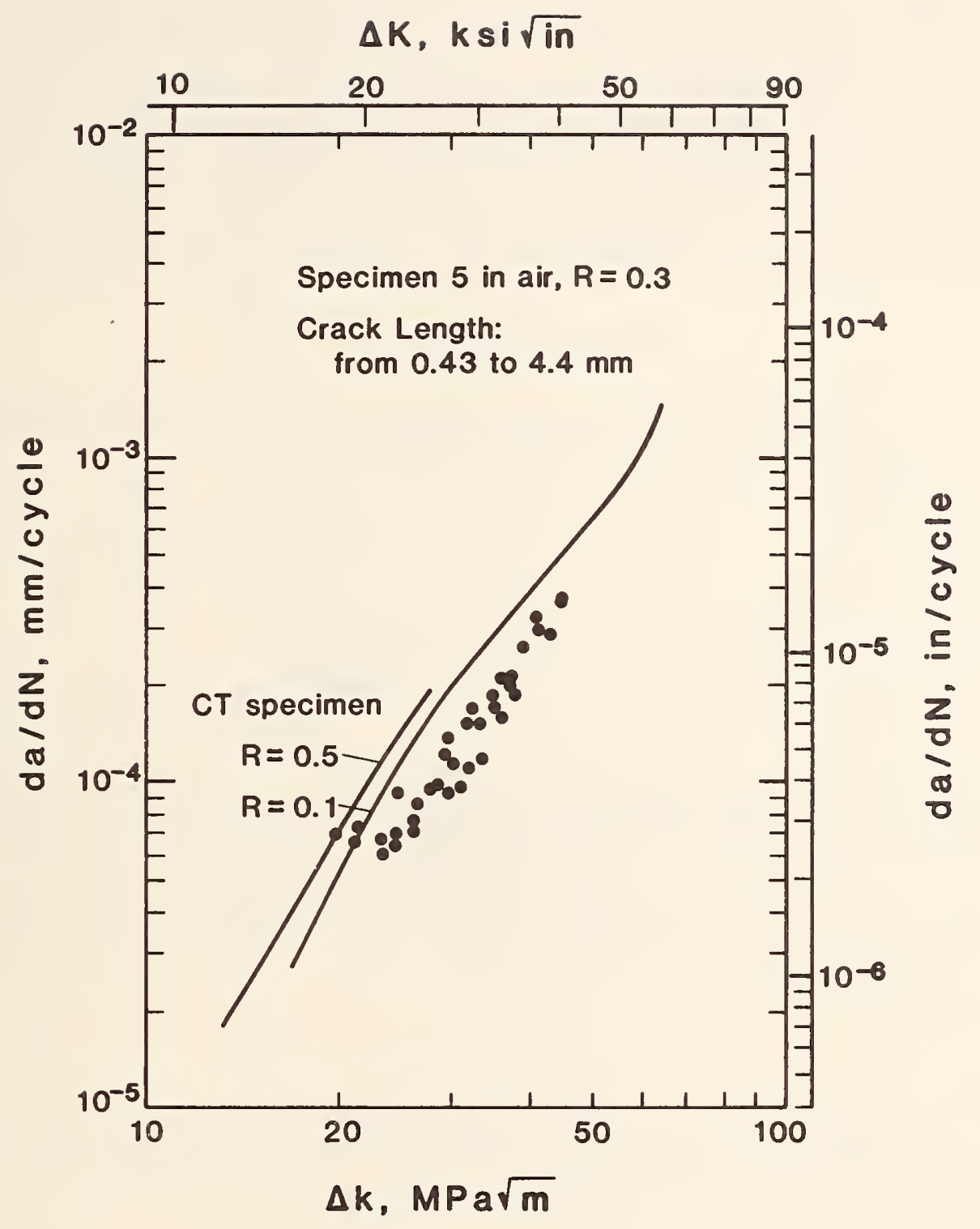

Figure 3. Theoretical and experimental stress intensity factor ranges as a function of crack length: in saltwater. 
The FCGRs plotted in figures 4 and 5 are much lower than those of specimen 4 (figure 2), which had no prior overloading. The solid line in figure 4 was derived from Newman analysis [5], and the dots were inferred from the experimental method. The different behaviors exhibited by specimens 4 and 5 can be explained as follows: Since the hole edge of specimen 5 was yielded during prior overloading, beneficial compressive residual stresses were developed upon unloading. Moreover, when a crack is present in the prior yielded region, the crack surfaces will touch each other before the specimen is unloaded to the minimum load. This means that, in addition to a compressive residual stress field at the crack tip, crack closure occurs and the FCGR decreases. However, small-crack behavior counterbalanced the retardation effect at crack lengths less than $0.5 \mathrm{~mm}$ ( $\mathrm{figure} 5$ ).

Summary and Conclusions

The retardation in fatigue crack growth rates owing to high/low stress amplitude was studied with hole-in-plate specimens. The following observations were made:

1. The retardation effects were similar in elastic stress fields and at the edges of a yielded hole.

2. The retardation effects were similar in air and in saltwater.

3. The Bowie analysis overestimated the stress intensity factors, when compared with experimental results.

4. The simple engineering approach gave accurate stress intensity factors, when compared with experimental results, except in areas close to the edges of a circular hole. There the stress intensity factors were overestimated because the crack length was overestimated.

5. Tensile overload prior to crack initiation appeared to retard the subsequent fatigue crack growth rates in areas of stress concentration. The retardation was explained by the presence of beneficial residual stresses and crack closure.

\section{Acknow ledgments}

This work was supported by the Department of Interior, Minerals Management Service. Drs. H. I. McHenry and D. T. Read provided helpful discussions. 


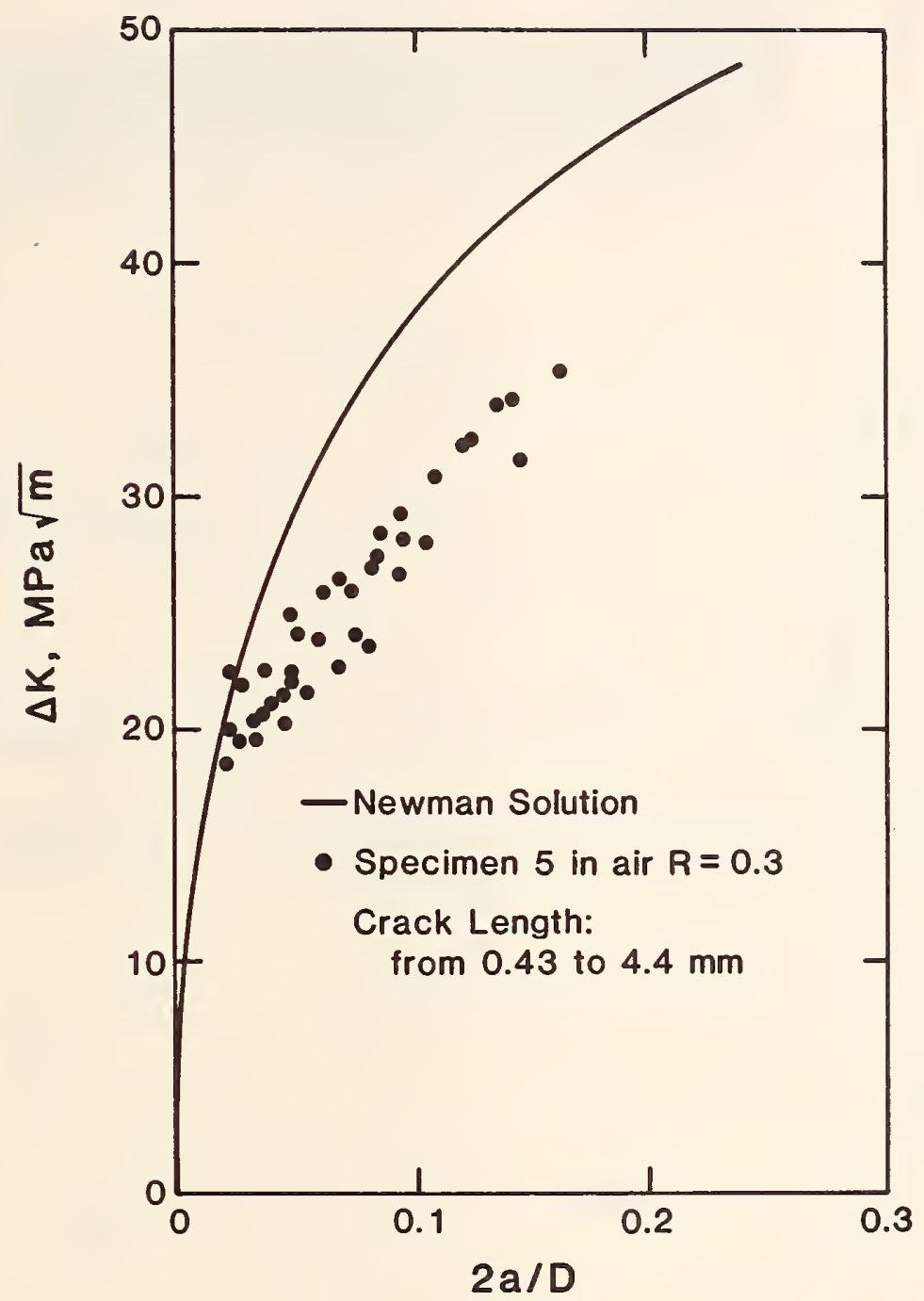

Figure 4. Theoretical and experimental stress intensity factor ranges as a function of the crack length-to-hole diameter ratio: in air. a is the crack length and $D$ is the hole diameter. 


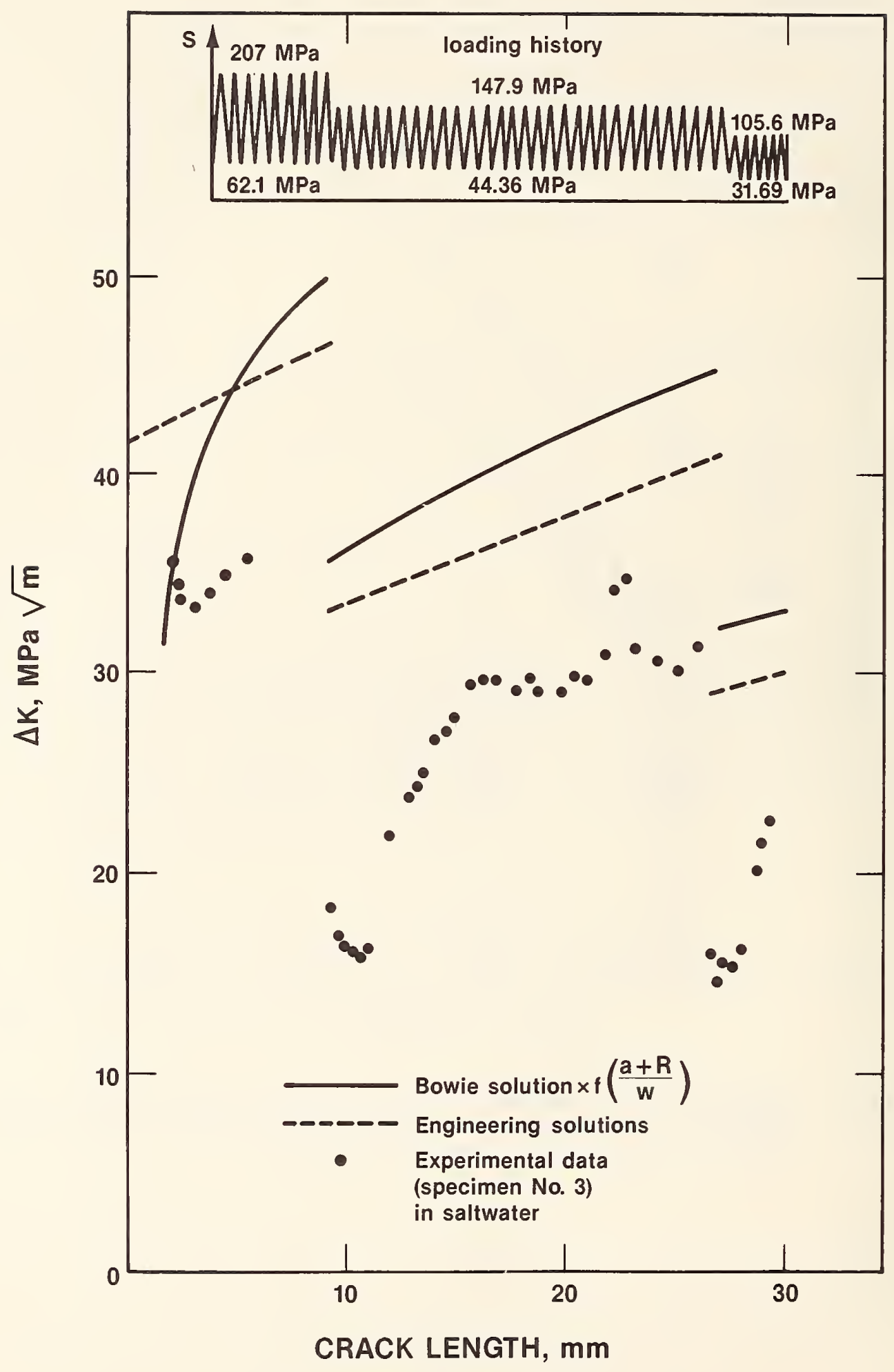

Figure 5. Comparison of fatigue crack growth rates at a preyielded hole with those of CT specimens. 
[1] C. M. Hudson and H. F. Hardrath, "Investigation of the Effects of Variable-Amplitude Loadings on Fatigue Crack Propagation Patterns," TND-1803, NASA (1963).

[2] E. F. J. von Euw, R. W. Hertzberg, and R. Roberts, "Delay Effects in Fatigue Crack Propagation," in: Stress Anlaysis and Growth of Cracks, ASTM STP 513, American Society for Testing and Materials, Philadelphia (1972), pp. 230-259.

[3] R. I. Stephens, D. K. Chen, and B. W. Hom, "Fatigue Crack Growth with Negative Stress Ratios Following Single Overloads in 2024-T3 and 7075-T6 Aluminum Alloys," in: Fatigue Crack Growth under Spectrum Loads, ASTM STP 595, American Society for Testing and Materials, Philadelphia (1976), pp. 27-40.

[4] P. N. Li and Y. W. Cheng, "Fatigue Crack Growth in Areas of Stress Concentration -- Plasticity and Small-Crack Effects," in this report, pp. 43-54.

[5] H. Tada, P. C. Paris, and G. R. Irwin, The Stress Analysis of Cracks Handbook, Del Research Corp., Hellerton, Pennsylvania (1973), pp. 19.2, 19.4, and 19.9 .

[6] D. Broek, Elementary Engineering Fracture Mechanics, 3rd edition, Martinus Nijhoff Publishers, The Hague, The Netherlands (1982).

[7] Y. W. Cheng, "The Fatigue Crack Growth of a Ship Steel in Saltwater under Spectrum Loading," in this report, pp. 15-30.

[8] J. S. Cargill, J. K. Malpani, and Y. W. Cheng, "Disk Residual Life Study," AFML-TR-79-4173, Air Force Materials Laboratory, Dayton, Ohio (1979).

[9] J. Willenborg, R. M. Engle, and H. A. Wood, "A Crack Growth Retardation Model Using an Effective Stress Concept," AFFDL-TM-71-1-FBR, Air Force Flight Dynamics Laboratory, Dayton, Ohio (1971). 
N85.114A (REV. 2-8C)

U.S. DEPT. OF COMM.

1. PUBLICATION OR

2. Performing Organ. Report No.,

3. Publication Date

BIBLIOGRAPHIC DATA

SHEET (See instructions) REPORT NO.

NBS TN-1088

August 1985

4. TITLE AND SUBTITLE

Fitness-for-Service Criteria for Assessing the Significance

of Fatigue Cracks in Offshore Structures

\section{AUTHOR(S)}

Yi-Wen Cheng

6. PERFORMING ORGANIZATION (If jolnt or other thon NBS, see Instructions)

7. Contracu Grani No.

NATIONAL BUREAU OF STANDARDS

DEPARTMENT OF COMMERCE

8. Type of Report \& Period Covered

WASHINGTON, D.C. 20234

9. SPONSORING ORGANIZATION NAME AND COMPLETE ADDRESS (Street, City, State, ZIP)

Department of the Interior

Minerals Management Service

Reston, Va 22091

10. SUPPLEMENTARY NOTES

Document describes a computer program; SF-185, FIPS Software Summary, is attached.

11. ABSTRACT (A 200-word or less factual summary of most significane information. If document includes a significant bibliography or literature survey. mention it here)

Results of a research program to develop fitness-for-service criteria for assessing the significance of fatigue cracks in offshore structures are presented in five papers. Each paper describes the goals and approaches to a specific task and details the results of the study.

12. KEY WORDS (Six 10 twelve entries; alphabetical order; capitalize only proper names; and separate key words by semicolons)

fatigue crack growth; fitness-for-service criteria; fracture mechanics; offshore structures; random-loading fatigue

13. AVAILABILITY

Unlimited

For Official Distribution. Do Not Release to NTIS

[X] Order From Superintendent of Documents, U.S. Government Printing Office, Washington, D.C. 20402.

Order From National Technical Information Service (NTIS), Springfield, VA. 22161

14. NO. OF

PRINTED PAGES

72

15. Price 


\section{Technical Publications}

\section{Periodicals}

Journal of Research-The Journal of Research of the National Bureau of Standards reports NBS research and development in those disciplines of the physical and engineering sciences in which the Bureau is active. These include physics, chemistry, engineering, mathematics, and computer sciences. Papers cover a broad range of subjects, with major emphasis on measurement methodology and the basic technology underlying standardization. Also included from time to time are survey articles on topics closely related to the Bureau's technical and scientific programs. As a special service to subscribers each issue contains complete citations to all recent Bureau publications in both NBS and non-NBS media. Issued six times a year.

\section{Nonperiodicals}

Monographs-Major contributions to the technical literature on various subjects related to the Bureau's scientific and technical activities.

Handbooks-Recommended codes of engineering and industrial practice (including safety codes) developed in cooperation with interested industries, professional organizations, and regulatory bodies.

Special Publications-Include proceedings of conferences sponsored by NBS, NBS annual reports, and other special publications appropriate to this grouping such as wall charts, pocket cards, and bibliographies.

Applied Mathematics Series-Mathematical tables, manuals, and studies of special interest to physicists, engineers, chemists, biologists, mathematicians, computer programmers, and others engaged in scientific and technical work.

National Standard Reference Data Series--Provides quantitative data on the physical and chemical properties of materials, compiled from the world's literature and critically evaluated. Developed under a worldwide program coordinated by NBS under the authority of the National Standard Data Act (Public Law 90-396).

NOTE: The Journal of Physical and Chemical Reference Data (JPCRD) is published quarterly for NBS by the American Chemical Society (ACS) and the American Institute of Physics (AIP). Subscriptions, reprints, and supplements are available from ACS, 1155 Sixteenth St., NW, Washington, DC 20056.

Building Science Series-Disseminates technical information developed at the Bureau on building materials, components, systems, and whole structures. The series presents research results, test methods, and performance criteria related to the structural and environmental functions and the durability and safety characteristics of building elements and systems.

Technical Notes-Studies or reports which are complete in themselves but restrictive in their treatment of a subject. Analogous to monographs but not so comprehensive in scope or definitive in treatment of the subject area. Often serve as a vehicle for final reports of work performed at NBS under the sponsorship of other government agencies.

Voluntary Product Standards-Developed under procedures published by the Department of Commerce in Part 10, Title 15, of the Code of Federal Regulations. The standards establish nationally recognized requirements for products, and provide all concerned interests with a basis for common understanding of the characteristics of the products. NBS administers this program as a supplement to the activities of the private sector standardizing organizations.

Consumer Information Series-Practical information, based on NBS research and experience, covering areas of interest to the consumer. Easily understandable language and illustrations provide useful background knowledge for shopping in today's technological marketplace.

Order the above NBS publications from: Superintendent of Documents, Government Printing Office, Washington, DC 20402.

Order the following NBS publications-FIPS and NBSIR's-from the National Technical Information Service, Spring field, VA 22161.

Federal Information Processing Standards Publications (FIPS PUB)-Publications in this series collectively constitute the Federal Information Processing Standards Register. The Register serves as the official source of information in the Federal Government regarding standards issued by NBS pursuant to the Federal Property and Administrative Services Act of 1949 as amended, Public Law 89-306 (79 Stat. 1127), and as implemented by Executive Order 11717 (38 FR 12315, dated May 11, 1973) and Part 6 of Title 15 CFR (Code of Federal Regulations).

NBS Interagency Reports (NBSIR)-A special series of interim or final reports on work performed by NBS for outside sponsors (both government and non-government). In general, initial distribution is handled by the sponsor; public distribution is by the National Technical Information Service, Springfield, VA 22161, in paper copy or microfiche form. 
Penalty for Private Use $\$ 300$

POSTAGE AND FEES PAID U.S. DEPARTMENT OF COMMERCE COM-215

SPECIAL FOURTH-CLASS RATE BOOK 